A CASE STUDY OF SECONDARY SCHOOL LEADERS' PERCEPTIONS OF ATTENDANCE POLICIES AND PROCEDURES USED TO INCREASE ATTENDANCE

A Dissertation
Presented to
the Faculty of the Graduate School
at the University of Missouri-Columbia
In Partial Fulfillment
of the Requirements for the Degree
Doctor of Education
MARK A. BULLIMORE
Dr. Carole A. Edmonds, Dissertation Supervisor
May 2018


(C) Copyright by Mark A. Bullimore 2018

All Rights Reserved 
The undersigned, appointed by the dean of the Graduate School, have examined the dissertation entitled

SECONDARY SCHOOL LEADERS' PERCEPTIONS OF ATTENDANCE

POLICIES AND PROCEDURES USED TO INCREASE ATTENDANCE

presented by Mark A. Bullimore,

a candidate for the degree of doctor of education,

and hereby certify that, in their opinion, it is worthy of acceptance.

Dr. Carole Edmonds

Dr. Timothy Wall

Dr. Chad Brinton

Dr. Matt Symonds 


\section{DEDICATION}

This dissertation is dedicated to my family. First, to my amazing and beautiful bride Melea, the love of my life. This journey was far more difficult for you, and you NEVER complained. You cared for our children, took care of our home, sacrificed time as a couple, and always made things work. I could have never completed this journey without your support, we accomplished this together. I love you.

To my children, Aames, Asher, and Isla. The goal was to finish this journey before you became older and more involved, so I could avoid missing out on our precious time together. My hope is for you to never remember the sacrifices of this journey, while also appreciating that a dedication to reading, writing, learning, and leading is important in life. Although I am incredibly proud of this accomplishment, being married to your mom, and father to you three amazing children, will always be the shining moment in my life. Husband and daddy will always be my favorite titles. My love for my family is the most important to me. 


\section{ACKNOWLEDGEMENTS}

The completion of my dissertation highlights a long, but rewarding four year journey. This educational journey included many personal and professional sacrifices, all which were worth the opportunities and experiences provided, knowledge attained, and new friends and colleagues established. The finality of earning my doctorate degree would not have occurred without the support of my family, friends, and educational advisors. Thanks to Melea, Aames, Asher, and Isla for your unwavering love and support. I am humbled and truly blessed as a husband, father, and friend.

To my parents - Betsy Bing and Mark E. Bullimore. Mom, you have provided me inspiration and determination throughout my life and the motivation to continue my own growth with a love for learning; all while modeling for me the importance of making a difference in children's lives. Thanks Mom! Dad, I've learned that the truly special things in life require dedication, perseverance, sacrifice, and sometimes forgiveness. Without these lessons from both of you, I may not have even imagined becoming all that I am. Your son's a doctor!

Tremendous thanks must be made to my advisor and dissertation committee. This learning experience would not have been so rewarding if not for the expertise and wisdom of Dr. Carole Edmonds, Dr. Tim Wall, and my committee members. Many late night or early morning text and email exchanges with Dr. Edmonds were above and beyond her call of duty, and I would not be here, now, without her support and guidance. I will continue to follow your lead and pay-it-forward to those who follow in these educational footsteps. Dr. Wall, thank you for your expertise and drive to push me to be a better learner, leader, and researcher - while remembering family is MOST 
important. Dr. Brinton, and Dr. Symonds, as my committee members, your knowledge on the subject matter and practical viewpoints provided invaluable insight and support. I commend and thank all of you for being there to help me in this remarkable journey.

To the entire ELPA Cohort, I greatly enjoyed the summers, and will never forget the time we spend together in Columbia, MO. To the NWMSU Cohort—whether in person or via many different attempts at online collaboration - I truly enjoyed our time together! It was a tremendous four years we spent together, and I will never forget our experience.

Specifically to my Kansas City cohort brothers, Chad, Shiloh, and Joe. I wish you nothing but the best. The friendships and professional contacts will be everlasting. It would also be in poor taste to not mention our many hours spent at Minsky's working through this journey together. I could not have accomplished this without the unwavering support of hot pizza, a quiet place to write and collaborate on Wednesday nights, and free WiFi. Thank you, Men.

Thank you to all who have made this possible. 


\section{TABLE OF CONTENTS}

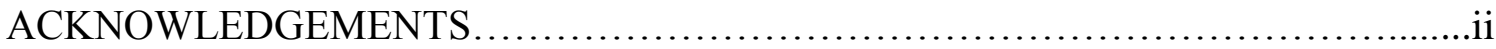

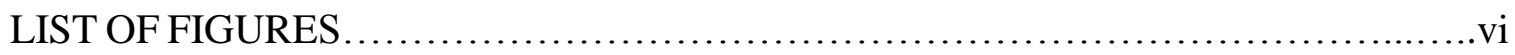

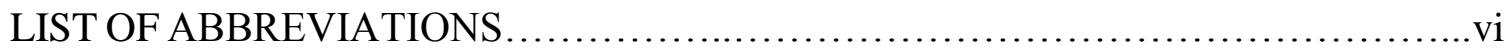

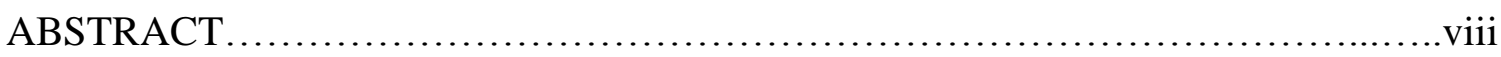

\section{SECTION}

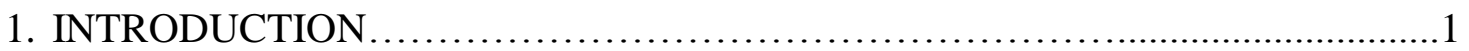

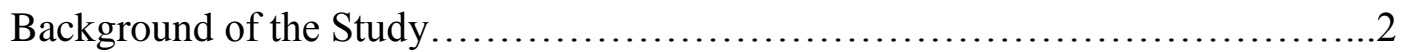

Statement of the Problem....................................................... 5

Purpose of the Study ..................................................... 8

Research Questions.......................................................... 9

Conceptual Underpinning .................................................. 10

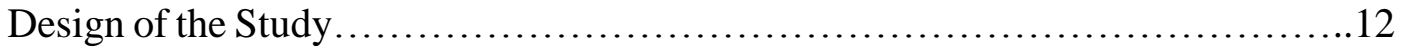

Site Description and Selection........................................13

Participant Sample....................................................14

Research Methods and Data Collection......................................14

Data Analysis.................................................... 15

Limitations, Delimitations, and Assumptions............................. 16

Definition of Key Terms................................................. 16

Significance of the Study .................................................. 19

Summary.........................................................20

2. PRACTITIONER SETTING FOR THE STUDY $\ldots \ldots \ldots \ldots \ldots \ldots \ldots \ldots \ldots \ldots \ldots . . . \ldots \ldots$

Introduction for this Section.............................................. 21

History of the Organization.............................................. 21

Organizational Analysis................................................ 32

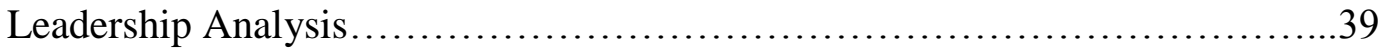

Implications for Research in the Practitioner Setting ........................43

Summary.........................................................45

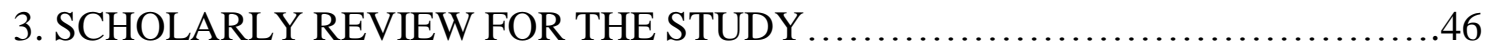

Introduction for this Section.............................................46

Statement of the Problem...............................................46

Conceptual Underpinning................................................ 49

Key Variables.......................................................... 52

Conclusion and Future Implications....................................61 
4. CONTRIBUTION TO PRACTICE .........................................62

Practitioner Presentation Document...................................63

5. CONTRIBUTION TO SCHOLARSHIP ................................. 88

Submission-Ready Journal Article .....................................89

6. SCHOLARLY PRACTITIONER REFLECTION............................116

Introduction for this Section..........................................116

Dissertation Influenced Practice as Educational Leader........................116

Leadership Theory and Practice........................................... 117

Dissertation Process Influencing Scholarship..............................118

Content and Context of Learning........................................ 118

Conclusion.......................................................... 120

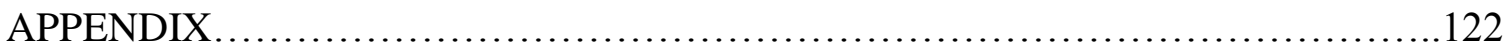

Interview Questions.................................................122

Focus Group Questions............................................. 123

Informed Consent...................................................... 124

Focus Group Informed Consent........................................ 126

IRB Approval...................................................... 128

Permission to Conduct Research.......................................... 130

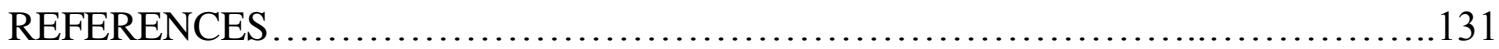

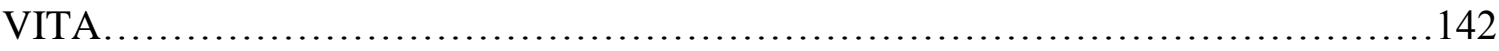




\section{LIST OF FIGURES}

Figure 1: Illustration of the Conceptual Underpinning and lenses used to guide study

Figure 2: The Five Basic Parts of Organizations

Figure 3: Organizational Structure for United States Department of Education

Figure 4: Organizational Structure for Missouri Department of Elementary and

Secondary Education

Figure 5: Organizational structure and hierarchy for The Valley View Conference member schools 


\section{LIST OF ABBREVIATIONS}

1. 90/90- $90 \%$ of students attending $90 \%$ of the minutes (Proportional Attendance Rate)

2. APR-Annual Performance Report

3. ADA- Average Daily Attendance

4. ASCD- Association for Supervision and Curriculum Development

5. DESE- Missouri Department of Elementary and Secondary Education

6. MSIP 5- Missouri School Improvement Plan 5

7. MSIP 6- Missouri School Improvement Plan 6

8. MSBA- Missouri School Board Association

9. NCLB- No Child Left Behind

10. USDE- United States Department of Education

11. VVC- Valley View Conference 


\begin{abstract}
Nationwide, pressures from outside influences such as politicians and educational policy makers are placing schools in precarious situations to make drastic changes in attendance policies to meet state accountability standards. The researcher used interviews and a focus group with school leaders, and archival data to find common themes which were then viewed through the conceptual underpinning of accountability. This case study adds to the field of education a deeper understanding of school leaders' perspectives on the impact attendance accountability standards have on the overall effectiveness of school improvement. The findings suggest: the new proportional attendance policy is detrimental to a school leaders' ability to focus on other school improvement practices while creating negative unintended consequences for schools and students; incentives and punitive consequences have short-term success while decaying school-family relationships; and district-wide and community awareness programs seemed to have the greatest impact on long term attendance improvement. Based on these findings, the following three practices should be implemented by districts: Systematic monitoring of attendance data, the use of low cost incentives and simple rewards, and the implementation of district-wide engagement and education of family and community awareness programs.
\end{abstract}

Keywords: Attendance, School Leadership, Accountability, School Improvement, Missouri School Improvement Plan 


\section{SECTION ONE}

\section{INTRODUCTION}

It's Friday morning at Sunnyhill Middle School, and Ms. Anderson peeks her head into Principal Smith's office. It's her second hour plan period and she wonders if it would be a good time to hold a classroom post-observation meeting to discuss instructional strategies and student engagement. Mr. Smith is vigilantly hustling through a few emails he needs to get out before lunch, and still has two phone calls he needs to return to upset parents regarding student grades. He informs Ms. Anderson that he must re-schedule in order to complete these other tasks before the weekly attendance review meeting. In ever-increasing fashion, teacher effectiveness and parent communication are put on the back-burner, or rushed, in the name of attendance accountability.

At Sunnyhill, each Friday morning the attendance review committee (principal, assistant principal, two counselors, school resource officer, attendance secretary, and school district social worker) prepares for a weekly two-hour attendance review meeting. To conduct this meeting, the registrar and a counselor have spent two hours pulling student attendance data and organizing it into a sort-able document that can be shared electronically with the attendance review committee. This file has many different components that allow the committee members to sort, rank, and file students attendance based on overall school year attendance (per student), recent attendance trends per student, grade-level attendance, and many other factors that must be taken into account. The members hustle around on each Friday morning to complete needed tasks knowing that they will spend the next two hours in a conference room pouring over attendance data and brainstorming strategies to get students to school. 
Following this meeting, each member of the committee spends the next several days contacting identified students and parents about attendance, assigning discipline and tutoring hours, writing encouraging notes, running attendance percentage letters to be folded and mailed home, and in extreme cases, spending several hours on the phone making hotline reports to the department of family services. All told, each member will spend an additional five to seven hours that week focused purely on attendance matters in attempt to meet attendance accountability standards as set by the state. This task doesn't include the tangible and intangible resources used to design and implement incentive programs to reward and encourage students to attend school.

In 2012, Sunnyhill met attendance accountability standards and achieved all available attendance Annual Performance Report (APR) points using average daily attendance (ADA) percentage calculations (Missouri Department of Elementary \& Secondary Education, 2012a). Since the implementation of a new proportional attendance accountability standard, things have changed for Mr. Smith, Sunnyhill, and the entire school district. In the 2014-2015 school year, only 82\% of Sunnyhill's students were at school $90 \%$ of the time. In the old system of calculating attendance using ADA (how many students are at school each day) the student with perfect attendance "hid", or made up, for the chronically absent students (Missouri Department of Elementary \& Secondary Education, 2015a).

\section{BACKGROUND}

Nationwide, state accountability attendance standards have new outside influences impacting school and district's accountability scores for APR (DarlingHammond, 2004, 2010a, 2012; Darling-Hammond \& Wise, 1985; Hanushek \& 
Raymond, 2005; O'Day, 2002; Thoonen, Sleegers, Oort, \& Peetsma, 2012). From

national and local politicians to educational policy makers, pressures are placing schools in precarious attendance situations to make drastic changes in attendance policies (Mellor \& Griffith, 2015; Missouri Association of School Administrators, 2015a, 2015b) . These policies are forcing schools and districts to spend more time and resources on addressing attendance woes.

\section{Missouri School Improvement Plan}

The issue of student attendance and the expectations placed on school districts from the state through the Missouri School Improvement Plan (MSIP5) accreditation benchmarks has become a hot topic throughout K-12 public education. As the new MSIP6 draws closer for upcoming school years, new research in attendance and achievement could play a major factor in several different scenarios moving forward.

Sunnyhill schools have begun to face a major attendance problem the last few years as the Missouri Department of Elementary and Secondary Education (DESE) has changed the district benchmark from 95\% Average Daily Attendance (ADA) to a proportional attendance average (Missouri Department of Elementary \& Secondary Education, 2015b). Prior to 2013, DESE and the MSIP5 accreditation and grading criteria used for attendance was based on a benchmark expectation of 95\% school district attendance based on an overall average daily attendance (ADA). Beginning in 2013, the MSIP5 benchmark for school districts student attendance shifted to a proportional attendance calculation. The new DESE MSIP5 and APR accountability benchmark now requires $90 \%$ of a district's students to attend school $90 \%$ of the time (90/90) (Missouri Department of Elementary \& Secondary Education, 2016a). In the past, DESE and 
MSIP5 required an overall average daily attendance of a school district to be $95 \%$.

Thoughts surrounding the reason behind the change are that with an overall average daily attendance calculation schools were able to hide the fact that students with much higher percentage of attendance making up for many students with much lower percentages.

The MSIP was originally designed to promote excellence in the public schools of the state. According to the original Missouri School Improvement Program Standards and Indicators Manual (Missouri Department of Elementary \& Secondary Education, 2012b) the first installment of MSIP was originally designed to promote excellence in the public schools of the state through a twofold responsibility. The MSIP was used as a measure of the responsibility in guaranteeing that all schools meet certain basic standards and in ensuring that the public schools continue to strive for excellence in an increasingly competitive world. MSIP 5 now has five stated policy goals: Articulate the state's expectations for student achievement with the ultimate goal of all students graduating ready for success in college and careers; Distinguish performance of schools and districts in valid, accurate and meaningful ways so that districts in need of improvement can receive appropriate support and interventions, and high-performing districts can be recognized as models of excellence; Empower all stakeholders through regular communications and transparent reporting of results; Promote continuous improvement and innovation within each district (Missouri Department of Elementary and Secondary Education, 2015a).

\section{Attendance Validity}

Concerning the validity of attendance as an accreditation benchmark, the Association for Supervision and Curriculum Development (ASCD) has been calling for 
more meaningful accountability systems to promote continuous support and improvement and align with the broader outcomes stakeholders collectively want for students. In particular, ASCD seeks to develop accountability systems should incorporate a variety of measures that reflect a comprehensive definition of student success, accurately measure student learning, and systematically track educators' efforts to engage and support learners (Mellor \& Griffith, 2015).

\section{Statement of the Problem}

\section{Problem of Practice}

A gap in knowledge exists failing to clearly define the connection between attendance and accountability demands placed on school districts from policy makers (Brokowski \& Dempsey, 1979; Lee-Partridge, Snyder, Jarmoszko, D'Onofrio, \& Petkova, 2014; Wilkins, 2008). Increased attendance accountability has led to major policy changes at the school and district level (Missouri Department of Elementary \& Secondary Education, 2015c, 2015d). The issue of student attendance and the expectations placed on school districts from the Missouri Department of Elementary and Secondary Education (DESE) through the Missouri School Improvement Plan (MSIP) accreditation benchmarks has become a hot topic throughout K-12 public education. Attendance has leaped to the forefront of school districts attention in order to meet the state's changed expectations (benchmarks) for MSIP5 and APR accreditation. Changes during the MSIP5 accountability cycle from ADA to proportional attendance standards has led to major policy changes and serious discussions regarding student attendance for schools and its validity as an accreditation benchmark (Missouri Association of School 
Administrators, 2015a, 2015b). Educators find themselves struggling with the new guidelines and finding ways to ensure every student has acceptable attendance.

Policy creation and accountability standards in K-12 education has evolved from a largely local and state function to now include federal oversight and mandates (Ambrosio, 2013; Bolman \& Deal, 2013). At the national and state levels the accountability has grown to be largely measured through standardized input values and have been utilized to assess a value-added measurement for administrator and teacher effectiveness (Ingram, Seashore Louis, \& Schroeder, 2004; Lamdin, 1996; Mellor \& Griffith, 2015).

Federal accountability constructs such as No Child Left Behind (United States Department of Education, 2001) and Race to the Top (United States Department of Education, 2010b), have fostered an era of disillusionment with educators and school administrators. Just as teachers may feel compelled to 'teach to the test', administrators feel obligated to allocate resources, specifically time and money, towards meeting accountability standards. Meeting these accountability standards and making changes to meet student's needs may not always result in the same needs, as policies leave schools to focus on how to get students to school and keep them there, but no motivation to improve their quality of education once they arrive (Darling-Hammond, 2004, 2010a, 2012; Hanushek \& Raymond, 2005; O'Day, 2002).

\section{Existing Gap in Literature}

The majority of research concerning the link between attendance and school improvement as measured by student achievement, has come from higher education (Chan \& Shum, 1997; Lamdin, 1996). More specifically, much of this research comes 
from individual classroom or course expectations, not facility-wide policies (Chakrabarti \& Schwartz, 2013; Chan \& Shum, 1997; Lee-Partridge et al., 2014; Marburger, 2006). Additionally, little accountability research exists surrounding the use of attendance as an accountability measure. Much of the research that does exist, focuses on the impact of compulsory attendance policies and grade outcomes in specific courses or classes (Snyder, Lee-Partridge, Jarmoszko, Petkova, \& D’Onofrio, 2014). Furthermore, research regarding the impact of attendance on a school district's accountability and accreditation cannot be found. Most research done in this area has used a quantitative approach in an attempt to capture the correlation between attendance and achievement (Snyder et al., 2014). Little qualitative research exists to investigate the participant's stories. Research also proves nonexistent in the perceptions of leaders in educational settings.

A gap in knowledge exists failing to clearly define the connection between attendance and accountability demands placed on school districts from policy makers. The results of prior studies are mixed and contradictory, as evidenced by the research of Lee-Partridge et al. (2014) when compared to the findings of Brokowski and Dempsey (1979) and Wilkins (2008). Additionally, little accountability research exists surrounding the use of attendance as an accountability measure. Much of the research that does exist, focuses on the impact of compulsory attendance policies and grade outcomes in specific courses or classes (Snyder et al., 2014).

For instance, Snyder Lee-Partridge et al. (2014) suggests that higher attendance for all students only significantly increases achievement and performance for those highachieving students that are already extremely invested in their education and future. Contrarily, Brokowski and Dempsey (1979) contend that implementation of an 
attendance policy may result in improved performance in attendance and achievement for certain students (high I.Q.), certain groups (low I.Q.) demonstrated a significant increase in number of disciplinary suspensions they were issued when the policy was in operation.

Furthermore, research regarding the impact of attendance on a school district's accountability and accreditation cannot be found. Moreover, there is very little research investigating the impact greater accountability on a school's attendance has on instruction, school procedures, and leader focus.

\section{Purpose of the Study}

While districts across the state are feeling the pressure to increase their proportional attendance rates, little research has been offered describing the influence these increased efforts may have on other school initiatives/factors. This study aims is to add to the existing body of knowledge and fill needed gaps concerning attendance policies, and the impact these policies and procedures have on school leaders and other key components of education (Chan \& Shum, 1997; Ginsburg, Jordan, \& Chang, 2014; Lee-Partridge et al., 2014; Reid, 2008; Sheppard, 2010; Wilkins, 2008). Research into attendance, achievement, school improvement practices, and accountability policies and procedures could provide needed guidance to schools and districts in the future.

Therefore, the purpose of this study was to explore the secondary school leaders' perceptions of attendance policies and procedures used to increase attendance in an attempt to meet accountability standards through school improvement practices. Further research can help determine if educational leaders feel these policies and the resources being allocated towards these efforts are helping to meet the stated goals of the MSIP 5 proportional attendance policy of increasing student attendance and ultimately increasing 
student performance and achievement (Missouri Department of Elementary and Secondary Education, 2015a).

\section{Research Question}

The overarching research question (Creswell, 2013) guiding this study is: What are secondary school leaders' perceptions of attendance policies and procedures? This single overarching question captures the basic goals of the study in one major question and serves as a basis for initial and emerging sub-questions. As Agee (2009) explains, a clearly stated overarching question can give direction for the study design and collection of data and offer potential for developing more specific questions during data collection and analysis.

The following sub-questions helped to narrow and focus the inquiry. Further, these sub-questions provided guidelines for the researchers' exploration during interview and focus group questions (Creswell, 2013). Sub questions guiding this study are:

- What are school leader perceptions regarding the impact of increased accountability on their attendance?

- What are school leader perceptions of the impact new attendance policies have on other school improvement factors?

- What are principals' perceptions regarding the change in their role after Missouri's new attendance accountability standard and the impact it has had on instruction, school procedures, and leader focus? 


\section{Conceptual Underpinning}

The conceptual underpinning for this study is accountability as introduced in the early work of Levin (1974). In addition to Levin's research, the accountability underpinning has continued to be examined and used as a lens for research by Chakrabarti and Schwartz (2013), Darling-Hammond (2004, 2010a, 2012); DarlingHammond and Wise (1985), and Ingram et al. (2004). According to Levin, regardless of the context in which an institution or governing body implements accountability standards, it is rarely addressing the underlying concepts which link diverse issues.

One assumption underlying accountability policies and the approach most commonly used by state agencies is that results from measurable sources such as attendance, standardized tests, and other sources will be used to make decisions about school and classroom practice simply because they are measurable (Chakrabarti \& Schwartz, 2013; Ingram et al., 2004). This approach of accreditation and accountability focuses on the assignment of rewards and potential harsh sanctions for schools based on measurable outcomes, regardless if they are proven to impact student learning and school improvement (Chakrabarti \& Schwartz, 2013; Ingram et al., 2004).

According to Ingram et al. (2004), for standards and accountability policies to be effective in changing the core technology of education - teaching and learning - schools must use accountability data to make decisions about whether they are meeting standards or not and, if not, then use data to change practices and monitor the effectiveness of those changes. Despite the pivotal role of data use in this and other current school improvement policies, there is little empirical research on how these policies affect practice (Chakrabarti \& Schwartz, 2013; Darling-Hammond, 2004; Ingram et al., 2004) 
Although accountability measures and accreditation standards are necessary, unfortunately many outside pressures are placed on The Department of Elementary and Secondary Education (DESE) which determine these goals. Many times student learning and achievement are not the top priority of these political pressures. Using measurable data to hold school districts accountable and to determine the accreditation status of school districts is key to school improvement. The crux of the issue is deciding what data is pertinent to determining accreditation status, and if data such as attendance should be used simply because it is measurable.

The key variables of this research are attendance, school improvement, and school leadership as viewed through an accountability conceptual underpinning lens. The key variables of attendance, school leadership, and school improvement are based on the work of researchers and scholars such as: Arthurs, Patterson, and Bentley (2014); Brokowski and Dempsey (1979); Lee-Partridge et al. (2014); Paredes and Ugarte (2011); Reid (2008); Wilkins (2008); and others. 


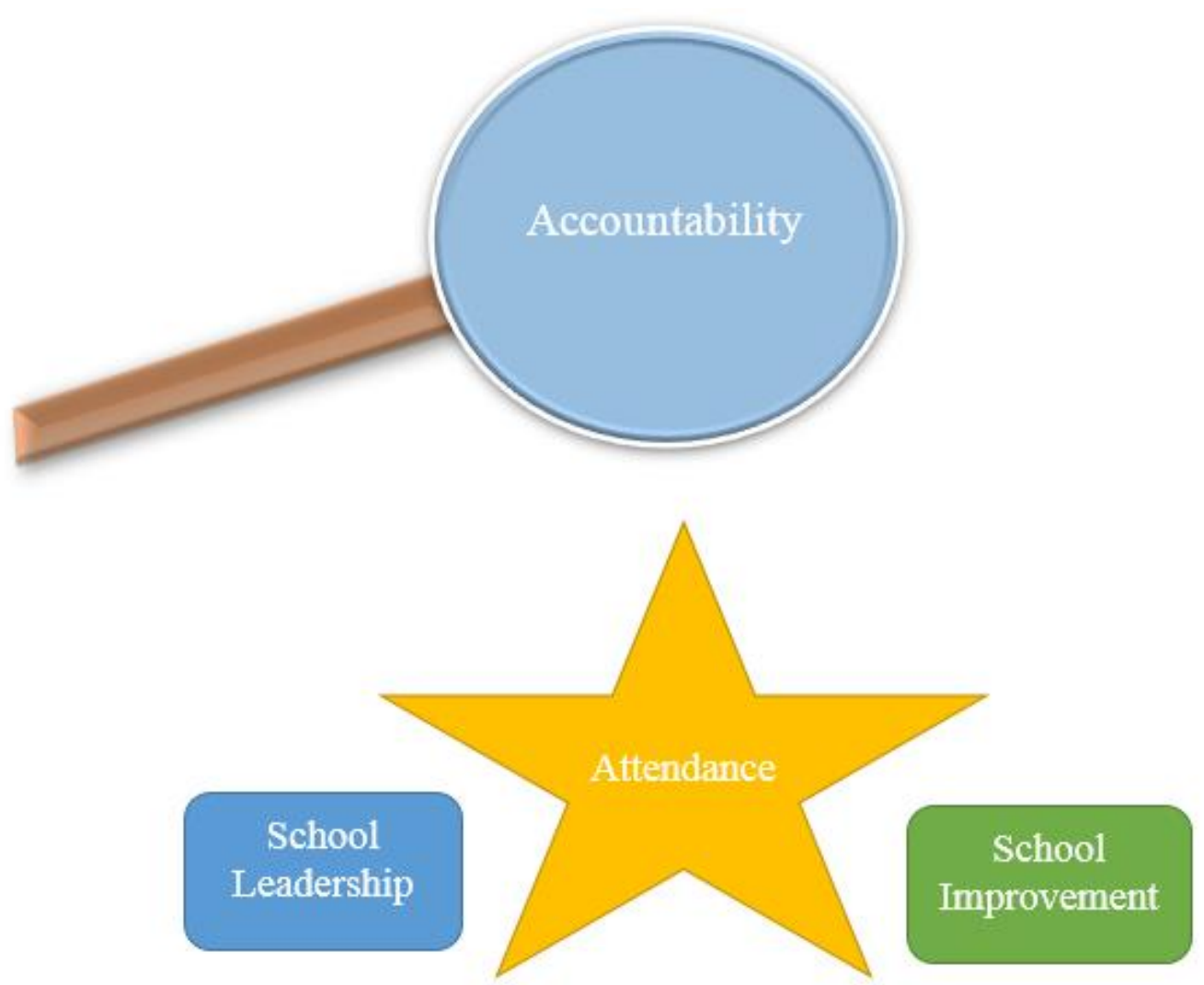

Figure 1. Illustration of the Conceptual Underpinning and lenses used to guide this study.

\section{Design of the Study}

This study was created for school districts and policy makers to learn from the perspectives of school leaders and challenges facing them when implementing new attendance policies and procedures in an effort to meet state accountability standards. With the main purpose of adding to the field of education and deepening the understanding of the impact that accountability, specifically attendance policies, can have on the overall effectiveness of school improvement.

The research method used was a descriptive case study of a bounded system (Merriam \& Tisdell, 2015) grounded in the interests of deepening the understanding of the impact accountability and attendance policies can have on school leaders and overall 
school improvement practices (Merriam \& Tisdell, 2015). Creswell (2013) describes the nature of this research as a qualitative case study as inquiry to render the complexity of the situation regarding accountability and attendance policies.

This descriptive case study of a bounded system (Merriam \& Tisdell, 2015) investigated the perceptions of secondary school administrators in member schools of The Valley View Conference (VVC). Although this research was qualitative, the use of basic quantitative statistics including school attendance percentages, student achievement data, and school MSIP APR scores helped in the triangulation of qualitative data collected. Triangulation occurred through the use of multiple sources of data, increasing the internal validity of this study (Merriam \& Tisdell, 2015). The triangulation of this data helped to create a richer, thicker, more in-depth description of the research.

\section{Site Description and Selection}

Sunnyhill School District and the other members of The Valley View Conference (VVC) was a bounded system purposefully selected due to their conference affiliation, regional locations, similar population distributions, and similar histories of attendance and accountability measures now being negatively affected by new accountability and attendance policies on the MSIP APR Grade card. For example, Sunnyhill and other VVC member schools were able to achieve all the attendance accountability points for attendance from 2002-2011 based on the previous ADA benchmark, but has failed to meet the new proportional benchmark since 2012 (Missouri Department of Elementary \& Secondary Education, 2015b). 


\section{Participant Sample}

Secondary building leaders of schools that are members of The VVC. The participant selection process for the individual interviews and focus groups was based on purposeful sampling of specific administrators and attendance review committees within the VVC regarding the topic (Creswell, 2013; Merriam \& Tisdell, 2015; Seidman, 2013).

\section{Research Methods and Data Collection}

A variety of qualitative research methods were used to identify secondary school leaders perceptions of the impact attendance accountability standards have on overall school improvement. The researcher utilized state archival documents to identify themes, as well as to ensure all parties are represented in the research. Interviews were held with VVC secondary school leaders, including but not limited to the following: current and former superintendents, current and former administrators, and members of individual school attendance committees. Triangulation occurred through the use of multiple sources of data, increasing the internal validity of this study (Merriam \& Tisdell, 2015).

Interviews were conducted face-to-face. The face-to-face interviews were short in length, ranged from 20-30 minutes. Interview protocols and questions were developed and field tested using guidelines by Fink (2013). Application of Fink's (2013) reliability and validity tests using pilot interviews were used to ensure interview questions provided consistency in the data analysis and coding process.

In addition to archival documents and interviews, a focus group was held consisting of Sunnyhill secondary schools attendance committee members. Focus groups were used to generate conversations amongst school leaders to allow for the researcher to see a range of ideas and feelings, understand different perspectives, as well as to uncover 
factors that influence opinions, behavior and motivation (Krueger \& Casey, 2009). The ideas that emerged through the focus groups were important to the researcher in uncovering emerging themes. These conversations also helped to provide a rich, thick description of the entire story behind attendance and accountability policies impact on school improvement.

Prior to both the interviews and focus group, the researcher obtained informed consent according to the recommendations of the American Educational Research Association from all participants (American Educational Research Association, 2011). The informed consent included the purpose of the study, procedures involved in the research, all foreseeable risks and discomforts to the subject, successes of the research, length of time, statement of voluntary participation, as well as the participants' right to confidentiality and right to withdrawal (Fink, 2013).

Archival data used includes MSIP APR data obtained through DESE that assisted in the triangulation and validation of the perceptions of school leaders. This data was also used to help the researcher identify recommendations and implications of this research on future state and school accountability policies.

\section{Data Analysis}

Once all of the data was gathered through interviews, focus groups, and archival documents, the researcher searched for patterns and themes through coding (Creswell, 2013; Merriam \& Tisdell, 2015). Member check was used to validate the accuracy of transcription (Merriam \& Tisdell, 2015). The researcher first performed open coding to allow themes to emerge from the data (Merriam \& Tisdell, 2015, p. 229). After specific themes were identified, the researcher recoded the data using axial coding, grouping the 
open codes by identifying relationships among them related within the central research question (Merriam \& Tisdell, 2015, p. 229). The researcher upheld Fink's (2013) recommendation that data should be coded twice, at least two weeks apart from one another.

\section{Limitations, Delimitations, and Assumptions}

Limitations of the study. A limitation of this study is that surveys and focus groups were conducted with school leaders from a limited number of schools belonging to a single conference affiliation. Regarding the limitation of qualitative research, as Creswell (2013) stated, "the researcher keeps a focus on learning and meaning that the participants hold about the program or issue, not the meaning that the researchers bring to the research or writers express in the literature" (p. 175). Personal researcher bias related to the topic of accountability standards and school leaders role in school improvement must be addressed as the researcher has served an administrator in a K-12 secondary education setting, observed and led school improvement strategies in secondary settings, and has served on attendance review committee programs.

Delimitations of the study. The boundaries of the study where all research and data collection took place was in the members school districts of the Valley View Conference in the Kansas City, MO region. There are no urban settings represented in this study. Other parameters of the study include participants who have served as secondary school leaders for at least two years. Due to these parameters, it is possible the researcher missed out on some considerations of those who have been in the field for less than two years, or have served in other non-leadership roles that could contribute valuable insight. 
Assumptions. The researcher may have encountered multiple assumptions while working with participants of the research study. The first assumption was trust established in the researcher (Merriam \& Tisdell, 2015). It is the hope of the researcher that participants want to contribute to the learning of others and provide truthful informative answers during the study; however, it is possible questions were not answered honestly in an interview format where the researcher is face-to-face with the participant.

The second assumption the researcher made is that everyone working as a leader in secondary public education has led school improvement and accountability strategies. The reality based on the researcher's work in public education, is that some districts take varied levels of strategic approaches when addressing school improvement and accountability. Additionally, some districts are in situations in which the level to which they must spend resources and time to address accountability and school improvement measures, may vary greatly from other districts or schools. The researcher assumed all participants had the desire for continuous school improvement, aim to meet school accountability measures, and strive to be excellent at his or her position.

\section{Definition of Key Terms}

Accountability. Thurlow (2009) defined "accountability as the assignment of responsibility for conducting activities in a certain way or producing specific results."

Compulsory Attendance Law. Section 167.031, RSMo, "at the age of seven children must enroll and attend regularly attend public, private, parochial, home school or a combination of schools for the full term of the school year" (Missouri Department of Elementary \& Secondary Education, 2016a). 


\section{Missouri Department of Elementary and Secondary Education (DESE).}

Missouri Department of Elementary and Secondary Education is a result of the Missouri Constitution in 1945 (Missouri Department of Elementary \& Secondary Education, 2016a).

Missouri School Improvement Plan 5 (MSIP 5). This document is used for public school accountability. The first year of implementation for MSIP was 1990 and is now in its fifth cycle. The purpose of this document is to reference resource and process standards, as well as report data to meet established goals (Missouri Department of Elementary and Secondary Education, 2015a).

Proportional Attendance Rate. Attendance targets use the individual student's attendance rate and set the expectation that $90 \%$ of the students are in attendance $90 \%$ of the time.

School Leader. For the purpose of this paper a school leader is defined as a person, typically an administrator, who provides or has provided oversight to school improvement or accountability measures.

School Improvement. For the purpose of this paper school improvement is defined as reform efforts aimed at improving the educational system in support for better student outcomes (Thoonen et al., 2012).

Secondary Education. Formal education of students in grades six through 12.

Student Achievement. An indicator used to determine academic growth from year to year and between students within the same educational setting or cohort. 
United States Department of Education (USDE). This department was

founded in 1867 to aid in the collection of data about schools and teaching (United States Department of Education, 2017b).

\section{Significance of the Study}

This study has many potential application possibilities for the educational field, and builds upon prior research completed in areas of accountability, attendance, school improvement, and K-12 school leadership. Regarding accountability, this study can be used assist in the development of recommendations for policies and procedures for school districts regarding attendance. This study could provide recommendations for not only the stated research questions, but also overarching questions that guide school improvement such as: "What are common policies and procedures in place for attendance in high achieving schools?" Additionally, this study can be used to begin to investigate the perceptions of stakeholders (school leaders) regarding the correlation between attendance and school improvement as measured by student achievement, and the perception of the validity in using $90 \%$ attendance as an accountability standard for schools. As Lee-Partridge et al. (2014) explained, while there continues to be an increasing amount of research supporting the relationship between attendance and achievement, the research exploring the relationship between attendance and performance when attendance is compulsory, however, is not conclusive.

Researchers (Brokowski \& Dempsey, 1979; Lee-Partridge et al., 2014; Marburger, 2006; Reid, 2008) agree that further investigation is needed to determine the relationship between attendance and school improvement as measured by achievement due to the many underlying factors within attendance that are still unknown. Therefore, 
further research should also investigate the attendance-achievement relationship and the school and instructional accountability model.

\section{Summary}

Research gaps exist that fail to investigate the perceptions of leaders in educational settings. Additional research is needed that seeks to understand the perception of school leaders, and the impact these attendance accountability standards have on their ability to fulfill their duties as instructional leaders of their buildings. This research was warranted in order to redefine where the focus of school and instructional improvement efforts should be, how these efforts are assessed, what accountability is, and how it should be sought and measured (Brokowski \& Dempsey, 1979; Klinger, Maggi, \& D'Angiulli, 2011). As Klinger et al. (2011) offer, instead of being used as a punitive device for districts, accountability frameworks and policies should be used as a method to measure and monitor student achievement and to increase responsibility in focusing instruction and improving subsequent student and school performance. 


\section{SECTION TWO}

\section{PRACTITIONER SETTING FOR THE STUDY}

The examination into the history and background of educational agencies from The United States Department of Education (USDE) down to the local school districts provides the setting for this study. Leadership and organizational analysis provided by the Bolman and Deal (2013) structural frame demonstrate hierarchy in the organization from the USDE to the local school district, while Mintzberg (1979/2005) Five Basic Parts of Organizations is used to display the organizational structure at the school level. All of these structures set the stage for this study and provide the context for desired research which include the perceptions of school leaders on the impact accountability standards have on their ability to ensure school improvement.

This section explains the history and background of USDE, Department of Elementary and Secondary Education (DESE), The Missouri School Improvement Plan (MSIP), and The Valley View Conference (VVC) organizations. Additionally, this section gives an organizational analysis of those educational agencies and analyzes the leadership involved. Implications for research in the practitioner setting are also explained.

\section{History of Organization}

\section{United States Department of Education}

The U.S. Department of Education is the agency of the federal government that establishes policy for, administers and coordinates most federal assistance to education. It assists the president in executing his education policies for the nation and in implementing laws enacted by Congress (United States Department of Education, 2010a). 
The mission of the Department of Education is to promote student achievement and preparation for global competitiveness by fostering educational excellence and ensuring equal access (United States Department of Education, 2010c). The USDE was founded in 1867 to aid in the collection of data about the nation's schools and teaching (United States Department of Education, 2010a). The Department was also charged with providing assistance to states when creating schools. To this day, the focus for the USDE is to provide policymakers and teachers with ideas of what works in education (United States Department of Education, 2010c, 2017b).

In the 1860 s, a budget of $\$ 15,000$ and four employees handled education factfinding. By 1965, the Office of Education had more than 2,100 employees and a budget of $\$ 1.5$ billion. In 2007-08, the Department's elementary and secondary school programs served approximately 55 million students (pre-K through grade 12) attending some 100,000 public schools and 34,000 private schools. Department programs also provided grant, loan and work-study assistance to about 10 million undergraduate students. As of mid-2010, the Department has nearly 4,300 employees and a budget of about $\$ 60$ billion.

\section{Missouri Department of Elementary and Secondary Education}

The mission of the Missouri Department of Elementary and Secondary Education is to guarantee the superior preparation and performance of every child in school and in life (Missouri Department of Elementary \& Secondary Education, 2016e). The Missouri Department of Elementary and Secondary Education came into existence as a result of the Missouri Constitution in 1945 which created the positions of the Commissioner's Office and the State Board of Education. Hubert Wheeler was the first Commissioner of Education and served in the position from 1947-1971 (Missouri Department of 
Elementary \& Secondary Education, 2016b). The Department of Elementary and Secondary Education (DESE) is the administrative arm of the State Board of Education. It is primarily a service agency that works with educators, legislators, government agencies, community leaders and citizens to maintain a strong public education system. Through its statewide school-improvement activities and regulatory functions, the Department strives to assure that all citizens have access to high-quality public education. The Department does not regulate, monitor or accredit private, parochial or home schools.

\section{State Board of Education}

According to the Missouri Constitution (Constitution of the United States, 2015), the supervision of instruction in the public schools shall be vested in a state board of education, consisting of eight lay members appointed by the governor, by and with the advice and consent of the senate; provided, that at no time shall more than four members be of the same political party. The term of office of each member shall be eight years, except the terms of the first appointees shall be from one to eight years, respectively. While attending to the duties of their office, members shall be entitled to receive only actual expenses incurred, and a per diem fixed by law. Under federal law, the Board serves as the state-level governing body for career and technical education programs provided by local school districts, community colleges and four-year institutions (Missouri Department of Elementary \& Secondary Education, 2016c).

Major duties of the Board include (Missouri Department of Elementary and Secondary Education, 2015b): (a) Appointing the Commissioner of Education and setting policies for the Department of Elementary and Secondary Education; (b) Defining 
academic performance standards and assessment requirements for public schools; (c) Accrediting local school districts. The Board accredits school districts through the "Missouri School Improvement Program," (Missouri Department of Elementary \& Secondary Education, 2015d) which includes minimum standards for: (a) high school graduation; (b) Curriculum; (c) student testing; (d) support services, and; (e) other areas of school operations. The Board also establishes requirements for the (a) education, (b) testing, (c) assessment, (d) certification and (e) recertification of all public school teachers and administrators.

\section{Missouri School Improvement Plan (MSIP)}

The MSIP was originally designed to promote excellence in the public schools of the state. According to the original Missouri School Improvement Program Standards and Indicators Manual (Missouri Department of Elementary \& Secondary Education, 2015d) the first installment of MSIP was originally designed to promote excellence in the public schools of the state through a twofold responsibility. The MSIP was used as a measure of the responsibility in guaranteeing that all schools meet certain basic standards and in ensuring that the public schools continue to strive for excellence in an increasingly competitive world.

MSIP 5 now has four stated policy goals: (a) Articulate the state's expectations for student achievement with the ultimate goal of all students graduating ready for success in college and careers; (b) Distinguish performance of schools and districts in valid, accurate and meaningful ways so that districts in need of improvement can receive appropriate support and interventions, and high-performing districts can be recognized as models of excellence; (c) Empower all stakeholders through regular communications and 
transparent reporting of results, and; (d) Promote continuous improvement and innovation within each district (Missouri Department of Elementary and Secondary Education, 2015a).

Currently, DESE is working with stakeholder to create MSIP 6. The Missouri School Improvement Program (Missouri Department of Elementary \& Secondary Education, 2017) works to prepare every child for success in school and life. MSIP 6 is the state's school accountability system for reviewing and accrediting public school districts in Missouri. MSIP began in 1990 and is preparing to enter its sixth version. The Department believes high expectations, a clear vision, and a few very focused high impact goals will be critical to drive the improvement efforts necessary to bring about positive results (Missouri Department of Elementary \& Secondary Education, 2017). DESE is beginning the work of reviewing and revising MSIP 5, the current version of the MSIP to address the following measures of success of schools: Academic achievement; Climate and culture; Effective educators and instructional practices; Effective and stable leadership and governance; Success ready graduates, and; Systems and processes.

\section{Valley View Conference (VVC)}

The Valley View Conference (VVC) was originally formed as the BIG FIVE Conference in 1928. Two more schools were added in 1934, transitioning the conference to the BIG SEVEN. An eighth school was added in 1941, leading to the formation of a committee to rename the conference. This is when the VVC was founded. Sunnyhill was a Charter Member of the Big Five Conference, did not compete in football in 1942 due to World War II, and withdrew from VVC competition following the 1970-71 school years. Sunnyhill re-entered the VVC (West) for the 2008-2009 School year, in which the 
conference divided into 2 divisions, according to school district student enrollment. The East division was made up of the smallest six schools, while the West comprised the six largest districts. The member schools of the VVC West include: Sunnyhill, Oaks Manor, Prairie Heights, Hairston, Otterville, and Great Views. According to the conference bylaws, the purpose of the VVC is to promote and enhance interscholastic activities for the students of the member schools.

VVC leadership structure. The governing boards within the VVC include:

- Board of Superintendents: Consists of the superintendent of each member school

- Board of Principals: Consists of the high school principal of each member school

- Board of Athletic Directors: Consists of the athletic/activities director of each member school

- Coaches/Sponsors Committees: Consists of the coach/sponsor of each activity for each member school

The VVC president and vice president for each board/committee will follow an annual alphabetical rotation of VVC schools and will serve as the host school for the year. The president presides at all meetings and prepares the agenda in conjunction with the VVC secretary. The Board of Superintendents employs the VVC secretary with consideration given to a recommendation from the Board of Principals. The Board of Superintendents determines the salary. 


\section{Background of VVC (West) Member Schools}

Sunnyhill School District. As of the census (United States Census Bureau, 2011) of 2010, there were 11,084 people, 4,278 households, and 2,836 families residing in the city. The population density was $1,062.7$ inhabitants per square mile $(410.3 / \mathrm{km} 2)$. There were 4,771 housing units at an average density of 457.4 per square mile (176.6/km2). The racial makeup of the city was $92.6 \%$ White, $2.8 \%$ African American, 0.7\% Native American, $0.5 \%$ Asian, $0.1 \%$ Pacific Islander, $0.8 \%$ from other races, and $2.4 \%$ from two or more races. Hispanic or Latino of any race were $3.3 \%$ of the population. The average household size was 2.46 and the average family size was 2.99 .

The median age in the city was 36.6 years. Population and age ranges included: $24.9 \%$ of residents were under the age of $18 ; 10.6 \%$ were between the ages of 18 and 24 ; $24.6 \%$ were from 25 to $44 ; 25 \%$ were from 45 to 64 ; and $14.9 \%$ were 65 years of age or older. The gender makeup of the city was $48.3 \%$ male and $51.7 \%$ female.

Educational facilities. The district operates the following seven schools: Elkhorn Elementary (K-5), Lewis Elementary (K-5), Westview Elementary (K-5), Excelsior Springs Middle School (6-8), Excelsior Springs High School (9-12), Excelsior Springs Area Career Center (10-12), and Job Corps Technical High School (9-12). The District has a total of 359 employees, including 18 administrative personnel, 204 teachers and 137 non-certified employees.

Great Views School District. Great Views is located in the Kansas City Metropolitan Area and is a suburb of Kansas City, Missouri. It is approx. 23 miles east of Kansas City. Great Views was founded in the 1870 s and was named for the general character of the region. 
As of the census (United States Census Bureau, 2011) of 2010, there were 12,854 people, 4,566 households, and 3,395 families residing in the city. The population density was 2,121.1 inhabitants per square mile $(819.0 / \mathrm{km} 2)$. There were 4,867 housing units at an average density of 803.1 per square mile $(310.1 / \mathrm{km} 2)$. The racial makeup of the city was 92.6\% White, 2.5\% African American, 0.6\% Native American, 0.6\% Asian, 0.1\% Pacific Islander, $1.2 \%$ from other races, and $2.3 \%$ from two or more races. Hispanic or Latino of any race were $4.9 \%$ of the population. The average household size was 2.81 and the average family size was 3.22.

The median age in the city was 30.5 years. Population and age ranges included: $32.1 \%$ of residents were under the age of $18 ; 7.5 \%$ were between the ages of 18 and 24; $35.2 \%$ were from 25 to $44 ; 18.3 \%$ were from 45 to 64 ; and $6.8 \%$ were 65 years of age or older. The gender makeup of the city was $48.9 \%$ male and $51.1 \%$ female.

Educational facilities. The district operates the following eight schools: Matty, Sni, Prairie, and Stony Elementary Schools (K-5), Great Views Early Childhood Center (Pre-K), Great Views North Middle School (6-8), Great Views South Middle School (68), and Great Views High School (9-12). The district has a total of 370 certified staff and 4,251 students.

Hairston School District. Hairston was founded in 1837 upon land donated to Cass County by Congress for county purposes, and was named for Congressman Albert G. Harrison, who was instrumental in obtaining the land grant. As of the census of 2010, there were 10,019 people, 3,854 households, and 2,516 families residing in the city. The population density was $1,014.1$ inhabitants per square mile $(391.5 / \mathrm{km} 2)$. There were 4,144 housing units at an average density of 419.4 per square mile $(161.9 / \mathrm{km} 2)$. The 
racial makeup of the city was $95.0 \%$ White, $1.1 \%$ African American, $0.7 \%$ Native American, $0.6 \%$ Asian, $0.8 \%$ from other races, and $1.7 \%$ from two or more races. Hispanic or Latino of any race were $2.6 \%$ of the population. The average household size was 2.49 and the average family size was 3.07 . The median age in the city was 35.5 years. Population and age ranges included: $27.1 \%$ of residents were under the age of 18 ; $8.4 \%$ were between the ages of 18 and $24 ; 26.6 \%$ were from 25 to $44 ; 22.4 \%$ were from 45 to 64 ; and $15.5 \%$ were 65 years of age or older. The gender makeup of the city was $47.2 \%$ male and $52.8 \%$ female.

Educational facilities. The district operates the following six schools: Hairston and Mcwee Elementary Schools (K-5), Hairston Early Childhood Center (Pre-K), Hairston Middle School (6-8), Hairston Career Center (9-12), and Hairston High School (9-12). The district has a total of 233 certified staff and 2,452 students.

Oats Manor School District. The population was 7,795 at the 2010 census. As of the census (United States Census Bureau, 2011) of 2010, there were 7,795 people, 2,791 households, and 2,068 families residing in the city. The population density was 1,263.4 inhabitants per square mile $(487.8 / \mathrm{km} 2)$. There were 2,990 housing units at an average density of 484.6 per square mile $(187.1 / \mathrm{km} 2)$. The racial makeup of the city was 94.7\% White, 1.1\% African American, 0.8\% Native American, 0.7\% Asian, 0.1\% Pacific Islander, $0.8 \%$ from other races, and 1.8\% from two or more races. Hispanic or Latino of any race were $3.7 \%$ of the population. The average household size was 2.76 and the average family size was 3.16 .

The median age in the city was 32.4 years. Population and age ranges included: $30.6 \%$ of residents were under the age of $18 ; 8.8 \%$ were between the ages of 18 and 24 ; 
$28.3 \%$ were from 25 to $44 ; 20.4 \%$ were from 45 to 64 ; and $11.8 \%$ were 65 years of age or older. The gender makeup of the city was $48.5 \%$ male and $51.5 \%$ female.

Educational facilities. The district operates the following four schools: Oats Elementary School (K-5), Oats Primary School (K-5), Oats Middle School (6-8), and Oats High School (9-12). The district has a total of 165 certified staff and 2,041 students.

Prairie Heights School District. The population was 8,113 at the 2010 census. According to the 2010 census (United States Census Bureau, 2011), the city has a total area of 8.18 square miles $(21.19 \mathrm{~km} 2)$, of which, 8.01 square miles $(20.75 \mathrm{~km} 2)$ is land and 0.17 square miles $(0.44 \mathrm{~km} 2)$ is water.[1] Prairie Heights is located at the convergence of Missouri Highway 7 and Missouri Highway 58 and is approximately 8.7 miles south of US Highway 50.

As of the census of 2010, there were 8,113 people, 2,959 households, and 2,196 families residing in the city. The population density was 1,012.9 inhabitants per square mile (391.1/km2). There were 3,169 housing units at an average density of 395.6 per square mile (152.7/km2). The racial makeup of the city was $95.3 \%$ White, $0.7 \%$ African American, $0.5 \%$ Native American, $0.5 \%$ Asian, $0.1 \%$ Pacific Islander, 1.2\% from other races, and $1.7 \%$ from two or more races. Hispanic or Latino of any race were $3.7 \%$ of the population. The average household size was 2.71 and the average family size was 3.13.

The median age in the city was 33.7 years. Population and age ranges included: $29.5 \%$ of residents were under the age of $18 ; 8.2 \%$ were between the ages of 18 and 24 ; $28.8 \%$ were from 25 to $44 ; 21.9 \%$ were from 45 to 64 ; and $11.7 \%$ were 65 years of age or older. 
Educational facilities. The district operates the following five schools: Prairie Heights Primary School (PK-2), Prairie Heights Elementary School (3-4), Prairie Heights Intermediate (5-6), Prairie Heights Middle School (7-8), and Prairie Heights High School (9-12). The district has a total of 192 certified staff and 2,328 students.

Otterville School District. The population was 5,300 at the 2010 census. According to the 2010 census (United States Census Bureau, 2011), the city has a total area of 4.13 square miles $(10.70 \mathrm{~km} 2)$, of which, 4.10 square miles $(10.62 \mathrm{~km} 2)$ is land and 0.03 square miles $(0.08 \mathrm{~km} 2)$ is water. Otterville is located roughly 45 minutes from downtown Kansas City, Missouri and about three hours from St. Louis, Missouri.

As of the census of 2010, there were 5,300 people, 2,077 households, and 1,427 families residing in the city. The population density was 1,292.7 inhabitants per square mile $(499.1 / \mathrm{km} 2)$. There were 2,280 housing units at an average density of 556.1 per square mile $(214.7 / \mathrm{km} 2)$. The racial makeup of the city was $94.8 \%$ White, $1.4 \%$ African American, $0.4 \%$ Native American, $0.4 \%$ Asian, $0.3 \%$ from other races, and 2.6\% from two or more races. Hispanic or Latino of any race were $2.2 \%$ of the population. The average household size was 2.52 and the average family size was 3.00.

The median age in the city was 35.2 years. Population and age ranges included: $27 \%$ of residents were under the age of $18 ; 8.8 \%$ were between the ages of 18 and 24 ; $26.6 \%$ were from 25 to $44 ; 22.8 \%$ were from 45 to 64 ; and $14.8 \%$ were 65 years of age or older. The gender makeup of the city was $48.2 \%$ male and $51.8 \%$ female.

Educational facilities. The district operates the following four schools: Otterville Elementary School (K-2), Otterville Upper Elementary School (3-5), Otterville Middle 
School (6-8), and Otterville High School (9-12). The district has a total of 170 certified staff and 2,041 students.

\section{Organizational Analysis}

The State Board of Education, Department of Elementary and Secondary Education, the VVC Conference and member schools are like many organizations; they are complex with many moving parts. A simple hierarchy presented by Bolman and Deal (2013) can be used to demonstrate how the organization has many members represented that provide the structure for USDE, DESE, and down to VVC member schools. Additionally, Bolman and Deal (2013) provide a structural framework that helps bring clarity and meaning to organizations. The structural frame focuses on the architecture of

the organization, including the design of units and subunits, rules and roles, and goals and policies (Bolman \& Deal, 2013). Each of the VVC member school districts that participated in this study share a similar type of organizational hierarchy.

The leadership analysis uses Mintzberg's (1979/2005) Five Basic Parts of Organizations to display VVC members school's organizational structure. Mintzberg (1979/2005) differentiates five major components in organizational structure: operating core, strategic apex, middle line, technostructure, and support staff. 


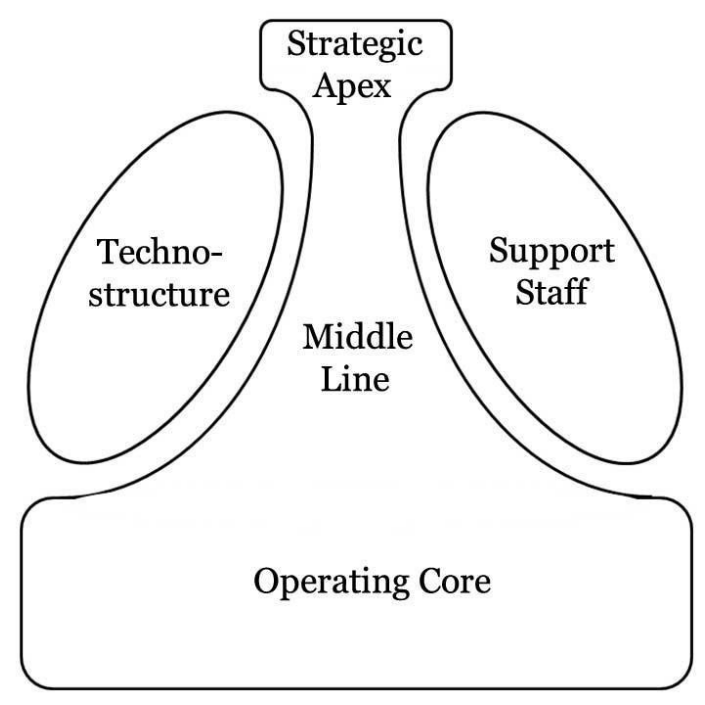

Figure 2. The Five Basic Parts of Organizations. This figure shows a small strategic apex connected by a widening middle line to a large, flat operating core. The technostructure and the support staff are shown off to the sides to indicate that they are separate from the main line and only indirectly influence the operating core. Adapted from "The five basic parts of the organization" by H. Mintzberg, 1979, Reprinted Classics of Organizational Theory, J Sharfritz, J. Ott, \& Y Jang (Eds), 2005, p. 220.

\section{United States Department of Education}

The secretary of education leads the Department and promotes public understanding of the Department's mission, goals and objectives. The secretary is nominated by the president and confirmed by the Senate. As a member of the president's Cabinet, the secretary is the principal adviser to the president on federal policies, programs and activities related to education in the United States (United States Department of Education, 2010a). The organizational structure and hierarchy of the Board of Education is as follows (United States Department of Education, 2017a): 


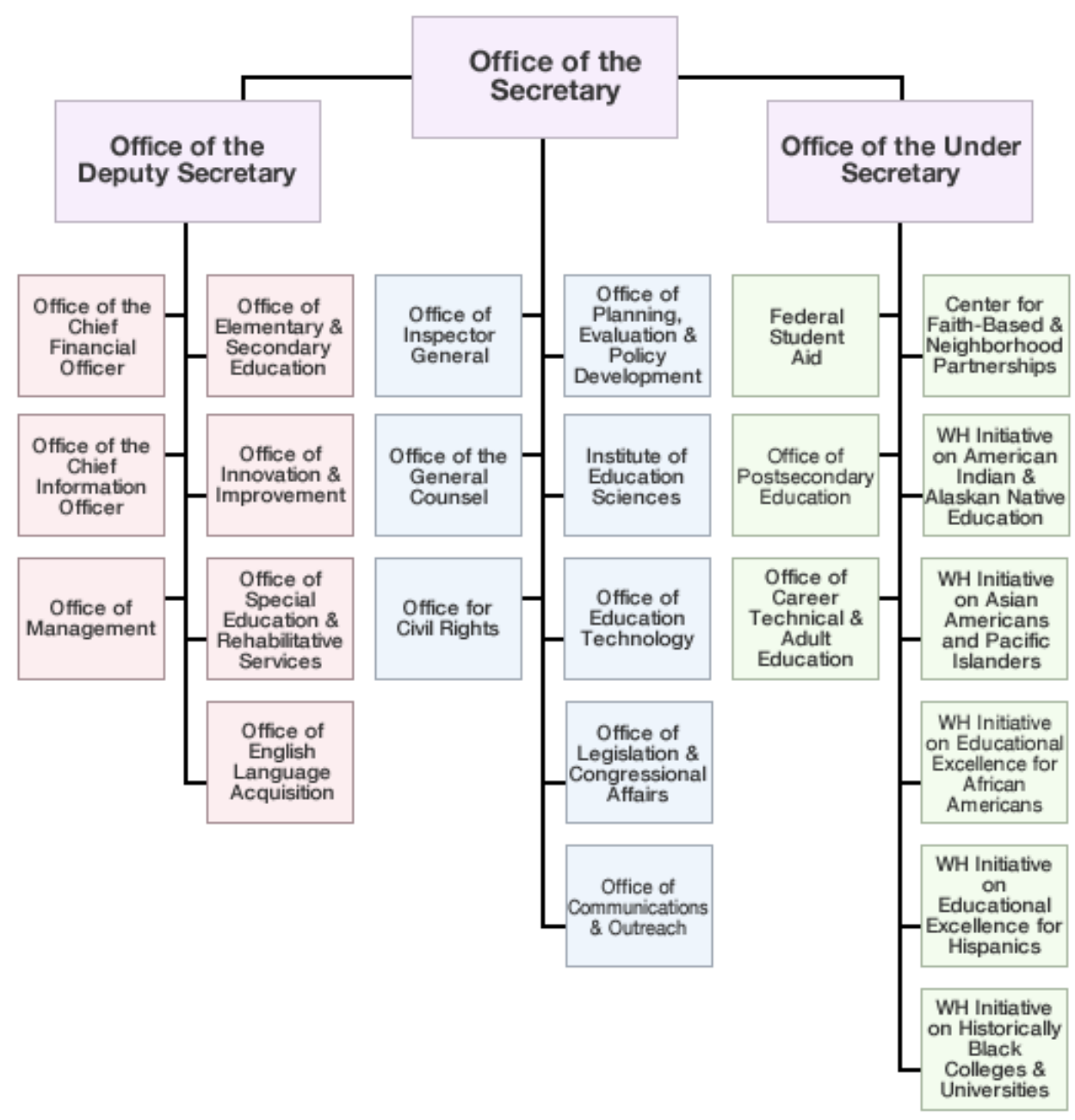

Figure 3. Organizational structure for United States Department of Education

Figure 3 displays the many hierarchical levels to the USDE. The deputy secretary plays a pivotal role in overseeing and managing the development of policies, recommendations and initiatives that help define a broad, coherent vision for achieving the president's education priorities. The undersecretary oversees policies, programs and activities related to postsecondary education, vocational and adult education, and federal student aid (United States Department of Education, 2010a). 


\section{State Board of Education}

The Missouri State Board of Education leads the Department of Elementary and Secondary Education. This Board is comprised of eight citizens appointed by the Governor and confirmed by the Senate (Missouri Department of Elementary \& Secondary Education, 2016c). These appointed citizens serve an eight-year term and are sanctioned by political party affiliation and county of residence (Missouri Department of Elementary \& Secondary Education, 2016b).

One of the major jobs of the Missouri State Board of Education is to appoint the commissioner. In addition to the appointment of a Commissioner, The Missouri State Board of Education has many duties, some of which include: sets policies; defines academic performance standards and assessment requirements for public schools; accredits local schools; establishes assessment requirements; establishes certification requirements; establishes federal programs and funding; oversees fiscal management; establishes school bus safety; makes recommendations to the Missouri Legislature regarding the annual budget; and oversees vocational rehabilitation and sheltered workshops (Missouri Department of Elementary \& Secondary Education, 2016c). The Board does not have direct authority over higher education institutions. However, the Board sets standards for and approves courses and professional programs for teachers and school administrators in Missouri's public and private higher education institutions.

\section{Missouri Department of Elementary and Secondary Education}

DESE is the administrative arm of the State Board of Education and is headed by the commissioner of education. The Commissioner of Education directs DESE and fulfills other duties as prescribed by law. According to DESE, the Commissioner shall 
"seek in every way to elevate the standards and efficiency of the instruction given in the public schools of the state" (Missouri Department of Elementary and Secondary

Education, 2015b). Figure 3 displays the hierarchical layers of DESE, led by the

Commissioner of Education. Two deputy commissioners report to the commissioner

regarding the division of learning services, and the division of financial and

administration services.

The organizational structure and hierarchy of the Board of Education is shown in

Figure 4 (Missouri Department of Elementary \& Secondary Education, 2016d).

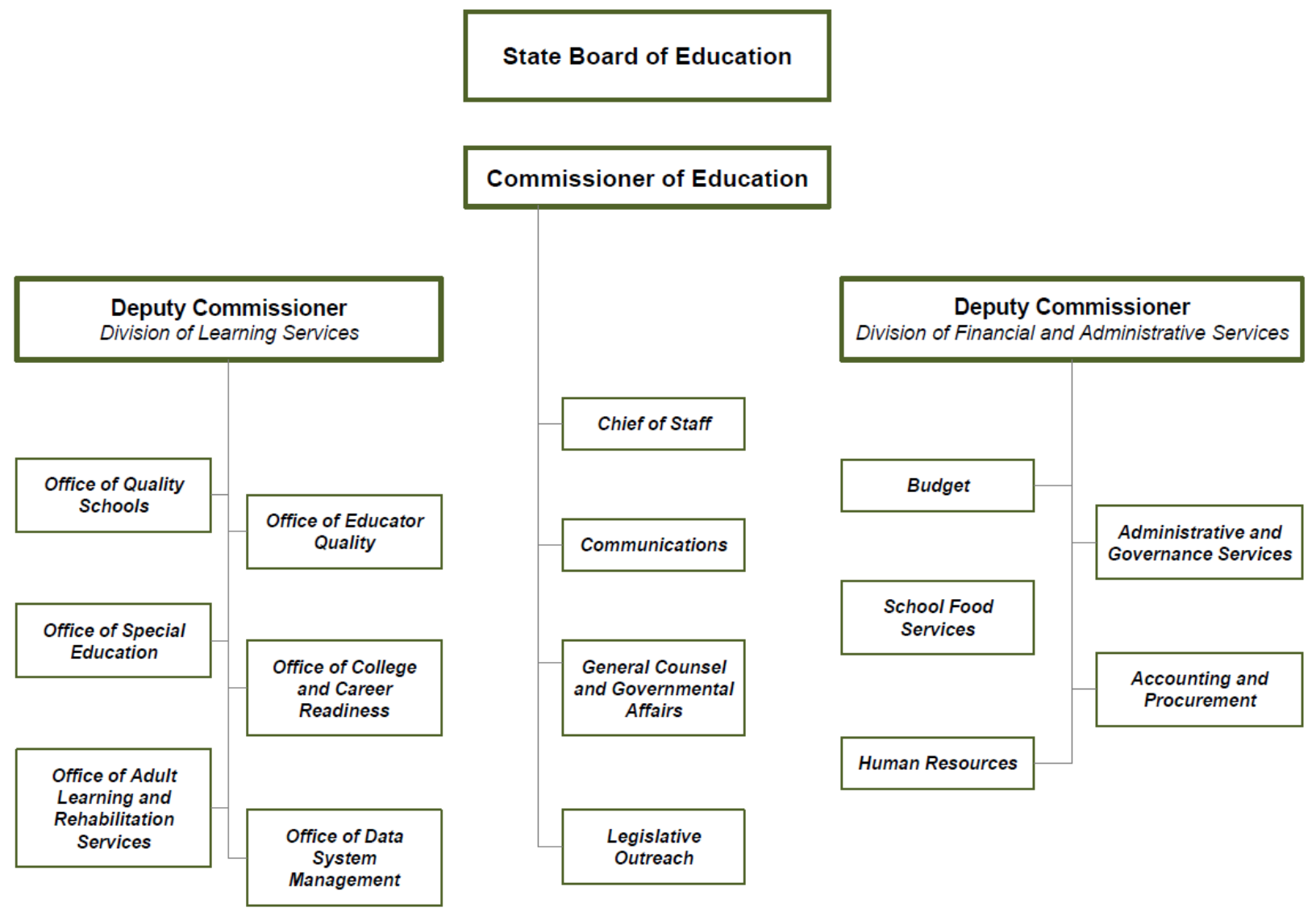

Figure 4. Organizational structure for Missouri Department of Elementary and Secondary Education 
Through its statewide school-improvement activities and regulatory functions, the Department strives to assure that all citizens have access to high-quality public education. The Department does not regulate, monitor or accredit private, parochial or home schools. The Department's responsibilities range from early childhood to adult education services. The Department employs about 1,700 people throughout the state and has a total budget of about $\$ 5.4$ billion. About 96 percent of the budget consists of state and federal funds that are distributed to local school districts and other agencies.

\section{VVC (West) and Member Schools}

The Valley View Conference is an example of a more traditional bureaucracy with a hierarchical leadership style. This is evident by their slow adaption and change throughout the years. Updating a policy or enacting a procedural change within the conference by-laws is a convoluted process dictated by several votes of different boards within the district, a very political process. The secretary of the board is elected by the Superintendents, and continues to be the Athletic Director with the most tenure in the conference in order to protect the history of how things have been done in the past. Suggestions for change within bylaws are typically and most-often brushed aside as evidenced by it taking six years of coach's appeals to add a goalie to the soccer allconference team.

The political frame as explained by Bolman and Deal (2013) suggests that cultural or social norms of the group are often determined through the influence of social power. The social power of the VVC conference is created and manipulated by its individual long-tenured members aligning in order to make decisions and determine group norms (Bolman \& Deal, 2013). Understanding the culture of the VVC 
organization and the political powers at play can play a vital role in determining why certain attendance policies are or are not successful within my own school. Are VVC schools policies effective because that is the way it has always been done, or is the perception of school leaders lend to other factors affecting school attendance?

The individual school districts are governed by a seven-member Board of Education. The members of the Board are elected by the voters of the district for threeyear staggered terms with two or three members being elected each year. All Board members are elected at-large and serve without compensation. The Board is responsible for all policy decisions. The President of the Board is elected by the Board from among its members for a term of one year and has no regular administrative duties. The Secretary and Treasurer are appointed by the Board and may or may not be members of the Board.

The Board of Education appoints the Superintendent of Schools who is the chief administrative officer of the District responsible for carrying out the policies set by the Board. Additional members of the administrative staff are appointed by the Board of Education upon recommendation by the Superintendent.

Organizational structure. Using Mintzberg's (1979/2005) Five basic parts of the organization, the organizational structure and hierarchy of the member schools of VVC are displayed in Figure 5: 
1. President of the Board of Education (Strategic Apex)

2. Board of Education (Strategic Apex)

3. Superintendent (Strategic Apex)

4. Superintendent's Cabinets: (Strategic Apex)

1. Assistant and/or Deputy Superintendent(s);

2. Director(s);

5. Building Principals (Middle Managers)

6. Building Staff (Operating Core, Technostructure, Support Staff)

Figure 5. Organizational structure and hierarchy for The Valley View Conference member schools.

The VVC member schools are like many school districts of their size. Within the organizations themselves, they exemplify the five basic parts of an organization as defined by Mintzberg (1979/2005). Understanding the organization is important in understanding the leadership and accountability hierarchy when it comes to student attendance, school improvement, and building leaders' impact on these factors. Building leaders are responsible for leading school improvement practices through the day to day operations, and report to the appropriate director, deputy superintendent, or superintendent.

\section{Leadership Analysis}

Northouse (2015) describes leadership as a process, not a singular trait or characteristic residing in an individual, whereby an individual influences a group of individuals to achieve common goals. Leadership means many different things to many different people (Northouse, 2015). Effective building leaders in today's school accountability world, must be willing and able to change with the task and 
responsibilities issued from a manager to a subordinate, such as new accountability standards being passed down from USDE and DESE, through the direct supervision of the superintendent's office (Northouse, 2015). As Bolman and Deal (2013) suggest, in order to achieve a higher level of performance, leadership and accountability standards must have clear goals, be mission focused with well-defined roles, and include a close alignment of structure and tasks.

\section{National and State Level Leadership}

The Office of DESE is a division of the USDE; which supports many initiatives provided to state education agencies. The USDE and DESE are charged with initiating and developing statewide school-improvement accountability standards, activities, and regulatory functions, in order to assure that all citizens have access to high-quality public education. These two departments regulate, monitor, and accredit schools according to these standards. The Office of Academic Improvement oversees funding related to school reform. The Office of Quality Schools manages state accreditation for public school districts which directly relates to receiving funds for the many programs provided through the USDE and furthermore, the Office of Academic Improvement (United States Department of Education, 2010c). Under the Office of Quality Schools, data is also provided to grade schools based on MSIP 5. This is then directed down to the local education agencies. Figure 2 and Figure 3 provide visual reference and clarity for this hierarchy.

\section{District and Building Level Leadership}

Missouri School Board Association (MSBA) is the provider of policy to multiple school districts throughout Missouri while DESE provides resource standards and process 
standards for meeting state achievement standards as leaders plan a budget year (Missouri Department of Elementary \& Secondary Education, 2016b). School superintendents, assistant superintendents, and directors then disseminate accountability standards and monitor building leaders' ability to meet these standards in varying degrees.

Building leaders are responsible for leading school improvement practices through the day to day operations, and report to the appropriate director, deputy superintendent, or superintendent. We know from existing effective schools research that effective principals influence a variety of school outcomes, yet some current school leaders have a restricted understanding of their role in the improvement of teaching and learning (Rhodes \& Brundrett, 2009; Rice, 2010). Consequently, the improved management of teaching and learning is being identified as a key role of school principals as accountability policies continue to include standards such as attendance that may not align with this focus (Rhodes \& Brundrett, 2009; Rice, 2010).

\section{Leadership in Accountability}

This approach of accreditation and accountability many times focuses on the assignment of rewards and potential harsh sanctions for schools based on measurable outcomes; such as student performance on standardized tests, school attendance, postsecondary placement of graduates. Regardless of the context in which an institution or governing body is using accountability, it is rarely addressing the underlying concepts which link diverse issues surrounding school improvement (Chakrabarti \& Schwartz, 2013). Unfortunately, in the past these accountability standards have been derived using a coercive top-down hierarchical leadership style. 
Although accountability measures and accreditation standards are necessary, unfortunately many outside pressures are placed on DESE which determines these goals. From Congress to statehouses to grassroots communities and parent groups, some people are trying to break the educational experience into units of accountability. This bureaucracy seeks to improve student learning by improving these individual measurable units by making other people more accountable for something in education (O'Day, 2002).

Fortunately, a more collective style using open forums and community/stakeholder input has been used for MSIP6 creation and implementation (Northouse, 2015). Utilizing Bolman and Deal (2013) structural frame to analyze current state; the core premises essential to performance include well understood goals, roles, and relationships with adequate coordination. The structure frame uses groups to divide up the work and use skills to address needs (Bolman \& Deal, 2013). The office of the Commissioner of Education and DESE have done a better job of attempting to mobilize district and community leaders to tackle the tough problems facing them regarding accountability (Missouri Department of Elementary \& Secondary Education, 2017). It is still to be determined if DESE will use the input gathered from school leaders for MSIP 6 , and provide them with the support needed; knowing that not doing so would likely result in harsh feedback and criticism from the community (Heifetz \& Laurie, 1997/2011; Northouse, 2015).

\section{VVC Leadership and Accountability}

As mentioned in the previous section, VVC leadership is an example of a traditional bureaucracy with a hierarchical leadership style. This is evident by their slow 
adaption and change throughout the years. The influence of social power and cultural norms (Bolman \& Deal, 2013) of the VVC conference is created and manipulated by its individual long-tenured members. Understanding the culture of the VVC organization and the political powers at play can play a vital role in determining why certain attendance policies are or are not successful within my own school.

The leadership and accountability hierarchy within VVC member schools is like many school districts of their size. Within individual school districts, although different leadership styles vary leader by leader, the make-up of the accountability structure is very similar as displayed in Figure 4 above. When it comes to student attendance, school improvement, and building leaders' impact on these factors is straight forward for

member schools. While individual school Boards are responsible for all policy decisions, building leaders are responsible for leading school improvement practices through the day to day operations, and report to the appropriate director, deputy superintendent, or superintendent.

\section{Implications for Research in Practitioners Setting}

Due to the unknown factors behind absenteeism and the need of research in this area (Arthurs et al., 2014; Brokowski \& Dempsey, 1979; Wilkins, 2008), more research is needed to determine if attendance should be used as an indicator to determine school accreditation as with the MSIP5 90/90 proportional attendance policy. If we continue to use attendance as an accountability tool for school districts, forcing schools to institute more restrictive and punitive attendance policies, we could be creating a greater chasm between our high and low achievers as researchers suggest. 
The MSIP 5 attendance accountability standards for each district requires districts to maintain high levels of attendance; $90 \%$ of your students attending $90 \%$ or more of the minutes required (Missouri Department of Elementary \& Secondary Education, 2016a). This leaves schools to focus on how to get students to school and keep them there, but no motivation to improve their quality of education when they are there. Instead of being used as a punitive device for districts, accountability frameworks and policies should be used as a method to measure and monitor student achievement and to increase responsibility in focusing instruction and improving subsequent student and school performance.

This study has many potential application possibilities for the educational field, and will build upon prior research completed in areas of accountability, achievement, attendance, and school improvement. Regarding accountability, this study could be used assist in the development of recommendations for policies and procedures for school districts regarding attendance. Additionally, this study could be used to begin to investigate the perceptions of school leaders regarding the correlation between attendance and school improvement as measured by student achievement, and the perception of the validity in using $90 \%$ attendance as an accountability standard for schools. This study also aims to collect school leaders' perceptions of effective school improvement and attendance strategies that can be shared with school districts and building leaders.

As Lee-Partridge et al. (2014) explained, while there continues to be an increasing amount of research supporting the relationship between attendance and achievement, the research exploring the relationship between attendance and performance when attendance is compulsory, however, is not conclusive. Researchers (Brokowski \& Dempsey, 1979; 
Lee-Partridge et al., 2014; Marburger, 2006; Reid, 2008) agree that further investigation is needed to determine the relationship between attendance and school improvement as measured by achievement due to the many underlying factors within attendance that are still unknown.

\section{Summary}

Accountability standards in public education has evolved from a local and state function to now include federal oversight and mandates (Ambrosio, 2013; Bolman \& Deal, 2013). At the national and state levels the accountability has grown to be largely measured through standardized input values (Ingram et al., 2004; Lamdin, 1996; Mellor

\& Griffith, 2015) and have been utilized to assess a value-added measurement for school improvement, accountability, and accreditation; while also being used to measure administrator and teacher effectiveness.

Through the analysis of interviews and focus groups focusing on school leaders perceptions of accountability standards, research will be available to public school governing agencies, school districts, and building leaders that can help to highlight the successes and challenges of using attendance as an accountability standard for school improvement. Once created, this research can be presented to local school districts, at state conferences, and even on the national level. The researcher's hope is to provide districts with solid research that can assist in the development of recommendations for policies and procedures for school districts regarding attendance. 


\section{SECTION THREE}

\section{SCHOLARLY REVIEW FOR THE STUDY}

In 2012, Sunnyhill Middle School met attendance accountability standards and achieved all available attendance Annual Performance Report (APR) points using average daily attendance (ADA) percentage calculations (Missouri Department of Elementary \& Secondary Education, 2012a). At Sunnyhill, ADA hovers around 93-96\% daily attendance rate, which was perfect for previous school year's accountability standards. Since the implementation of a new proportional attendance accountability standard, things have changed for Sunnyhill Middle School, and school districts across the state (Missouri Department of Elementary \& Secondary Education, 2014). In the 2014-2015 school year, only $82 \%$ of Sunnyhill's students were at school $90 \%$ of the time. In the old system of calculating attendance using (ADA) (the percentage of students in school each day) the student with perfect attendance "hid", or made up, for the chronically absent students. The new state attendance standard has new outside influences, as well as the school and district's accountability scores for APR, pressuring schools in similar precarious attendance situations to make drastic changes in attendance policies. These policies are forcing schools and districts to spend more time and resources on addressing attendance woes.

\section{Statement of the Problem}

Nationwide, state accountability attendance standards continue to be influenced by outside pressures impacting school and district accountability scores for APR (Darling-Hammond, 2004, 2010a, 2012; Darling-Hammond \& Wise, 1985; Hanushek \& Raymond, 2005; O'Day, 2002; Thoonen et al., 2012). From national and local politicians 
to educational policy makers, pressures are placing schools in precarious attendance situations to make drastic changes in attendance policies in order to meet new standards (Mellor \& Griffith, 2015; Missouri Association of School Administrators, 2015a, 2015b). These policies are forcing schools and districts to spend more time and resources on addressing attendance woes.

Increased attendance accountability on schools from the state has led to major policy changes at the school and district level. The issue of student attendance and the expectations placed on school districts from the Missouri Department of Elementary and Secondary Education (DESE) through the Missouri School Improvement Plan (MSIP) accreditation benchmarks has become a hot topic throughout K-12 public education. Attendance has leaped to the forefront of school districts attention in order to meet the state's changed expectations (benchmarks) for MSIP5 and APR accreditation. During the MSIP5 accountability cycle, DESE changed the district accountability benchmark from an ADA calculation to a proportional attendance average requiring $90 \%$ of students attend school $90 \%$ of the time (Missouri Department of Elementary \& Secondary Education, 2016a). This has led to major policy changes and serious discussions regarding student attendance for schools and its validity as an accreditation benchmark. Educators find themselves struggling with the new guidelines and finding ways to ensure every student has acceptable attendance.

The majority of research concerning the link between attendance and school improvement as measured by student achievement, has come from higher education. More specifically, much of this research comes from individual classroom or course expectations, not facility-wide policies. Additionally, little accountability research exists 
surrounding the use of attendance as an accountability measure. Much of the research that does exist, focuses on the impact of compulsory attendance policies and grade outcomes in specific courses or classes (Snyder et al., 2014).

Furthermore, research regarding the impact of attendance on a school district's accountability and accreditation cannot be found. Most research done in this area have used a quantitative approach in an attempt to capture the correlation between attendance and achievement. Little qualitative research exists to investigate the participant's stories. Research also proves nonexistent in the perceptions of leaders in educational settings. This research will seek to understand the perception of school leaders, and the impact these attendance accountability standards have on their ability to fulfill their duties as instructional leaders of their buildings.

A gap in knowledge exists, failing to clearly define the connection between attendance, achievement, school improvement, and accountability demands placed on school districts from policy makers. Moreover, there is very little research investigating the impact greater accountability on a school's attendance has on instruction, school procedures, and leader focus. Understanding the perceptions of school leaders that are working the frontlines in our schools, would help give policymakers a better idea of what is working and what is not when it comes to our students and schools. What is most important is being able to focus accountability and school improvement on student success and achievement and motivating schools to improve their quality of education once students arrive (Darling-Hammond, 2004, 2010a, 2012; Hanushek \& Raymond, 2005; O'Day, 2002; Reid, 2008). 


\section{Conceptual Underpinning}

Accountability of schools is a hot topic endlessly debated throughout the world by educators, politicians, and school and community stakeholders alike. The conceptual underpinning for this study is accountability as introduced in the early work of Levin (1974). According to Levin, four relatively distinct concepts of accountability exist in schools: (a) as performance reporting; (b) as a technical process; (c) as a political process; (d) as an institutional process. In addition to Levin's research, the accountability underpinning has continued to be examined and used as a lens for research by Chakrabarti and Schwartz (2013), Darling-Hammond (2004, 2010a, 2012); DarlingHammond and Wise (1985), and Ingram et al. (2004). Regardless of the context in which an institution or governing body utilizes accountability standards, it is rarely addressing the underlying concepts which link Levin's four diverse issues.

\section{Accountability Policies}

One assumption underlying accountability policies and the approach most commonly used by state agencies is that results from measurable sources such as attendance, standardized tests, and other sources will be used to make decisions about school and classroom practice simply because they are measurable (Chakrabarti \& Schwartz, 2013; Ingram et al., 2004). This approach of accreditation and accountability focuses on the assignment of rewards and potential harsh sanctions for schools based on measurable outcomes, regardless if they are proven to impact student learning and school improvement (Chakrabarti \& Schwartz, 2013; Ingram et al., 2004).

Anderson (2005) suggest that accountability standards and policies should be workable, defensible systems that are built upon five aligned components including: 
objectives, assessments, instruction, resources, and rewards or sanctions. Currently, school accountability systems operate according to a set of principles laid out for them, and use a variety of implementation strategies, with particular attention given to the political and technical aspects of accountability. Anderson explained the difficult situation educators are placed in by explaining how different systems require two things simultaneously: "for what" and "to whom" (Anderson, 2005, p. 1). As Anderson explains, educators are to be accountable for student learning and adherence to standards and rules, while being held accountable to the bureaucracy, peers, and the general public. According to Ingram et al. (2004), for standards and accountability policies to be effective in changing the core technology of education - teaching and learning - schools must use accountability data to make decisions about whether they are meeting standards or not and, if not, then use data to change practices and monitor the effectiveness of those changes. Despite the pivotal role of data use in this and other current school improvement policies, there is little empirical research on how these policies affect practice (Chakrabarti \& Schwartz, 2013; Darling-Hammond, 2004; Ingram et al., 2004)

Although accountability measures and accreditation standards are necessary, unfortunately many outside pressures are placed on DESE which determines these goals. Many times student learning and achievement are not the top priority of these political pressures. In a political sense, these accountability standards are being dictated by a set of constituencies each with a set of priorities that determine new demands on the education sector reflecting the individual goals of these constituents according to their relative power in the society, as well as their success at forging meaningful coalitions (Bolman \& Deal, 2013; Levin, 1974). Using measurable data to hold school districts 
accountable and to determine the accreditation status of school districts is key to overall school improvement. The crux of the issue is deciding what data is pertinent to determining accreditation status, and if data such as attendance should be used simply because it is measurable.

To address some of these concerns, The Missouri Association of School Administrators (MASA) has sponsored a Show Me Accreditation Task Force commissioned to research and develop a framework for school accreditation. The study will identify and provide recommendations to the Commissioner of Education, Dr. Margie Vandeven, for guidance in changes for MSIP 6 accreditation and assessment and what indicators of success an accreditation system should include (Missouri Association of School Administrators, 2015a, 2015b, 2015c).

\section{Attendance Validity}

Concerning the validity of attendance as an accreditation benchmark, the Association for Supervision and Curriculum Development (ASCD) "has been calling for more meaningful accountability systems that promote continuous support and improvement and align with the broader outcomes we collectively want for our students. In particular, such systems should incorporate a variety of measures that more fully reflect a comprehensive definition of student success, accurately measure student learning, and systematically track educators' efforts to engage and support learners" (Mellor \& Griffith, 2015, p. 3).

Due to the unknown factors behind absenteeism and researchers admission of the need for additional research in this area (Arthurs et al., 2014; Brokowski \& Dempsey, 1979; Wilkins, 2008), should a characteristic such as attendance be used as an indicator 
to determine school accreditation and accountability? If we continue to use attendance as an accountability tool for school districts, forcing schools to institute more restrictive and punitive attendance policies, are we pushing kids out our doors as dropouts? Contrarily to using attendance for accountability, Klinger et al. (2011) suggest accountability frameworks should be used as a method to measure and monitor student achievement and to increase responsibility in focusing instruction and improving subsequent student and school performance.

The key variables of this research are based on attendance, school improvement, and school leadership as viewed through an accountability conceptual underpinning lens. The following sections of this paper are a synthesis and critique of literature related to these key variables, and their context within the accountability underpinning.

\section{Key Variables}

\section{Attendance}

According to Camera (2016), more than 6.5 million students nationwide miss 15 or more days of school in an academic year. Additionally, students who have two absences per month during a school year are also less likely to graduate from school contributing to ever-increasing dropout rates (Ginsburg et al., 2014). Due to alarming statistics such as those above, DESE tasked school districts with improving attendance through new attendance accountability standards. In 2013, under the Missouri School Improvement Plan (MSIP 5), the new proportional attendance policy was announced stating that attendance targets use the individual student's attendance rate and set the expectation that $90 \%$ of the students are in attendance $90 \%$ of the time (Missouri Department of Elementary \& Secondary Education, 2015d). 
Attendance and achievement. The literature and research examining the relationship between attendance and achievement/performance is vast (Brokowski \& Dempsey, 1979; Ginsburg et al., 2014; Lee-Partridge et al., 2014; Marburger, 2006). An abundant amount of research exists suggesting that regular attendance is a positive indicator of student achievement and performance. Upon further investigation, depending on the depth of the research, methodology being used, and groups of students being examined, many researchers (Lee-Partridge et al., 2014) are beginning to question the validity or correlation of attendance and achievement among the general population of students. Snyder Lee-Partridge et al. (2014) suggests that higher attendance for all students only significantly increases achievement and performance for those highachieving students that are already extremely invested in their education and future.

Contrary to the findings of Snyder et al. (2014), Brokowski and Dempsey (1979) contend that implementation of an attendance policy may result in improved performance in attendance and achievement for certain students (high I.Q.), certain groups (low I.Q.) demonstrated a significant increase in number of disciplinary suspensions they were issued when the policy was in operation. If low I.Q. students are compiling more discipline issues, pushing them further into the demographics resembling an "at-risk" student, this may further impede their ability to achieve at a high level, as it makes them more susceptible to become a dropout according to Wilkins (2008). The themes that Wilkins discovered that serve as motivators for at-risk students to attend school were: School climate, academic environment, discipline, and relationships with teachers. These themes suggest that if students are incurring more discipline and achieving at a lower academic level it decreases their motivation to attend school on a regular basis. Wilkins 
(2008) research suggests it is apparent "that the cause of students' detachment from school lay within the school itself” (p.12).

Attendance and accountability. When specifically considering MSIP 5's 90/90 proportional attendance policy, Paredes and Ugarte (2011) found academic performance in students who missed nine days during the school year reduced by at least 23 percent of the standard deviation of the score on standardized mathematics test. This stat suggests attendance policies have merit. Regarding specific thresholds, such as 90 percent in the new proportional attendance policy, Paredes and Ugarte (2011) found a "significant breakpoint at 13 absences, but contrary to what was expected, the academic performance of students after the threshold did not decrease, which questions the existence of minimum attendance requirements" (p. 200). Contrarily, Daugherty (2008) concluded that "higher rates of absenteeism reduced academic performance, as measured by standardized mathematics and language tests. After 15 absences, the average score on the mathematics test was below the required state limit" (p. 194).

School impact on attendance. Chronic absence is a result of a combination of factors: school, family and community ("Attendance and the early grades: A twogeneration issue," 2014). It is more difficult to develop a system that measures school efforts and effectiveness on working with their communities, schools, and families to build a culture of attendance. The research of Balfanz and Byrnes (2012) further supports the theory that schools may not be able to control many of the reasons that students do not come to school.

In their work, Balfanz and Byrnes (2012) designated three categories for school absences: students cannot come, will not come, or choose not to come to school. They 
also note that lack of transportation, housing instability, family responsibilities, and parents lacking to see the importance of coming to school every day. They do not value school and have the ability to miss class, especially for older students. What role schools play in addressing these factors, and to the extent they should be held accountable for regular attendance, is still debated (Balfanz \& Byrnes, 2012; Zalaznick, 2015).

As Zalaznick (2015) suggests, It's more important to get to the root of why students aren't coming to school and be able to align the solution with the problem, if school leaders take the punitive approach in efforts to reach accountability standards, more than likely schools are not going to see any improvement in attendance. It's important policy makers understand the causes of absenteeism and develop community policies that help parents keep kids in school, such as family leave policies and effective transportation systems; coupled with programs that help the child; and improved policies at the school level, such as collecting the right data and working with families to identify barriers to school attendance will ensure that every child succeeds ("Attendance and the early grades: A two-generation issue," 2014).

\section{School Improvement and School Leadership}

This section focuses on research surrounding the national interest in school leadership and school improvement. In many studies (Reid, 2008; Rhodes \& Brundrett, 2009; Rice, 2010) leadership and improvement have been closely linked and there is no doubt that this linkage plays an important role in K-12 education. The synthesis of the research in this section review present understandings and tenets surrounding leadership development and school improvement, and prompt further consideration of the advancement of research and theoretical understandings of the linkage between the two concepts. Additionally, seeking to understand the impact that accountability standards 
can have on leadership development, and the impact this may have on overall strides and direction in school improvement.

School improvement. In many countries, national and local politicians, educational policy makers, and practitioners are involved in reform efforts at improving the educational system in support for better student outcomes (Thoonen et al., 2012). Rhodes and Brundrett (2009) conceptualize school improvement by stating, "Improving schools has generally become associated with the engagement of change activities that will raise school effectiveness by increasing the desired outcomes for learners" (p. 361). If school improvement is characterized by improving desired outcomes for learners, or improving student achievement, this concept plays a major role, or should play a major role, in the development of accountability policies.

School improvement accountability. Hanushek and Raymond (2005) analysis shows that accountability systems introduced in the 1990's and through No Child Left Behind (NCLB) had a clear and positive impact on student achievement. The stronger concern that Hanushek and Raymond's research found was that although achievement had improved, the stronger accountability standards resulted in unintended consequences such as increased dropout rates. As compulsory attendance policies result in student discipline from lack of attendance, are we further abandoning and disenfranchising those students that already feel coming to school is unimportant (Arthurs et al., 2014; Marburger, 2006; Reid, 2008)?

Conversations surrounding education among reformers and policy-makers nationwide today is about accountability and school improvement. From Congress to statehouses to grassroots communities and parent groups, some people are trying to break 
the educational experience into units of accountability. This bureaucracy seeks to improve student learning by improving these individual measurable units by making other people more accountable for something in education (O'Day, 2002).

As Darling-Hammond and Wise (1985) surmised 37 years ago, when policy makers are instituting new accountability standards they must be conscious of direct and indirect consequences. For instance, if successful schools are held accountable to a new proportional attendance standard that results in them no longer meeting state standards, will efforts to improve attendance percentages result in reduced efforts aimed at teaching and learning?

Researchers agree that accountability measures and interventions should be focused on the improvement of instruction and student learning, and these efforts should be driven to foster improvement on information relevant to teaching and learning (Darling-Hammond, 2004, 2010a, 2010b, 2012; O'Day, 2002; Reid, 2008). Furthermore, researchers support placing an importance on motivating individuals and schools to use that information and expend effort to improve practice, build the knowledge base necessary for interpreting and applying the information to improve practice and the allocation of resources to this end (Darling-Hammond, 2004, 2010a, 2010b, 2012; O'Day, 2002; Reid, 2008).

Attendance accountability. According to Reid (2008), if you wish to improve school attendance, you may first have to raise the self-esteem levels of certain groups of vulnerable pupils. By instituting accountability policies agencies are increasing the use of punitive measures in an attempt to raise attendance, when in fact, we are failing to meet Reid's stated objective of needing to raise their self-esteem. Punitive consequences for 
lack of attendance would seem to increase the expectation of the student to not meet expectations, and the self-fulfilling prophecy continues.

Little accountability research exists surrounding the use of attendance as an accountability measure (Lee-Partridge et al., 2014). Much of the research that does exist, focuses on the impact of compulsory attendance policies and grade outcomes in specific courses or classes (Snyder et al., 2014). There is very little research investigating the impact greater accountability on a school's attendance has on instruction, school procedures, and leader focus. Furthermore, research regarding the impact of attendance on a school district's accountability and accreditation cannot be found.

Klinger et al. (2011) offer, instead of being used as a punitive device for districts, accountability frameworks and policies should be used as a method to measure and monitor student achievement and to increase responsibility in focusing instruction and improving subsequent student and school performance. The approach of using attendance as an accountability standard focuses on the assignment of rewards and potential harsh sanctions for schools based on measurable outcomes, regardless if they are proven to impact student learning and school improvement (Chakrabarti \& Schwartz, 2013; Ingram et al., 2004).

Role of leadership. The role of leadership in fostering improvement in teaching and learning to improve student outcomes is now attracting greater attention in a wider range of countries. For example, recent research has shown that in some schools, teacher leadership is underdeveloped and limits improvement efforts (Grant, 2006; Rhodes \& Brundrett, 2009). We also know from existing effective schools research that effective principals influence a variety of school outcomes, yet some current school leaders have a 
restricted understanding of their role in the improvement of teaching and learning (Rhodes \& Brundrett, 2009; Rice, 2010). Consequently, the improved management of teaching and learning is being identified as a key role of school principals as accountability policies continue to include standards such as attendance that may not align with this focus (Rhodes \& Brundrett, 2009; Rice, 2010).

Contrarily, studies analyzing the work of principals found that principals engage in over 40 different kinds of tasks daily (Horng, Klasik, \& Loeb, 2010; Rice, 2010). They spend most of their time on activities in two categories: administrative activities including student supervision, scheduling, and compliance issues; and organizational management tasks including personnel and budget matters. In contrast, less than 10 percent of principal time is spent on instructional-related activities such as classroom (Horng et al., 2010; Rice, 2010).

Leadership impact on school improvement. A meta-analysis conducted by Hallinger and Heck (2004) found that the general pattern of results drawn from 15 years of research supported the belief that principals exercised a measurable and statistically significant indirect effect on school effectiveness and student improvement. The concluded that while substantial progress has been made over the past 15 years in understanding the principal's contributions to school effectiveness, important scholarly and practical research still needs to be completed to have a more holistic understanding (Hallinger \& Heck, 2004).

For many years, school improvement has been associated with the quality of teaching and learning in classrooms while research on school improvement has also 
indicated that the quality of education experienced by learners is strongly influenced by school leadership (Leithwood \& Jantzi, 2000; Rhodes \& Brundrett, 2009).

Leadership impact on attendance. According to the work by Heck and Mayor (1993), school characteristics and school academic indicators help explain attendance and behavioral outcomes. According to their work, school grade levels, percentage of students on free/reduced lunch, and school size account for about $36 \%$ of variance. Additionally, Heck and Mayor found that administrator attitudes regarding a push for achievement and the number of teachers with five or more years' experience at the school are significantly related to attendance outcomes, adding about $9 \%$ of the explained variance. Taking these findings into account, we are holding schools accountable for an attendance standard that at least $36 \%$ of the variance is predicted by variables that schools cannot control, resulting in school leaders spending less time focused on increased achievement and teacher retention, which is positively related to increased attendance.

Leadership and community development. There is a growing body of research to show that working more closely with local communities has the potential for improving schools and learner outcomes through enhanced teacher and learner engagement in education (Balfanz \& Byrnes, 2012; Heck \& Mayor, 1993; Reid, 2008; Rhodes \& Brundrett, 2009; Rice, 2010; Zalaznick, 2015). Studies in the United States have shown that greater stakeholder involvement can contribute to better student behavior, youth and adult relationships, attendance and learning outcomes (Rhodes \& Brundrett, 2009; Zalaznick, 2015). The connection between leadership and attendance improves with community development, not compulsory accountability practices. 


\section{Conclusion \& Future Implications}

Due to the unknown factors behind absenteeism, researchers agree (Arthurs et al., 2014; Brokowski \& Dempsey, 1979; Wilkins, 2008) that further investigation is needed to determine the relationship between attendance and school improvement as measured by achievement due to the many underlying factors within attendance that are still unknown. Lee-Partridge et al. (2014) explained, while there continues to be an increasing amount of research supporting the relationship between attendance and achievement, the research exploring the relationship between attendance and performance when attendance is compulsory, however, is not conclusive. Therefore, further research should also investigate the attendance-achievement relationship and the school and instructional accountability model. Research gaps exist that fail to investigate the perceptions of leaders in educational settings.

Additional research is needed that seeks to understand the perception of school leaders, and the impact these attendance accountability standards have on their ability to fulfill their duties as instructional leaders of their buildings. This research is warranted in

order to redefine where the focus of school and instructional improvement efforts should be, how these efforts are assessed, what accountability is, and how it should be sought and measured (Brokowski \& Dempsey, 1979; Klinger et al., 2011). As Klinger et al. (2011) offer, instead of being used as a punitive device for districts, accountability frameworks and policies should be used as a method to measure and monitor student achievement and to increase responsibility in focusing instruction and improving subsequent student and school performance. 


\section{SECTION FOUR}

\section{CONTRIBUTION TO PRACTICE}

Who: Association for Middle Level Education (AMLE)

When: Fall, 2018

How: Through a PowerPoint presentation and executive summary handout. The presentation will be given by the researcher along with a visual presentation.

\section{Type of Document}

Document type will be a visual presentation that will be presented at the Fall 2018 AMLE National Conference. The visual presentation will inform the audience of leader perceptions of attendance policies and procedures used to increase attendance in an attempt to meet accountability standards through school improvement. The presentation will also include suggestions for attendance improvement strategies in school buildings. Upon request the full report can be made available.

\section{Rationale for this Contribution Type}

These intensive, innovative summits offer professional learning designed exclusively for middle grade and secondary educators. Attendees are presented with ideas to immediately implement in their school and classroom and network. New research, innovative instructional methods, trends, and special programs are featured. 


\title{
A Case Study of Secondary School Leaders' Perceptions of Attendance Policies and Procedures Used to Increase Attendance
}

\author{
Mark Bullimore \\ University of Missouri-Columbia \\ mab8vf@mail.missouri.edu
}

\section{INTRODUCTION}

Nationwide, state accountability attendance standards have new outside influences impacting school and district accountability scores for APR (Darling-Hammond, 2004, 2010a, 2012; Darling-Hammond \& Wise, 1985; Hanushek \& Raymond, 2005; O'Day, 2002; Thoonen, Sleegers, Oort, \& Peetsma, 2012). From national and local politicians to educational policy makers, pressures are placing schools in precarious attendance situations to make drastic changes in attendance policies (Mellor \& Griffith, 2015; Missouri Association of School Administrators, 2015a, 2015b) . These policies are forcing schools and districts to spend more time and resources on addressing attendance woes. 


\section{PURPOSE OF THE STUDY}

The purpose of this study is to fill the gap by exploring the secondary school leaders' perceptions of attendance policies and procedures used to increase attendance in an attempt to meet accountability standards through school improvement practices and the impact.

To add to the field of education a deeper understanding of school leaders perspectives on the impact attendance accountability standards on the overall effectiveness of school improvement.

\section{CONCEPTUAL FRAMEWORK}

The conceptual underpinning for this study is accountability as introduced in the early work of Levin (1974). In addition to Levin's research, the accountability underpinning has continued to be examined and used as a lens for research by Chakrabarti and Schwartz (2013), DarlingHammond (2004, 2010a, 2012); Darling-Hammond and Wise (1985), and Ingram et al. (2004). 


\section{OVERARCHING RESEARCH QUESTION}

The overarching research question (Creswell, 2013) guiding this study is: What are secondary school leaders' perceptions of attendance policies and procedures?

\section{QUESTIONS GUIDING RESEARCH}

The following sub-questions helped to narrow and focus the inquiry. Further, these subquestions provided guidelines for the researchers exploration during interview and focus group questions (Creswell, 2013):

- What are school leader perceptions regarding the impact of increased accountability on their attendance?

- What are school leader perceptions of the impact new attendance policies have on other school improvement factors?

- What are principals' perceptions regarding the change in their role after Missouri's new attendance accountability standard in MSIP5 (90/90 proportional attendance compared to average daily attendance) and the impact it has had on instruction, school procedures, and leader focus? 


\section{DESIGN OF THE STUDY}

Design of the Study

The research will used will be a descriptive case study of a bounded system (Merriam \& Tisdell, 2015) grounded in the interests of deepening the understanding of the impact accountability and attendance policies can have on school leaders and overall school improvement practices (Merriam \& Tisdell, 2015).

Triangulation will occur through the use of multiple sources of data, increasing the internal validity of this study (Merriam \& Tisdell, 2015). The triangulation of this data will help to create a richer, thicker, more in-depth description of the research.

This descriptive case study of a bounded system (Merriam \& Tisdell, 2015) will investigate the perceptions of secondary school administrators in member schools of The Valley View Conference (VVC). Although this research will be qualitative, the use of basic quantitative statistics including school attendance percentages, student achievement data, and school MSIP APR scores may help in the triangulation of the qualitative data collected. 


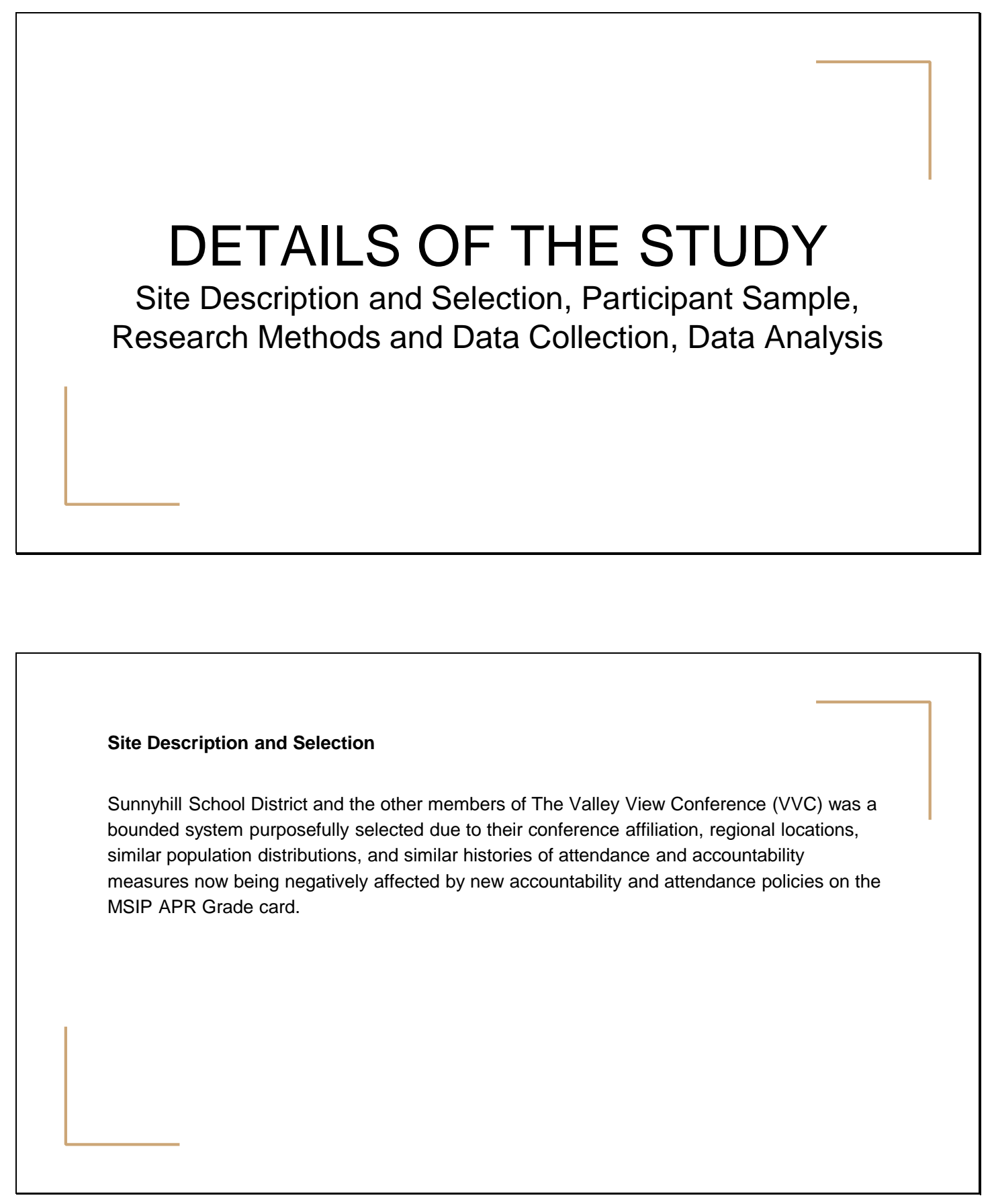




\section{Participant Sample}

Secondary building leaders of schools that are members of The VVC. The participant selection process for the individual interviews and focus groups are based on purposeful sampling of specific administrators and attendance review committees within the VVC regarding the topic (Creswell, 2013; Merriam \& Tisdell, 2015; Seidman, 2013).

\section{Research Methods and Data Collection}

A variety of qualitative research methods were used to identify secondary school leaders perceptions of the impact attendance accountability standards have on overall school improvement. Interviews, a focus Group, and archival data were used to triangulate results.

The researcher utilized state archival documents to identify themes, as well as to ensure all parties are represented in the research. Interviews will be held with VVC secondary school leaders, including but not limited to the following: current and former superintendents, current and former administrators, and members of individual school attendance committees. One focus group consisted of Sunnyhill secondary schools attendance committee members. Triangulation occurred through the use of multiple sources of data, increasing the internal validity of this study (Merriam \& Tisdell, 2015). 


\section{Data Analysis}

The researcher first performed open coding to allow themes to emerge from the data (Merriam \& Tisdell, 2015).

After specific themes were identified, the researcher re-coded the data using axial coding, grouping the open codes by identifying relationships among them related within the central research question (Merriam \& Tisdell, 2015).

Once all of the data was gathered through interviews, focus groups, and archival documents, the researcher searched for patterns and themes through coding (Creswell, 2013; Merriam \& Tisdell, 2015).

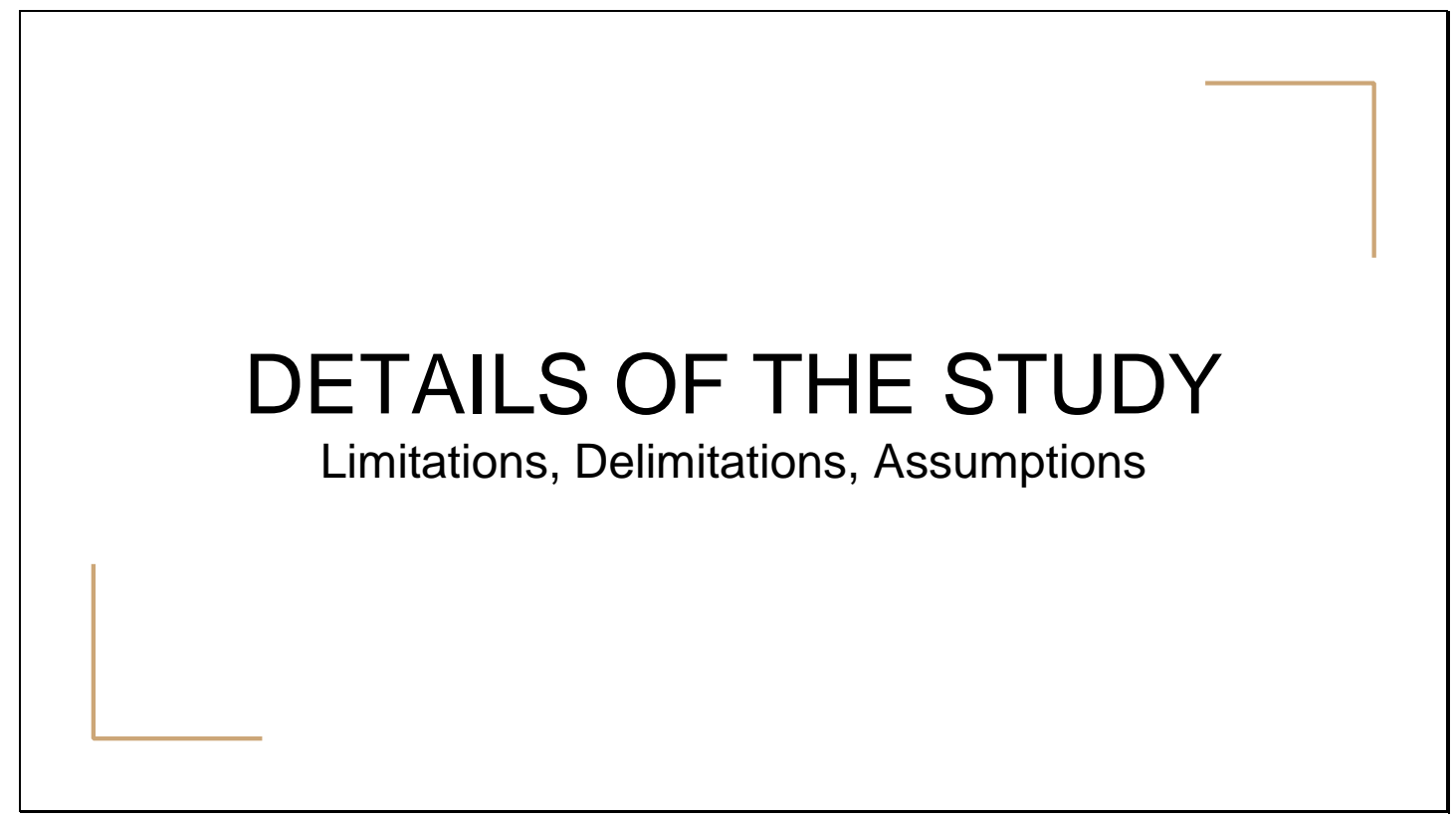


A limitation of this study is that surveys and focus groups were conducted with school leaders from a limited number of schools belonging to a single conference affiliation. Personal researcher bias related to the topic of accountability standards and school leaders role in school improvement must be addressed as the researcher has served an administrator in a $\mathrm{K}-12$ secondary education setting, observed and led school improvement strategies in secondary settings, and has served on attendance review committee programs.

\section{Limitations}

The boundaries of the study where all research and data collection took place was in the members school districts of the Valley View Conference in the Kansas City, MO region. There are no urban settings represented in this study. Other parameters of the study include participants who have served as secondary school leaders for at least two years. Due to these parameters, it is possible the researcher missed out on some considerations of those who have been in the field for less than two years, or have served in other non-leadership roles that could contribute valuable insight.

\section{Delimitations}

The first assumption was trust established in the researcher (Merriam \& Tisdell, 2015). It is the hope of the researcher that participants want to contribute to the learning of others and provide truthful informative answers during the study; however, it is possible questions were not answered honestly in an interview format where the researcher is face-to-face with the participant.

The second assumption is that everyone working as a leader in secondary public education has led school improvement and accountability strategies. The reality based on the researcher's work in public education, is that some districts take varied levels of strategic approaches when addressing school improvement and accountability.

The researcher assumed all participants had the desire for continuous school improvement, aim to meet school accountability measures, and strive to be excellent at his or her position.

\section{Assumptions}




\section{ACCOUNTABILITY LEADERSHIP ANALYSIS}

Accountability standards in public education has evolved from a local and state function to now include federal oversight and mandates (Ambrosio, 2013; Bolman \& Deal, 2013). At the national and state levels the accountability has grown to be largely measured through standardized input values (Ingram et al., 2004; Lamdin, 1996; Mellor \& Griffith, 2015) and have been utilized to assess a valueadded measurement for school improvement, accountability, and accreditation; while also being used to measure administrator and teacher effectiveness.

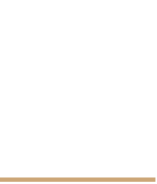

\section{WHAT DO THE SCHOLARS SAY?}




\section{Attendance as an Accountability Accreditation Benchmark}

Concerning the validity of attendance as an accreditation benchmark, the Association for Supervision and Curriculum Development (ASCD) "has been calling for more meaningful accountability systems that promote continuous support and improvement and align with the broader outcomes we collectively want for our students. In particular, such systems should incorporate a variety of measures that more fully reflect a comprehensive definition of student success, accurately measure student learning, and systematically track educators' efforts to engage and support learners" (Mellor \& Griffith, 2015, p. 3).

Due to the unknown factors behind absenteeism and researchers admission of the need for additional research in this area (Arthurs et al., 2014; Brokowski \& Dempsey, 1979; Wilkins, 2008), should a characteristic such as attendance be used as an indicator to determine school accreditation and accountability?

\section{Attendance and accountability.}

When specifically considering MSIP 5's 90/90 proportional attendance policy, Paredes and Ugarte (2011) found academic performance in students who missed nine days during the school year reduced by at least 23 percent of the standard deviation of the score on standardized mathematics test. This stat suggests attendance policies have merit. Regarding specific thresholds, such as 90 percent in the new proportional attendance policy, Paredes and Ugarte (2011) found a "significant breakpoint at 13 absences, but contrary to what was expected, the academic performance of students after the threshold did not decrease, which questions the existence of minimum attendance requirements" (p. 200). Contrarily, Daugherty (2008) concluded that "higher rates of absenteeism reduced academic performance, as measured by standardized mathematics and language tests. After 15 absences, the average score on the mathematics test was below the required state limit" (p. 194). 
School impact on attendance.

Chronic absence is a result of a combination of factors: school, family and community ("Attendance and the early grades: A two-generation issue," 2014). It is more difficult to develop a system that measures school efforts and effectiveness on working with their communities, schools, and families to build a culture of attendance. The research of Balfanz and Byrnes (2012) further supports the theory that schools may not be able to control many of the reasons that students do not come to school.

As Zalaznick (2015) suggests, It's more important to get to the root of why students aren't coming to school and be able to align the solution with the problem, if school leaders take the punitive approach in efforts to reach accountability standards, more than likely schools are not going to see any improvement in attendance.

\section{School improvement accountability.}

Conversations surrounding education among reformers and policy-makers nationwide today is about accountability and school improvement. From Congress to statehouses to grassroots communities and parent groups, some people are trying to break the educational experience into units of accountability. This bureaucracy seeks to improve student learning by improving these individual measurable units by making other people more accountable for something in education (O'Day, 2002).

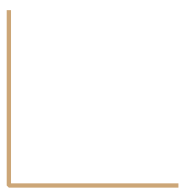

Researchers agree that accountability measures and interventions should be focused on the improvement of instruction and student learning, and these efforts should be driven to foster improvement on information relevant to teaching and learning (Darling-Hammond, 2004, 2010a, 2010b, 2012; O'Day, 2002; Reid, 2008). 
Attendance accountability.

According to Reid (2008), if you wish to improve school attendance, you may first have to raise the self-esteem levels of certain groups of vulnerable pupils. By instituting accountability policies agencies are increasing the use of punitive measures in an attempt to raise attendance, when in fact, we are failing to meet Reid's stated objective of needing to raise their self-esteem. Punitive consequences for lack of attendance would seem to increase the expectation of the student to not meet expectations, and the self-fulfilling prophecy continues.

Little accountability research exists surrounding the use of attendance as an accountability measure (Lee-Partridge et al., 2014). There is very little research investigating the impact greater accountability on a school's attendance has on instruction, school procedures, and leader focus. Furthermore, research regarding the impact of attendance on a school district's accountability and accreditation cannot be found.

\section{Attendance accountability (cont'd)}

Klinger et al. (2011) offer, instead of being used as a punitive device for districts, accountability frameworks and policies should be used as a method to measure and monitor student achievement and to increase responsibility in focusing instruction and improving subsequent student and school performance. The approach of using attendance as an accountability standard focuses on the assignment of rewards and potential harsh sanctions for schools based on measurable outcomes, regardless if they are proven to impact student learning and school improvement (Chakrabarti \& Schwartz, 2013; Ingram et al., 2004). 


\section{KEY FINDINGS}

KEY FINDINGS

In order to execute this study, eleven participants were interviewed and a focus group was held over the course of two weeks, and the narratives were analyzed. Through this analysis, five themes emerged that directly related to the research question. These themes are: The school leaders experience; Impact on attendance; Incentives vs punitive consequences; Family \& community impact, and; Unintended consequences. 


\section{KEY FINDINGS}

The School Leaders Experience

Impact on school leadership

A substantial portion of the respondents spoke to the direct impact the increased amount of time spent on attendance impacted the amount of time they were able to attend to other school improvement practices, such as teacher observations and professional development meetings.

"It's taking an increased amount of time. Unfortunately we haven't seen the growth of it (attendance) yet." (Participant 5)

KEY FINDINGS

The School Leaders Experience (cont'd)

\section{School improvement impact}

Participants were asked if the implementation of strategies in attempt to meet proportional attendance standard was taking away from the amount of time they had to put towards other school improvement or practices. Participants unanimously agreed that they had less time for other school improvement practices.

Additionally, all participants reported that attendance has become a major part of their building improvement plans and goals, while a substantial number of participants (82\%) spoke to the direct impact the increased amount of time spent on attendance impacted the amount of time they were able to attend to other school improvement practices, such as teacher observations and professional development meetings.

Some of the practice listed most often as being negatively impacted included: professional development of staff, professional development of individual teachers, getting into classrooms, meeting with teachers, student interactions, and teaching observations. 
KEY FINDINGS

\section{Impact on Attendance}

According to the participants, the impact that the proportional attendance policy has had on actual attendance has been controversial at best. Three common themes emerged in regards to the impact that the policy has actually had on attendance: Specificity in approach to attendance, student accountability, and using a school-wide approach.

\section{KEY FINDINGS}

\section{Specificity in Approach}

Impact on Attendance

The proportional attendance policy has increased the purposefulness and pragmatic approach to addressing attendance. Participants cited that over time, the policy forced them to develop strategies to identify fringe students, those that hover right below, or above $90 \%$, in order to try and get them to school more. The policy has also demanded a more formalized, data driven approach in order to monitor attendance trends.

Attendance committees are another common response when discussing more specific approaches to attendance. $72.7 \%$ of participants cited either the creation or, or a more focused intention by attendance committees.

"I think that what it does is it truly identifies more kids for us, to be more proactive in identifying students" (Participant 3) 
KEY FINDINGS

Impact on Attendance

\section{Student Accountability}

Student accountability and awareness was another trend identified by $45.5 \%$ of participants in helping to raise attendance. As Participant 2 stated, "I think the bigger thing is I think the kids, the kids are becoming more self aware about how important it is to be at school. I think they are taking a little bit more ownership for their own attendance."

The drawback each school leader noted when implementing these attendance strategies, was the amount of time and energy they required. "It was kind of a lot of work, for the office staff to consistently run those reports and be on top of those things. But it was the first time I really saw students actually caring and going out of their way to seek that information" (Focus Group Participant).

\section{KEY FINDINGS}

\section{Impact on Attendance}

\section{School-wide Approach}

Getting teachers involved in the attendance process was an important step cited by $72.7 \%$ of the participants. Holding teachers accountable for making contact with parents, so the teacher is more aware of the students that are missing their classes.

Additionally, having attendance committees and teachers throughout the building involved in attendance strategies helped to foster the student-teacher relationship. Three of the participants, as well as the focus group, spoke to the fact that it's been helpful is like being able to have like a whole team of teachers be responsible for a student.

"It's just building that relationship with those parents and sometimes now I'm finding that even the parents that before we wouldn't find that they would call are starting to call in" (Participant 9).

Participants noted that including teachers in more of the attendance strategies has helped to change their accountability and their approaches to helping kids. 
KEY FINDINGS

\section{Incentives vs Punitive Consequences}

All school leaders in this study cited the use of incentives to entice students to come to school, but some participants feel the perception of negative consequences for students and families can actually play a larger short-term role. The majority of participants cited punitive consequences, or coercive tactics, to be more effective in increasing proportional attendance percentages than positive incentives. Within this study, a punitive approach was most often cited as having a greater effect, but parents learn to "game the system" and without appropriate support from non-school agencies, the attendance regresses to the norm.

"Our incentive program It just petered out and we ended up flat lining at $88 \%-89 \%$. We still have that in place but we don't feel like it's giving us the incentive the kids who aren't here... It isn't getting them here. It's not making any difference." (Participant 5)

Most leaders cited policies that require some sort of attendance qualifier to be able to participate in, or attend, after-school activities and events. All participants cited districtwide policies that were more punitive in nature.

\section{KEY FINDINGS}

\section{Family \& Community Impact.}

All Participants described the impact that attendance policies were having on school-family relationships by creating rifts harmed the relationship, between school and home. Many respondents spoke to the fact that they felt forced into using an increasing amount of coercive strategies with families and homes due to the lack of success using other strategies.

"Then, To have this guy in a suit walk in their apartment and point their finger at them and tell them they need to get their kid to school. I do feel like it's hurting our relationship in that sense. Then they don't trust us and they feel like when we do come over there you're judging us and you're looking over what we're living in, you're going to go report it to DFS."

$$
\text { (Participant 5) }
$$

All participants felt that the increasing pressure to raise attendance to meet standards, was driving the use of these coercive tactics, and ultimately deteriorating their relationships with families. 


\section{KEY FINDINGS}

\section{Family \& Community Impact (cont'd)}

\section{District-wide approach.}

District-wide community awareness programs were cited by the majority of participants in seeming to have a greater impact on long term effects. These strategies not only educated parents and the community on the importance of attendance, but also had a positive impact on school-family relationship in some cases.

One school leader even noted that when the district ceased these intentional communications and efforts, attendance went down considerably the following two years:

"Three years ago we implemented an attendance policy across the district. We did see gains, it went up everywhere, in every building. Then, central office stepped away from it, and we have gone down in consecutive years" (Participant 5).

Participants cited the need to create a partnership with families, to create a coalition that was more than schools attempting to meet attendance accountability standards on their own.

\section{KEY FINDINGS}

\section{Unintended Consequences (positive)}

There have been positive unintended consequence of the proportional attendance policy, and the many strategies schools have implemented in attempts to achieve the benchmark. Some of these include: the development of attendance committees, focused efforts on students in specific attendance ranges, identification of effective and ineffective strategies, specificity in school-wide approaches, and increased student accountability. 


\section{KEY FINDINGS}

\section{Unintended Consequences (negative)}

There have also been negative unintended consequences of the proportional attendance policy, some of which are dangerously counter-intuitive to the fabric of successful education. For instance, the negative impact some of the punitive consequences are having on deteriorating school-family relationships.

"It (proportional attendance policy) has shifted away some of our resources in our counseling and social worker department from helping kids here to helping kids try to achieve that attendance goal." (Participant 5)

\section{KEY FINDINGS}

\section{Unintended Consequences (negative cont'd)}

Participants noted several additional negative unintended consequences which include:

- removing the importance of several hundred minutes of student attendance for high attendance students, while increasing the importance of the bubble students every minute;

- decreased the amount of attention paid to students with perfect attendance, and students who are more chronically absent, which may actually be the students that need our help the most;

- shifting away school resources in counseling and social worker departments from helping kids here to helping kids try to achieve that attendance goal;

- less time available for school leaders to spend on other school improvement strategies;

- strategies attempted that have include high cost incentives that have not produced results;

- increased pressure on school leaders to meet a proportional attendance benchmark. 


\section{DISCUSSION}

\section{DISCUSSION}

Policy changes, specifically in education pertaining to accountability, do not happen quickly. Policy makers need to collect input and data from stakeholders in order to make positive changes. The steps taken to create or change policy should be deliberate, purposeful, and transparent. However, until effective change regarding attendance accountability policies takes place, school leaders must continue spend more valuable time and resources in an attempt to assist their students and families in increasing or maintaining attendance standards. If truancy officers, truancy courts, and school district social workers are not viable options, and the department of family and social services will not assist, districts must continue to adjust their own accountability standards and policies in attempts to increase attendance. 
DISCUSSION

The findings suggest: the new proportional attendance policy is detrimental to a school leaders ability to focus on other school improvement practices while creating dangerous unintended consequences for schools and students; incentives and punitive consequences have short-term success while decaying school-family relationships; and whole-district and community awareness programs seemed to have the greatest impact on long term attendance improvement.

It is hoped these perspectives will contribute to scholastic research as well as practice. By placing a value on school leaders' perceptions, policy makers can used an informed and educated stakeholder group to deliberately and effectively create policy change. This research and research like it will be used to provide educators and educational accountability policy makers a different perspective, one that includes the school leaders' voice. Perhaps then, policy makers will make deliberate and purposeful change when examining practices and policies.

\section{IMPLICATIONS}




\section{IMPLICATIONS}

This research can help school leaders and policy makers alike to identify and understand the impact incentive and punitive consequences for attendance can have, the effect that can have on school-family relationships. Additionally, the unforeseen and unintended consequences that attendance accountability policies, specifically punitive policies, can create.

Based on the results and findings of this study, each of the following three practices were used with success by at least $72.7 \%$ of school leaders, and should be implemented by districts: Systematic monitoring of attendance data, low cost incentives and simple rewards, and district-wide engagement and education of family and community awareness programs should be implemented in each district.

There is a need for further research in the area attendance accountability and attendance improvement initiatives to help build a basis and more robust list of successful strategies in all regions and states.

\section{IMPLICATIONS}

\section{Systematic Monitoring of Attendance Data}

Ideally, every school should develop and implement a team to monitor attendance data. $63.6 \%$ of participants noted the importance of having an effective attendance committee played in efforts to increase attendance. This team should use this data to monitor trends over time, organize attendance improvement strategies, provide specific interventions to specific students, and ensure chronically absent students receive support. 


\section{IMPLICATIONS}

\section{Low Cost Incentives and Simple Rewards}

When discussing incentives, $100 \%$ of participants used varying low cost and simple rewards as motivation. $72.7 \%$ of participants did note that while still time-consuming, simple low-cost incentives, while not always resulting in high increases in attendance, did help to draw attention to the importance of school attendance while providing some motivation to attend.

\section{IMPLICATIONS}

\section{Engage Families and Communities}

District-wide initiatives aimed at educating and partnering with families on the importance of education and daily attendance seemed to have the greatest impact on long term attendance improvement. Furthermore, these whole-district initiatives avoided the unintended consequence of deteriorating the school-family relationship as punitive consequences have. Regardless of the attendance policy, whether proportional, average daily attendance, or other, partnering with families and the community on any initiative is good practice.

Furthermore, these district-wide initiatives avoided the unintended consequence of deteriorating the school-family relationship as punitive consequences have. Regardless of the attendance policy, whether proportional, average daily attendance, or other, partnering with families and the community on any initiative is good practice. 


\section{REFERENCES}

Ambrosio, J. (2013). Changing the subject: Neoliberalism and accountability in public education. Educational Studies, 49(4), 316-333.

Arthurs, N., Patterson, J., \& Bentley, A. (2014). Achievement for Students Who Are Persistently Absent: Missing School, Missing Out? Urban Review: Issues and Ideas in Public Education, 46(5), 860-876.

Attendance and the early grades: A two-generation issue. (2014). Retrieved from http://www.utahchildren.org/newsroom/item/517-attendance-and-the-early-grades-a-two-generationissue?highlight=WyJjaHJvbmljliwiYWJzZW5jZSIsImNocm9uaWMgYWJzZW5jZSJd

Balfanz, R., \& Byrnes, V. (2012). The importance of being in school: A report on absenteeism in the nation's public schools. The Education Digest, 78(2), 4.

Bolman, L. G., \& Deal, T. E. (2013). Reframing organizations: Artistry, choice and leadership (5th ed.). San Francisco, CA: John Wiley \& Sons.

Chakrabarti, R., \& Schwartz, N. (2013). Unintended consequences of school accountability policies: Evidence from Florida and implications for New York. Economic Policy Review - Federal Reserve Bank of New York, 19(1), $19-43$.

Creswell, J. W. (2013). Research design: Qualitative, quantitative, and mixed methods approaches. Thousand Oaks, CA Sage publications.

Darling-Hammond, L. (2004). Standards, Accountability, and School Reform. Teachers College Record, 106(6), 1047-1085. doi:10.1111/j.1467-9620.2004.00372.x

Darling-Hammond, L. (2010a). Restoring our schools. The Nation, 290(23), 14-20.

Darling-Hammond, L. (2010b). Teacher education and the American future. Journal of teacher education, 61(1-2), 35-47.

Darling-Hammond, L. (2012). Soaring systems. Education Review, 24(1), 24-33.

\section{REFERENCES}

Darling-Hammond, L., \& Wise, A. E. (1985). Beyond standardization: State standards and school improvement. The Elementary School Journal, 85(3), 315-336.

Daugherty, M. B. (2008). Attendance and other factors that influence student achievement in a Delaware public school district: ProQuest.

Hanushek, E. A., \& Raymond, M. E. (2005). Does school accountability lead to improved student performance? Journal of policy analysis and management, 24(2), 297-327.

Ingram, D., Seashore Louis, K., \& Schroeder, R. (2004). Accountability policies and teacher decision making: Barriers to the use of data to improve practice. The Teachers College Record, 106(6), 1258-1287.

Klinger, D. A., Maggi, S., \& D'Angiulli, A. (2011). School Accountability and Assessment: Should We Put the Roof Up First? Educational Forum, 75(2), 114-128. doi:10.1080/00131725.2011.552671

Lamdin, D. J. (1996). Evidence of student attendance as an independent variable in education production functions. The Journal of educational research, 89(3), 155-162.

Lee-Partridge, J. E., Snyder, J. L., Jarmoszko, A. T., D'Onofrio, M. J., \& Petkova, O. (2014). What Is the Influence of a Compulsory Attendance Policy on Absenteeism and Performance? Journal of Education for Business, 89(8), 433-440. doi:10.1080/08832323.2014.933155

Levin, H. M. (1974). A conceptual framework for accountability in education. The School Review, 363-391.

Mellor, M., \& Griffith, D. (2015). Multimetric accountability systems: A next-generation vision of student success. Alexandria, VA: ASCD.

Merriam, S. B., \& Tisdell, E. J. (2015). Qualitative research: A guide to design and implementation. San Francisco, CA: John Wiley \& Sons. 


\section{REFERENCES}

Missouri Association of School Administrators. (2015a). Show-me task force: Accreditation and assessment. Retrieved from http://www.masaonline.org/vnews//display.v/ART/55ba7fb180aec

Missouri Association of School Administrators. (2015b). Show-me task force: Accreditation and assessment: Part II. Retrieved from http://www.masaonline.org/vnews//display.v/ART/55ba7fb180aec

O'Day, J. (2002). Complexity, accountability, and school improvement. Harvard educational review, 72(3), 293-329.

Paredes, R. D., \& Ugarte, G. A. (2011). Should Students be Allowed to Miss? The Journal of educational research, 104(3), 194-201.

Reid, K. (2008). Behaviour and attendance: the national picture; a synopsis. Part of the special issue, Truancy, disaffection and anti-social behaviour, 60(4), 333-344. doi:10.1080/00131910802393365

Seidman, I. (2013). Interviewing as qualitative research: A guide for researchers in education and the social sciences. New York: Teachers college press.

Thoonen, E. E., Sleegers, P. J., Oort, F. J., \& Peetsma, T. T. (2012). Building school-wide capacity for improvement: The role of leadership, school organizational conditions, and teacher factors. School Effectiveness and School Improvement, 23(4), 441-460.

Wilkins, J. (2008). School characteristics that influence student attendance: Experiences of students in a school avoidance program. The high school journal, 91(3), 12-24.

Zalaznick, M. (2015). How Schools Are Tackling Truancy. The Education Digest, 80(9), 44. 


\section{SECTION FIVE \\ CONTRIBUTION TO SCHOLARSHIP}

\section{Target Journal}

The target journal for publication is the Middle School Journal. This journal is a refereed journal, an official publication of the Association for Middle Level Education (AMLE) and focuses on practice and research that promotes middle level education and contributes to an understanding of the educational and developmental needs of youth.

\section{Rationale for this Target}

The Middle School Journal publishes original research that significantly impacts theory and practice of middle level education and speaks directly to practitioners in the field. Selection of manuscripts for publication is based on at least one of the 16 characteristics of successful schools for young adolescents, as discussed in the most recent version of This We Believe. The Journal seeks reports of successful programs, descriptions of effective teaching and learning experiences and techniques, thoughtprovoking essays, and application of research. Articles accepted for publication offer clear benefits for the education of young adolescents. The vision of the Middle School Journal is to link research and practice. It is my hope the research presented will help to better inform policies and practice in the field of middle level and secondary education.

\section{Outline for Proposed Contents}

Title Page

Abstract

Introduction of the Problem

Purpose of the study

Research question

Conceptual framework

Research Design

Findings

Discussion

Implications for Practitioners

References

\section{Plan for Submission}

Who: Editors Joanne Previts and Dan Bauer (http://www.editorialmanager.com/msj) When: Fall 2018

How: The manuscript will be submitted electronically to the Middle School Journal. Manuscripts, including references, should be in the range of 10 to 20 double-spaced pages. Tables, charts, and figures should be kept to a minimum and placed at the end of the text. 


\section{A CASE STUDY OF SECONDARY SCHOOL LEADERS' PERCEPTIONS OF ATTENDANCE POLICIES AND PROCEDURES USED TO INCREASE ATTENDANCE}

Mark Bullimore received his Doctorate in Educational Leadership and Policy Analysis from the University of Missouri- Columbia. 


\title{
A CASE STUDY OF SECONDARY SCHOOL LEADERS' PERCEPTIONS OF ATTENDANCE POLICIES AND PROCEDURES USED TO INCREASE ATTENDANCE
}

\begin{abstract}
Nationwide, pressures from outside influences such as politicians and educational policy makers are placing schools in precarious situations to make drastic changes in attendance policies to meet state accountability standards. The researcher used interviews and a focus group with school leaders, and archival data to find common themes which were then viewed through the conceptual underpinning of accountability. This case study adds to the field of education a deeper understanding of school leaders' perspectives on the impact attendance accountability standards have on the overall effectiveness of school improvement. The findings suggest: the new proportional attendance policy is detrimental to a school leaders' ability to focus on other school improvement practices while creating negative unintended consequences for schools and students; incentives and punitive consequences have short-term success while decaying school-family relationships; and district-wide and community awareness programs seemed to have the greatest impact on long term attendance improvement. Based on these findings, the following three practices should be implemented by districts: Systematic monitoring of attendance data, the use of low cost incentives and simple rewards, and the implementation of district-wide engagement and education of family and community awareness programs.
\end{abstract}

Keywords: Attendance, School Leadership, Accountability, School Improvement, Missouri School Improvement Plan

\section{This We Believe characteristics:}

- Leaders are committed to and knowledgeable about this age group, educational research, and best practices.

- The school environment is inviting, safe, inclusive, and supportive of all.

- The school actively involves families in the education of their children.

Nationwide, state accountability attendance standards have new outside influences impacting school and district's accountability scores for APR (DarlingHammond, 2004, 2010a, 2012; Darling-Hammond \& Wise, 1985; Hanushek \& Raymond, 2005; O'Day, 2002; Thoonen et al., 2012). From national and local politicians to educational policy makers, pressures are placing schools in precarious attendance situations to make drastic changes in attendance policies (Mellor \& Griffith, 2015; Missouri Association of School Administrators, 2015a, 2015b). These policies are 
forcing schools and districts to spend more time and resources on addressing attendance woes.

\section{Introduction of the Problem}

\section{Problem of Practice}

A gap in knowledge exists failing to clearly define the connection between attendance and accountability demands placed on school districts from policy makers (Brokowski \& Dempsey, 1979; Lee-Partridge et al., 2014; Wilkins, 2008). Increased attendance accountability has led to major policy changes at the school and district level (Missouri Department of Elementary \& Secondary Education, 2015c, 2015d). The issue of student attendance and the expectations placed on school districts from the Missouri Department of Elementary and Secondary Education (DESE) through the Missouri School Improvement Plan (MSIP) accreditation benchmarks has become a hot topic throughout K-12 public education. Changes during the MSIP5 accountability cycle from average daily attendance (ADA) to proportional attendance standards has led to major policy changes and serious discussions regarding student attendance for schools and its validity as an accreditation benchmark (Missouri Association of School Administrators, 2015a, 2015b). Educators find themselves struggling with the new guidelines and finding ways to ensure every student has acceptable attendance. Meeting these accountability policies leaves schools increasing focus on how to get students to school and keep them there, but no motivation to improve students' quality of education once they arrive (Darling-Hammond, 2004, 2010a, 2012; Hanushek \& Raymond, 2005; O'Day, 2002). 


\section{Purpose of the Study}

While districts across the state are feeling the pressure to increase their proportional attendance rates, little research has been offered describing the influence these increased efforts may have on other school improvement initiatives. This study aims to add to the existing body of knowledge concerning attendance policies, and the impact these policies and procedures have on school leaders and other key components of education (Chan \& Shum, 1997; Ginsburg et al., 2014; Lee-Partridge et al., 2014; Reid, 2008; Sheppard, 2010; Wilkins, 2008).

Therefore, the purpose of this study was to explore the secondary school leaders' perceptions of attendance policies and procedures used to increase attendance in an attempt to meet accountability standards through school improvement practices.

\section{Research Questions}

The overarching research question (Creswell, 2013) guiding this study is: What are secondary school leaders' perceptions of attendance policies and procedures? The following sub-questions helped to narrow and focus the inquiry:

- What are school leader perceptions regarding the impact of increased accountability on their attendance?

- What are school leader perceptions of the impact new attendance policies have on other school improvement factors?

- What are principals' perceptions regarding the change in their role after Missouri's new attendance accountability standard and the impact it has had on instruction, school procedures, and leader focus? 


\section{Conceptual Underpinning}

The conceptual underpinning for this study is accountability as introduced in the early work of Levin (1974). In addition to Levin's research, the accountability underpinning has continued to be examined and used as a lens for research by Chakrabarti and Schwartz (2013), Darling-Hammond (2004, 2010a, 2012); DarlingHammond and Wise (1985), and Ingram et al. (2004). According to Levin, regardless of the context in which an institution or governing body implements accountability standards, it is rarely addressing the underlying concepts which link diverse issues.

Key variables of this research are attendance, school improvement, and school leadership as viewed through an accountability conceptual underpinning lens. The key variables of attendance, school leadership, and school improvement are based on the work of researchers and scholars such as: Arthurs et al. (2014); Brokowski and Dempsey (1979); Lee-Partridge et al. (2014); Paredes and Ugarte (2011); Reid (2008); Wilkins (2008); and others.

\section{Design of the Study}

The research design used is a descriptive case study of a bounded system (Merriam \& Tisdell, 2015) grounded in the interests of deepening the understanding of the impact accountability and attendance policies can have on school leaders and overall school improvement practices (Merriam \& Tisdell, 2015).

This study investigated the perceptions of secondary school administrators in member schools of The Valley View Conference (VVC). Triangulation occurred through the use of multiple sources of data, increasing the internal validity of this study, and 
created a richer, thicker, more in-depth description of the research. (Merriam \& Tisdell, 2015)

\section{Site Description and Selection}

Sunnyhill School District and the other members of The Valley View Conference (VVC) was a bounded system purposefully selected due to their conference affiliation, regional locations, similar population distributions, and similar histories of attendance and accountability measures now being negatively affected by new accountability and attendance policies on the MSIP APR grade card.

\section{Participant Sample}

Secondary building leaders of schools that are members of The VVC. The participant selection process for the individual interviews and focus groups are based on purposeful sampling of specific administrators and attendance review committees within the VVC regarding the topic (Creswell, 2013; Merriam \& Tisdell, 2015; Seidman, 2013).

\section{Research Methods and Data Collection}

A variety of qualitative research methods were used to identify secondary school leaders' perceptions of the impact attendance accountability standards have on overall school improvement. The researcher utilized state archival documents to identify themes, as well as to ensure all parties are represented in the research. Face-to-face interviews were held with VVC secondary and were short in length, ranging from 20-30 minutes. Interview protocols and questions were developed and field tested using guidelines by Fink (2013). Application of Fink's (2013) reliability and validity tests using pilot interviews were used to ensure interview questions provided consistency in the data analysis and coding process. 
In addition to archival documents and interviews, one focus group was held. The focus group consisted of Sunnyhill secondary schools' attendance committee members. The focus group was used to generate conversations amongst school leaders to allow for the researcher to see a range of ideas and feelings, understand different perspectives, as well as to uncover factors that influence opinions, behavior and motivation (Krueger \& Casey, 2009). The ideas that emerged through the focus groups were important to the researcher in uncovering emerging themes. These conversations also helped to provide a rich, thick description of the entire story behind attendance and accountability policies impact on school improvement.

Prior to both the interviews and focus groups, the researcher obtained informed consent according to the recommendations of the American Educational Research Association from all participants (American Educational Research Association, 2011). The informed consent included the purpose of the study, procedures involved in the research, all foreseeable risks and discomforts to the subject, successes of the research, length of time, statement of voluntary participation, as well as the participants' right to confidentiality and right to withdrawal (Fink, 2013).

\section{Data Analysis}

Once all of the data was gathered through interviews, focus groups, and archival documents, the researcher searched for patterns and themes through coding (Creswell, 2013; Merriam \& Tisdell, 2015). Member check was used to validate the accuracy of transcription (Merriam \& Tisdell, 2015). The researcher first performed open coding to allow themes to emerge from the data (Merriam \& Tisdell, 2015, p. 229). After specific themes were identified, the researcher recoded the data using axial coding, grouping the 
open codes by identifying relationships among them related within the central research question (Merriam \& Tisdell, 2015, p. 229). The researcher upheld Fink's (2013) recommendation that data should be coded twice, at least two weeks apart from one another.

\section{Findings}

In order to execute this study, eleven participants were interviewed and a focus group was held over the course of two weeks, and the narratives were analyzed. Through this analysis, five themes emerged that directly related to the research question. These themes are: The school leaders experience; Impact on attendance; Incentives vs punitive consequences; Family \& community impact, and; Unintended consequences.

Each interview was coded, first using the open coding approach, followed by the axial coding method. Open coding allowed for themes to emerge that correlated with the original research questions. Then, interview and focus group transcriptions were coded using the axial method, allowing for patterns to emerge, such as the words and strategies participants used to describe their perceptions. These narratives served to reflect each respondent's perception of her or his particular situation and the challenges their school encounters within attendance accountability.

\section{The School Leaders Experience}

Impact on school leadership. A substantial portion of the respondents spoke to the direct impact the increased amount of time spent on attendance impacted the amount of time they were able to attend to other school improvement practices, such as teacher observations and professional development meetings. As one school leader stated, "It's 
taking an increased amount of time. Unfortunately, we haven't seen the growth of it (attendance) yet" (Participant 5).

"I have three times a week, a Monday, Wednesday, and a Friday where I have it set in my schedule that I sit down and specifically look at attendance and start having those conversations with kids. Meeting with my family school liaison whereas before we still did those things it just wasn't this huge chunk of our day, or of our week. Whether it's phone calls to parents, and conversations, and team meetings with the teachers. So, yeah, I do. I think that I find myself in the classroom less." (Participant 3)

School improvement impact. Participants were asked if the implementation of strategies in attempt to meet proportional attendance standard was taking away from the amount of time they had to put towards other school improvement practices. Participants unanimously agreed that they had less time for other school improvement practices. Some of the practices listed most often as being negatively impacted included: professional development of staff, professional development of individual teachers, getting into classrooms, meeting with teachers, student interactions, and teaching observations.

In regards to attendance strategies and their impact on achievement, four participants reported that the impact attendance has had on achievement seems to be more linked to the academic rigor of courses that whether those students are attending or not. Participant 3 noted,

"I can give you an example of a student right now whose attendance is at about $67 \%$ but she can pass all of her classes with flying colors. Which makes me, 
honestly, more concerned about the academic rigor that's in our classes, so, trying to figure out how to get them to want to be here anyway even though they could pass those classes. But some of the time I could be spending on monitoring and evaluating the academic rigor is having to be spent trying to get the kids to school." (Participant 3)

Additionally, all participants reported that attendance has become a major part of their building improvement plans and goals, while a substantial number of participants $(81.8 \%)$ spoke to the direct impact the increased amount of time spent on attendance impacted the amount of time they were able to attend to other school improvement practices, such as teacher observations and professional development meetings. The proportional attendance standard has resulted in formerly successful schools no longer meeting state attendance standards, while increased efforts to improve attendance percentages have resulted in reduced efforts aimed at improving teaching and learning.

\section{Impact on Attendance}

According to the participants, the impact that the proportional attendance policy has had on actual attendance has been controversial at best. Three common themes emerged in regards to the impact that the policy has actually had on attendance: Specificity in approach to attendance, student accountability, and using a school-wide approach.

Specificities in approach to attendance. The proportional attendance policy has increased the purposefulness and pragmatic approach to addressing attendance. Participants cited that over time, the policy forced them to develop strategies to identify fringe students, those that hover right below, or above $90 \%$, in order to try and 
get them to school more. The policy has also demanded a more formalized, data driven approach in order to monitor attendance trends. As participant 2 noted, "The increased focus, I think it's good to, I think it helped us to identify kids that are some of those, what we call, not at risk but a board line kid if you will that are right at 90 or either just a little bit above or below 90. So identifying them so we make sure we're in contact with them more frequently." Participant 3 added, "I think that what it does is it truly identifies more kids for us, to be more proactive in identifying students".

Attendance committees are another common response when discussing more specific approaches to attendance. Of the participants interviewed, $72.7 \%$ cited either the creation or, or a more focused intention by attendance committees. According to participants, these committees may have been broader in the past looking at school-wide attendance trends, whereas the proportional attendance policy has forced them to look at a more individual basis. Several participants cited this specificity of looking at individual students has helped school leaders, "get to more of a reason why we have kids that are missing as much as they do" (Participant 6).

"I think it has made us really look at the kids individually and ask ourselves, "Why is student A, B, and C not here prior to 90 per 90 ? We look at the bottom line number. We're hitting $95 \%$ and that was considered, I don't wanna say the gold standard, but you're meeting expectations at that point. This really makes us look at those borderline kids and look at their individual needs and what we need to do individually to get them moving to school." (Participant 6)

Student accountability. Student accountability and awareness was another trend identified by $45.5 \%$ of participants in helping to raise attendance. As Participant 2 stated, 
"I think the bigger thing is I think the kids, the kids are becoming more self-aware about how important it is to be at school. I think they are taking a little bit more ownership for their own attendance." Some participants, $36.4 \%$, also cited increase accountability for students who participate in, or attend, extra-curricular activities. Strategies included: students having to have $90 \%$ attendance to participate in activities, mandatory tutoring during and after school to make up attendance percentages, students having to be present the entire day of an event to attend or participate.

The drawback each school leader noted when implementing these attendance strategies, was the amount of time and energy they required. "It was kind of a lot of work, for the office staff to consistently run those reports and be on top of those things. But it was the first time I really saw students actually caring and going out of their way to seek that information" (Focus Group Participant).

School-wide approach. Getting teachers involved in the attendance process was an important step cited by $72.7 \%$ of the participants. Having the teachers involved not only in the tracking of daily attendance, but also holding teachers accountable for making contact with parents, so the teacher is more aware of the students that are missing their classes. Participants noted that including teachers in more of the attendance strategies has helped to change their accountability and their approaches to helping kids.

Additionally, having attendance committees and teachers throughout the building involved in attendance strategies helped to foster the student-teacher relationship. Three of the participants, as well as the focus group, spoke to the fact that it's been helpful being able to have an entire team of teachers be responsible for a student. That having more eyes on kids, and have positive conversations and encouraging conversations on 
being in school and getting the teachers involved in reaching out to families has helped foster that relationship. "It's just building that relationship with those parents and sometimes now I'm finding that even the parents that before we wouldn't find that they would call are starting to call in" (Participant 9).

\section{Incentives vs Punitive Consequences}

All school leaders in this study cited the use of incentives to entice students to come to school, but some participants feel the perception of negative consequences for students and families can actually play a larger short-term role. The majority of participants cited punitive consequences, or coercive tactics, to be more effective in increasing proportional attendance percentages than positive incentives. Within this study, a punitive approach was most often cited as having a greater effect, but parents learn to "game the system" and without appropriate support from non-school agencies, the attendance regresses to the norm.

Incentives. The use of incentives was the topic school leaders first, and most often, cited when discussing attendance improvement strategies. Without fail, each school leader participant also noted both the lack of return in sustained attendance improvement seen from these incentives, as well as the high cost and time required to monitor such incentives. School leaders were often conflicted in regards to using extrinsic rewards to increase attendance.

For instance, incentives such as movie theatre tickets, field trips, gift card drawings, school apparel, pizza or popcorn parties, or even rewarding parents with monetary rewards, were all used in an attempt to motivate students and families to attend more often. When discussing these big-ticket incentive strategies, 63.6\% of participants 
noted that while the strategies usually resulted in a small short-term uptick in their proportional attendance, attendance inevitably flat-lined. For example, Participant 5 discussed a strategy they invested high amounts of time and money resources into, "Our incentive program, it just petered out and we ended up flat lining at $88 \%-89 \%$. We still have that in place but we don't feel like it's giving us the incentive the kids who aren't here... It isn't getting them here. It's not making any difference." Two participants spoke specifically to the inability to sustain such high-cost incentives, regardless of the return on investment.

When discussing incentives, $72.7 \%$ of participants did note that while still timeconsuming, low-cost incentives, while not having a huge return in increase attendance, did help to draw attention to the importance of school attendance while providing some motivation to attend. While participants noted that small, low-cost incentives could be effective, one school leader struggled with this approach, "I do think, with the incentives, I'm very conflicted about using the extrinsic incentive with the students because it does get short term benefits. But I feel like then we're always reacting, and I don't know that it has a long term impact" (Participant 6).

Punitive consequences. The use of punitive consequences was the second most noted strategy employed by schools and districts in attempts to meet the proportional attendance benchmark. Every participant not only noted the use of punitive consequences for lack of attendance, but also noted that these strategies seemed to be more effective than the high cost incentive strategies used. In addition to punitive strategies for student's lack of attendance, all participants cited district-wide policies that were more punitive in nature for students and parents/families with low attendance. 
For example, punitive strategies used by schools and districts included: an attendance qualifier to be able to participate in, or attend, after-school activities and events; grade reductions for lack of attendance; home visits from school administration, social worker, and/or truancy officer; juvenile court references; department of family and social services references; threatening letters sent home; student discipline consequences for lack of attendance; and tutoring, detention, or extra academic hours to be made up outside the normal school day.

The majority of participants, $81.8 \%$ cited negative consequences, or coercive tactics, to be effective in increasing the proportional attendance rate, but with short-term effects. Additionally, these coercive tactics began a deterioration of the school-family relationship. As four (36.6\%) of participants noted, this punitive approach seems to have the greatest amount of effect, but parents learned to "game the system" (Participant 2) and without appropriate support from non-school agencies, the attendance regresses to the norm.

\section{Family \& Community Impact}

School-family relationships. All Participants described the impact that attendance policies were having on school-family relationships by creating rifts harmed the relationship, between school and home. Many respondents spoke to the fact that they felt forced into using an increasing amount of coercive strategies with families and homes due to the lack of success using other strategies. All participants felt that the increasing pressure to raise attendance to meet standards, was driving the use of these coercive tactics, and ultimately deteriorating their relationships with families. Strategies such as 
the "threatening" letters home and home visits are really having a negative impact on relationships. As one participant explained it,

"Then, to have this guy in a suit walk in their apartment and point their finger at them and tell them they need to get their kid to school. I do feel like it's hurting our relationship in that sense. Then they don't trust us and they feel like when we do come over there you're judging us and you're looking over what we're living in, you're going to go report it to DFS.” (Participant 5)

All participants cited some sort of home visit to students and families struggling with attendance, and each of those stories ended the same way. Participants explained that ultimately the visits corroded the relationship with parents. The school leaders emphasized that eroding the relationship is not the intent when they go visit, the intent was to speak with families on their ground, because school leaders understand families coming up to the school might not be easy for them to do.

All of the participants also spoke to the role the attendance letters also played in the school-family relationship. Every school included in the case study sends out attendance letters for kids with poor attendance, and the majority spoke to attempting to be more proactive with that now more than ever. As Participant 6 explained, "We do get pushback from parents. So, I do think that we do have some relationship issues with parents. And they get, sometimes, very angry. Occasionally they'll simple tell me it's none of my business whether my kids at school or not."

Three respondents spoke to a prevailing attitude that school attendance just isn't as important as maybe it should be. That we could be seeing a change in our society towards students becoming more of an opt-out society. The majority of school leaders 
mentioned that kids sometimes just get to choose to stay home and their parents are okay with that, "I don't remember that being as frequent 10 years ago" (Participant 6). As several school leaders explained, students are rarely if ever home by themselves. When leaders do home visits, there is almost always an adult that is home enabling the chronic absenteeism.

District-wide approach. When discussing strategies that did work, district-wide community awareness programs were cited by the majority of participants in seeming to have a greater impact on long term effects. These strategies not only educated parents and the community on the importance of attendance, but also had a positive impact on school-family relationship in some cases.

Family and community awareness programs and strategies that were approached on a district-wide scale were not only cited as having the largest, sustained impact, but one school leader even noted that when the district ceased these intentional communications and efforts, attendance went down considerably the following two years: "Three years ago we implemented an attendance policy across the district. We did see gains, it went up everywhere, in every building. Then central office stepped away from it, and we have gone down in consecutive years" (Participant 5).

District-wide approaches that school leaders cited as having a sustained impact on attendance included: efforts on social media, giving parents information on how important it is to be at school as much as possible, after school and evening programs, information letters and phone calls home, and the formation of district wide attendance committees working with human resources personnel and police departments to create more city wide importance. The participants cited the need to create a partnership with 
families, to create a coalition that was more than schools attempting to meet attendance accountability standards on their own. As Participant 9 stated when discussing the importance of district-wide communication, "I think that information has been a lot more intentional as far as sending that out more regularly from the district level”.

The input from participants regarding the use of family and community awareness programs aligns with a growing body of research to show that working more closely with local communities has the potential for improving schools and learner outcomes through enhanced teacher and learner engagement in education (Balfanz \& Byrnes, 2012; Heck \& Mayor, 1993; Reid, 2008; Rhodes \& Brundrett, 2009; Rice, 2010; Zalaznick, 2015). The connection between leadership and attendance improves with community development, not compulsory accountability practices.

\section{Unintended Consequences}

All actions, or non-actions, can result in unintended consequences. When coding participant responses, the theme of unintended consequences weaved throughout the case study, many of which have already been discussed.

As previously discussed, there have been positive unintended consequence of the proportional attendance policy, and the many strategies schools have implemented in attempts to achieve the benchmark. Some of these include: the development of attendance committees, focused efforts on students in specific attendance ranges, identification of effective and ineffective strategies, specificity in school-wide approaches, and increased student accountability.

Contrarily, there have also been negative unintended consequences of the proportional attendance policy, some of which are dangerously counter-intuitive to the 
fabric of successful education. For instance, the negative impact some of the punitive consequences are having on deteriorating school-family relationships is documented above. Additionally, participants noted several negative unintended consequences which include: removing the importance of several hundred minutes of student attendance for high attendance students, while increasing the importance of the bubble students every minute; decreased the amount of attention paid to students with perfect attendance, and students who are more chronically absent, which may actually be the students that need our help the most; shifting away school resources in counseling and social worker departments from helping kids here to helping kids try to achieve that attendance goal; less time available for school leaders to spend on other school improvement strategies; strategies attempted that have include high cost incentives that have not produced results; and the increased pressure on school leaders to meet a proportional attendance benchmark.

As Participant 9 stated, "I think that's also just kind of one of those unintended consequences is that it can cost people like me and you our job and it's not because we're not trying to implement things and trying to do things, it's just sometimes the cards are stacked a little bit against you and I just don't know that there's any proven policies or practices that you can make work."

As researchers have pointed out, a stronger concern is that although achievement may be improved by compulsory attendance accountability standards, the stronger accountability standards also resulted in unintended consequences such as increased dropout rates. As compulsory attendance policies result in student discipline from lack of attendance, we are further abandoning and disenfranchising students and families that 
already feel coming to school is unimportant (Arthurs et al., 2014; Marburger, 2006; Reid, 2008).

\section{Discussion}

Policy changes, specifically in education pertaining to accountability, do not happen quickly. The steps taken to create or change policy should be deliberate, purposeful, and transparent. However, until effective change regarding attendance accountability policies takes place, school leaders must continue spend more valuable time and resources in an attempt to assist their students and families in increasing or maintaining attendance standards. If truancy officers, truancy courts, and school district social workers are not viable options, and the department of family and social services will not assist, districts must continue to adjust their own accountability standards and policies in attempts to increase attendance.

It is hoped these perspectives will contribute to scholastic research as well as practice. By placing a value on school leaders' perceptions, policy makers can use an informed and educated stakeholder group to deliberately and effectively create policy change. This research and research like it will be used to provide educators and educational accountability policy makers a different perspective, one that includes the school leader's voice. Perhaps then, policy makers will make deliberate and purposeful change when examining practices and policies.

Despite a lack of consistent research into the validity and effect that attendance accountability policies have on school leadership, school improvement, and accountability, these policies continue to exist. On the broader question of the original research question, the study found that the 11 school leaders of Valley View Conference 
schools believe the new proportional attendance policy is detrimental to a school leaders' ability to focus on other school improvement practices while creating negative unintended consequences for schools and students; incentives and punitive consequences have short-term success while decaying school-family relationships; and district-wide and community awareness programs seemed to have the greatest impact on long term attendance improvement.

\section{Implications for Practitioners}

This study has many potential application possibilities for the educational field, and will build upon prior research completed in areas of accountability, achievement, attendance, and school improvement. Regarding accountability, this study could be used assist in the development of recommendations for policies and procedures for school districts regarding attendance. This study also aims to collect school leaders' perceptions of effective school improvement and attendance strategies that can be shared with school districts and building leaders.

This case study had a small sample size of school leaders associated with the Valley View Conference; however, the participants have contributed to the scholastic learning of other school leaders through their perceptions of attendance accountability standards, specifically the proportional attendance policy, by the reality of their daily work. Based on the results and findings of this study, through analysis of participant interviews, focus group, and archival data, three practices were used with success by at least $72.7 \%$ of school leaders. These three practices are recommended to practitioners and policy makers to be implemented by districts: Systematic monitoring of attendance 
data, the use of low cost incentives and simple rewards, and implementation of districtwide engagement and education of family and community awareness programs.

\section{Systematic Monitoring of Attendance Data}

Ideally, every school should develop and implement a team to monitor attendance data. $63.6 \%$ of participants noted the importance of having an effective attendance committee played in efforts to increase attendance. This team should use this data to monitor trends over time, organize attendance improvement strategies, provide specific interventions to specific students, and ensure chronically absent students receive support. The best way to identify students with chronic absence, is to use the attendance data already collected by schools to examine which and how many students are between 87 92\%. Schools can also use data prior to the beginning of the school year to assess how many students are likely to need additional supports and then determine how to put in place sufficient resources.

Expanding data-teams and attendance committees to include teacher input and classroom strategies, builds capacity within schools to work together to adopt best practices for improving attendance. The following people were mentioned as members of attendance committees: (a) Principal and/or another high level administrator; (b) School social worker; (c) Nurse; (d) Guidance counselor; (e) Attendance or school secretary; (f) Teachers, and; (g) District staff (as needed).

Participants and the focus group cited the activities below as being strategies they implement. Based on this input, schools should implement an attendance committee to engage in the following activities: 
- Examine every week the list of students with attendance issues to ensure that each student receives appropriate supports.

- Look at other data (grades, test scores, behavioral referrals, health issues, etc.) to develop a full picture of what is happening in a student's life.

- Use trend data to identify which sub-groups of students are most vulnerable to absenteeism.

- Connect families and students to need-based resources.

- Help communicate the importance of attendance to the entire school staff and clearly spell out how each staff member can help students who are chronically absent.

- Work with the administration to establish positive expectations for good attendance with students and their families. This includes tiered interventions to provide support and consequences.

- Examine normal and unusual trend information patterns every quarter.

- Assess the impact of programmatic efforts such as attendance incentives on reducing rates of chronic absence.

- Monitor progress.

\section{Low Cost Incentives and Simple Rewards}

When discussing incentives, $100 \%$ of participants used varying low cost and simple rewards as motivation. Many participants $(72.7 \%)$ did note that while still timeconsuming, simple low-cost incentives, while not always resulting in high increases in attendance, did help to draw attention to the importance of school attendance while providing some motivation to attend. According to Attendance Works (2017), by 
providing regular recognition and incentives to students and families who have good and improved attendance, school communities can send a clear message that going to school every day is a priority. Participants noted that these small incentives can take advantage of the fact that students often respond better to positive recognition. Participants specifically noted that incentives students seemed to enjoy and respond to the most included: recognition through certificates or assemblies, extra free time, class or homework passes, or even dancing in the hallways. These simple, low-cost rewards and incentives can go a long way toward motivating students. Examples of simple rewards used by school leaders in this study include:

- Positive notes home to parents that appreciate their efforts to get their children to school on time.

- Team certificates for the best record or most improved record.

- Name on the "Attendance Wall" in the school.

- Certificate/award at student assembly.

- Breakfast/lunch with the principal or local celebrity.

- School supplies (pencil with logo, or flash drives).

- Recognition/party for class with best attendance.

- Donated products (movie, tickets, gift certificate).

- Traveling trophy for grade-level homeroom with best monthly attendance.

- Rewards for most improved attendance.

- Parking space near building for teacher whose class has most improved attendance.

- "Gift Cards" for the school store. 


\section{Engage Families and Communities}

The engagement of families and communities in school, and attendance awareness, is an effective strategy noted by both the study participants and other researchers. Within the study, $54.5 \%$ of participants noted that a district-wide approach aimed at educating and partnering with families on the importance of education and daily attendance seemed to have the greatest impact on long term attendance improvement. Not only did these strategies have the most sustained impact on attendance, they resulted in better school-family relationships, whereas other punitive strategies many times deteriorated that dynamic. Additionally, attendance improves when a school community offers a warm and welcoming environment that emphasizes building relationships with families and stresses the importance of going to class every day (Attendance Works, 2017).

The engagement of families and communities begins with a task force. The task force should bring together leadership from a variety of school and community agencies. Use this task force to launch an awareness campaign to convey that attendance every day is important. Community leaders can send a clear message about the importance of school attendance and the adverse impact of missing too much school. This task force should:

- Focus programs to support parents as attendance advocates for change in the school environment. Make it easy for parents to access data and find resources that will help them improve their children's attendance.

- Sponsor workshops, courses, and presentations that educate and support parents and the community to improve knowledge of school policies, 
procedures, and preparedness for their future. This should include a focus on attendance and timeliness and the impact on success.

- Provide activities that promote parent-school relationships and parental leadership within the school so they can help construct and promote regular attendance.

- Be specific and pragmatic in the recruitment of parent leaders who are representative of the student population to participate in the aforementioned opportunities.

Furthermore, district-wide initiatives avoided the unintended consequence of deteriorating the school-family relationship as punitive consequences have. Regardless of the attendance policy, whether proportional, average daily attendance, or other, partnering with families and the community on any initiative is good practice. What we do now know is, improving attendance is a unified team effort, not a solo adventure, and ultimately requires a systemic approach emphasizing caring relationships, effective messaging and a positive school-family climate to motivate daily attendance. 


\section{References}

American Educational Research Association. (2011). Code of ethics. Educational Researcher, 40(3), 145-156.

Arthurs, N., Patterson, J., \& Bentley, A. (2014). Achievement for Students Who Are Persistently Absent: Missing School, Missing Out? Urban Review: Issues and Ideas in Public Education, 46(5), 860-876.

Attendance Works. (2017). Strategies for Schools. Retrieved from http://www.attendanceworks.org/chronic-absence/addressing-chronicabsence/strategies-for-school-sites/

Balfanz, R., \& Byrnes, V. (2012). The importance of being in school: A report on absenteeism in the nation's public schools. The Education Digest, 78(2), 4.

Brokowski, W. W., \& Dempsey, R. A. (1979). Attendance Policies and Student Performance. Clearing House, 53(3), 129-130.

Chakrabarti, R., \& Schwartz, N. (2013). Unintended consequences of school accountability policies: Evidence from Florida and implications for New York. Economic Policy Review - Federal Reserve Bank of New York, 19(1), 19-43.

Chan, K. C., \& Shum, C. (1997). Class attendance and student performance in principles of finance. Financial Practice \& Education, 7(2), 58-65.

Creswell, J. W. (2013). Research design: Qualitative, quantitative, and mixed methods approaches: Sage publications. 
Darling-Hammond, L. (2004). Standards, Accountability, and School Reform. Teachers College Record, 106(6), 1047-1085. doi:10.1111/j.1467-9620.2004.00372.x

Darling-Hammond, L. (2010). Restoring our schools. The Nation, 290(23), 14-20.

Darling-Hammond, L. (2012). Soaring systems. Education Review, 24(1), 24-33.

Darling-Hammond, L., \& Wise, A. E. (1985). Beyond standardization: State standards and school improvement. The Elementary School Journal, 85(3), 315-336.

Fink, A. (2013). How to conduct surveys : a step-by-step guide (5 ed.). Thousand Oaks, CA: SAGE.

Ginsburg, A., Jordan, P., \& Chang, H. (2014). Absences add up: How school attendance influences student success. Portland, OR: Attendance Works.

Hanushek, E. A., \& Raymond, M. E. (2005). Does school accountability lead to improved student performance? Journal of policy analysis and management, 24(2), 297-327.

Heck, R. H., \& Mayor, R. A. (1993). School characteristics, school academic indicators and student outcomes: implications for policies to improve schools. Journal of Education Policy, 8(2), 143-154. doi:10.1080/0268093930080203

Ingram, D., Seashore Louis, K., \& Schroeder, R. (2004). Accountability policies and teacher decision making: Barriers to the use of data to improve practice. The Teachers College Record, 106(6), 1258-1287. 
Krueger, R., \& Casey, M. (2009). Focus groups: a practical guide for applied research Thousand Oaks, CA: SAGE. (Reprinted from: 4).

Lee-Partridge, J. E., Snyder, J. L., Jarmoszko, A. T., D'Onofrio, M. J., \& Petkova, O. (2014). What Is the Influence of a Compulsory Attendance Policy on Absenteeism and Performance? Journal of Education for Business, 89(8), 433440. doi:10.1080/08832323.2014.933155

Levin, H. M. (1974). A conceptual framework for accountability in education. The School Review, 363-391.

Marburger, D. (2006). Does Mandatory Attendance Improve Student Performance? The Journal of Economic Education, 37(2), 148-155. doi:10.3200/JECE.37.2.148-155

Mellor, M., \& Griffith, D. (2015). Multimetric accountability systems: A next-generation vision of student success. Alexandria, VA: ASCD.

Merriam, S. B., \& Tisdell, E. J. (2015). Qualitative research: A guide to design and implementation. San Francisco, CA: John Wiley \& Sons.

Missouri Association of School Administrators. (2015a). Show-me task force: Accreditation and assessment. Retrieved from http://www.masaonline.org/vnews//display.v/ART/55ba7fb180aec

Missouri Association of School Administrators. (2015b). Show-me task force: Accreditation and assessment: Part II. Retrieved from http://www.masaonline.org/vnews//display.v/ART/55ba7fb180aec 
Missouri Department of Elementary \& Secondary Education. (2015a). MSIP 5 facts.

Retrieved from dese.mo.gov/quality-schools/mo-school-improvementprogram/msip-5

Missouri Department of Elementary \& Secondary Education. (2015b). MSIP 5:

Preparing every child for success in school and in life. Retrieved from https://dese.mo.gov/sites/default/files/MSIP_5_2015_Comprehensive_Guide.pdf

O'Day, J. (2002). Complexity, accountability, and school improvement. Harvard educational review, 72(3), 293-329.

Paredes, R. D., \& Ugarte, G. A. (2011). Should Students be Allowed to Miss? The Journal of educational research, 104(3), 194-201.

Reid, K. (2008). Behaviour and attendance: the national picture; a synopsis. Part of the special issue, Truancy, disaffection and anti-social behaviour, 60(4), 333-344. doi:10.1080/00131910802393365

Rhodes, C., \& Brundrett, M. (2009). Leadership development and school improvement. Educational Review, 61(4), 361.

Rice, J. K. (2010). Principal Effectiveness and Leadership in an Era of Accountability: What Research Says. Brief 8. National center for analysis of longitudinal data in education research.

Seidman, I. (2013). Interviewing as qualitative research: A guide for researchers in education and the social sciences. New York: Teachers college press.

Sheppard, A. (2010). Raising school attendance. Psychologist, 23(6), 482. 
Thoonen, E. E., Sleegers, P. J., Oort, F. J., \& Peetsma, T. T. (2012). Building schoolwide capacity for improvement: The role of leadership, school organizational conditions, and teacher factors. School Effectiveness and School Improvement, 23(4), 441-460.

Wilkins, J. (2008). School characteristics that influence student attendance: Experiences of students in a school avoidance program. The high school journal, 91(3), 12-24.

Zalaznick, M. (2015). How Schools Are Tackling Truancy. The Education Digest, 80(9), 44. 


\section{SECTION SIX}

\section{SCHOLARALY PRACTITIONER REFLECTION}

Leadership theory and application to professional practice, as well as content and context of leadership were both a major focus of the doctoral program. Working through this program, and completing the dissertation process, allowed me to gain knowledge and insight through these lenses and made me a better student, researcher, and leader. This program was a personal and professional goal I had for myself as a leader in K-12 education. The opportunities this familial cohort style program provided, as well as the discipline and diligence required throughout the program, were experiences I will always remember and encourage others to experience in their leadership development.

\section{Dissertation Influenced Practice as Educational Leader}

Northouse (2015) describes leadership as a process, not a singular trait or characteristic residing in an individual, whereby an individual influences a group of individuals to achieve common goals. Additionally, The Gallup Organization (StrengthsQuest, 2015), explains that the most effective people are those who understand their strengths and behaviors and are able to understand and utilize these strategies and abilities to meet and exceed the demands of their daily lives. Reflecting on what I have learned throughout this amazing, yet arduous, endeavor with my perspective at the time

of the many opportunities this process provided through those reflections, has allowed me to experience my growth through the context of my own thoughts and writing. The dissertation process has provided me the opportunity to identify, develop, and hone my abilities as a learner and leader. 


\section{Leadership Theory and Practice}

\section{Scholarly Background}

The art of defining or describing leadership may be the most ambiguous task faced throughout the EdD adventure. Northouse (2015) summarizes that defining leadership is both complex and continually in flux. In fact, many of the experts we studied instead work to describe the characteristics of leadership, positive and negative, in an effort to conceptualize leadership rather than define it (Kezar, Carducci, \& Contreras-McGavin, 2006; Kotter, 1990; Rooke \& Torbert, 2005; Schilling, 2009).

Similarly, experts outside the scope of coursework deeply connected to leadership development follow suite focusing efforts on describing characteristics of strong leadership, what it looks like, and how to improve your capacity to lead (Collins, 2001; Goodwin, Cameron, \& Hein, 2015; Maxwell, 2002, 2007). In reflection of my leadership development, I have taken the opportunity to synthesize my knowledge gained throughout our educational doctoral (EdD) program.

\section{Application to Professional Practice}

When applying what I have learned throughout the dissertation process, I continue to implement more strategies in utilizing shared leadership qualities (Northouse, 2015). I have found, that sharing the leadership responsibility within the school setting, especially when considering the amount of stakeholders that exist, provides the opportunity for different types of members to thrive within the team and develop leader qualities, while also maximizing our team's effectiveness (Northouse, 2015). Within my school, using shared leadership on our Building Leadership Team (BLT) creates a coalition that collaborates in order to reach our shared goals; such as increasing our student's 
achievement, performance, and teacher development. I need to work to continue to create more opportunities and teams like our BLT.

Analyzing and reflecting on the results of the questionnaires, self-assessments, and StrengthsQuest characteristics as well as the experiences of this EdD program has had a profound impact on my development as a leader within my professional practice. As Northouse (2015) concludes, the common component to nearly all conceptualizations of leadership is the individual influence on the process of assisting groups of individuals towards goal attainment. I continue to use what I have learned as a guide for our staff as we evaluate our building practices and initiatives.

\section{Dissertation Influencing Scholarship}

\section{Content and Context of Learning}

In all organizational settings, and specifically applicable to my profession in education, it is important to create a culture of professional development and continuous learning in order to achieve organizational success (Bolman \& Deal, 2013; Levi, 2015; Schein, 2005). Establishing a culture of shared learning and growth within an educational setting requires a deep conceptual understanding adult learning theories, which are intensified by a transformational learning approach (Caffarella \& Daffron, 2013; Jack Mezirow, 2000; J Mezirow \& Taylor, 2009).

Transformative learning not only expedites the learning process of adults, it is also an effective way to create a culture of learning throughout an organization (Bruffee, 1999; Caffarella \& Daffron, 2013; Merriam \& Bierema, 2013). Individual learning and collaborative learning can be combined to make a more powerful product in program delivery as individuals bring personal experience and knowledge to share and collaborate 
together. As Bruffee (1999) points out, this "requires willingness to grant authority to peers, courage to accept the authority granted to oneself by peers, and skill in the craft of interdependence" (p.12). This process requires establishing dialogue that allows learners to understand other viewpoints, cultures, and backgrounds; allowing for deeper understanding (Lawrence \& Paige, 2016).

\section{Application to Professional Practice}

As I work towards improving the climate of my organization, using appropriate teaching and learning strategies helps to create a culture of established trust, willingness, common understanding, and collaborative norms in the learning environment (Caffarella \& Daffron, 2013). I have worked to create a culture of transformative learning throughout staff professional development so teacher learners retain more knowledge when responding and discussing questions with peers resulting in lasting change beyond the time spent in training (Bruffee, 1999; Caffarella \& Daffron, 2013; Merriam \& Bierema, 2013; Jack Mezirow, 2000; J Mezirow \& Taylor, 2009).

An important aspect of creating a culture of organization learning and

development is planning. Mankins and Steele (2006) discuss the importance of evaluation in strategic planning including the creation of strategic plans that include each individual setting goals or professional development plans. I continue to use and refine the use of teacher individual professional development plans (PDP's) aligning individual growth and goals with the goals of the building. The PDP's relate to strategic planning as each individual is growing to help meet the needs and goals of the overall organization.

The evaluation phase, or judgment process, involves bringing together various pieces of information gathered and supplying answers to the evaluation questions 
(Caffarella \& Daffron, 2013). Judgments about our professional development programs, or program delivery, using specific measurable data based on criteria related to the program process or outcomes and are reached by comparing results of our data analysis of teacher growth with the criteria set for each evaluation and our building goals (Bardach \& Patashnik, 2016; Bolman \& Deal, 2013; Caffarella \& Daffron, 2013; Gill, 2009).

Additionally, when evaluating programming delivered for organizational or individual learning, it has been important to collect feedback from attendees to better understand the story of why unsuccessful attendees or presenters were unsuccessful, and how to improve the programming for those participants (Brinkerhoff \& Dressler, 2002; Gill, 2009). Implementing what I have learned throughout this program, we have begun a process to identify the most and least successful participants of our professional development programs to better understand their experience. Asking follow-up questions regarding their experiences, and then comparing and contrasting these open-ended questions could provide some direction in needed future changes.

\section{Conclusion}

I have utilized the concepts learned throughout this process in my role as a building and district leader. We have begun to evaluate current policies, make positive changes to our climate and culture, institute professional development based around adult learning theories, and become more systematic in our approach to diversity and ethics in our organization. This program has provided me the opportunity to continue to be a reflective practitioner and help identify steps I can take in order to function more effectively and completely as an educational leader in helping individuals and teams I 
work with reach our common goals. As an educational leader I will continue to provide direction and model the behavior and work ethic desired for the team to successfully achieve its desired goal. As Maxwell (2007) stated, "A leader is one who knows the way, goes the way, and shows the way" (p.4). This dissertation process has taught me a valuable lesson, the importance of continuous improvement in my ability to learn and lead. 
Appendix A

\section{INTERVIEW QUESTIONS}

- What impact has increased focus on attendance played in your overall school improvement practices?

- What new policies have you put in place to address attendance in the last few years (or: since the inception of the 90/90 rule?)?

- Please describe for me your experiences during the implementation of new attendance policies.

- What types of success of failures are you seeing with the innovations or strategies used to increase attendance?

- What are school leader perceptions of the impact new attendance policies have on achievement?

- Does an increase in focus on attendance take any time away from your focus on other areas of school improvement?

- How has the school district demonstrated commitment to improve attendance recently (since 90/90?)?

- Please explain how you feel your roles have changed after new attendance accountability acts and the impact it has had on instruction.

- Do you think there have been any unintended consequences of the new attendance accountability acts? If yes, what are those? 
Appendix B

\section{FOCUS GROUP QUESTIONS}

- What impact has increased focus on attendance played in your overall school improvement practices?

- What new policies have you put in place to address attendance in the last few years (or: since the inception of the 90/90 rule?)?

- Please describe for me your experiences during the implementation of new attendance policies.

- What types of success of failures are you seeing with the innovations or strategies used to increase attendance?

- Does an increase in focus on attendance take any time away from your focus on other areas of school improvement?

- How has the school district demonstrated commitment to improve attendance recently (since 90/90?)?

- Please explain how you feel your roles have changed after new attendance accountability acts and the impact it has had on instruction.

- Do you think there have been any unintended consequences of the new attendance accountability acts? If yes, what are those?

- Do you feel there has been an increased effort and emphasis placed on attendance in the last few year? If yes, Please describe how this has impacted student achievement and attendance

- How do you think attendance has impacted discipline procedures or referrals in your school?

- What changes have teachers made to improve the level of attendance?

- What is the difference in the perceptions of administrators regarding attendance patterns since the inception of the 90/90 rule?

- What attendance interventions were implemented by school districts in response to the Accountability Acts? 
Appendix C

\section{INFORMED CONSENT}

\section{A CASE STUDY OF SECONDARY SCHOOL LEADERS' PERCEPTIONS OF ATTENDANCE POLICIES AND PROCEDURES USED TO INCREASE ATTENDANCE}

\section{Purpose of Study:}

The purpose of this study is to explore the secondary school leaders' perceptions of attendance policies and procedures used to increase attendance in an attempt to increase achievement and meet accountability standards and the impact.

\section{Principal investigator:}

Mark Bullimore

markabullimore@gmail.com

816-261-9091

\section{Institute:}

Northwest Missouri State University

University of Missouri Columbia

\section{Introduction:}

You are invited to participate in an interview that will become the data for this study. The study will help add to the existing body of knowledge and fill needed gaps concerning attendance policies, and the impact these policies and procedures have on school leaders and other key components of education. Additionally, research into attendance, achievement, school improvement practices, and accountability policies and procedures could provide needed guidance to schools and districts in the future.

\section{Background Information:}

This is research for a dissertation within the Educational Doctorate Program through the University of Missouri-Columbia and Northwest Missouri State University.

\section{Procedures:}

Interviews: In this study, you will be asked a series of open-ended questions, which will be audio

recorded. Those recordings will be transcribed verbatim. Your name will be changed to a pseudonym in the transcriptions and in the study in order to protect your privacy. All other distinguishing characteristics that might disclose your identity will also be changed. This interview should take no more than 20 minutes.

\section{Possible Risks or Benefits:}

There is no risk involved in this study except your valuable time. This research has the potential of having an impact on other schools and districts who are examining their attendance and accountability policies. 


\title{
Right of Refusal to Participate and Withdrawal:
}

You are free to choose to participate in the study. You may also withdraw at any time from the study. You may also refuse to answer some or all of the questions.

\section{Confidentiality:}

Any information you provide will remain confidential. Nobody except the principal investigators will have an access to it. Your name and identity will also not be disclosed at any time.

\section{Available Sources of Information:}

If you have further questions, you may contact Dr. Carole Edmonds (cake@nwmissouri.edu), the researcher's dissertation advisor.

\author{
AUTHORIZATION \\ I have read and understand this consent form, and I volunteer to participate in this \\ research study. I understand that I will receive a copy of this form. I voluntarily choose to \\ participate, but I understand that my consent does not take away any legal rights in the \\ case of negligence or other legal fault of anyone who is involved in this study. I further \\ understand that nothing in this consent form is intended to replace any applicable federal, \\ state, or local laws. \\ Participant's Name (Printed or Typed): \\ Participant's Signature: \\ Date: \\ Principal Investigator's Signature: \\ Date:
}

If you have any questions regarding your rights as a participant in this research and/or concerns about the study, or if you feel under any pressure to enroll or to continue to participate in this study, you may contact the University of Missouri Campus Institutional Review Board (which is a group of people who review the research studies to protect participants' rights) at (573) 8829585 or umcresearchcirb@missouri.edu.

\section{CONSENT TO BE AUDIO-RECORDED DURING THE INTERVIEW}

I consent to be audio-recorded during the approximately 20 minute interview. I understand I can decline to be recorded at any time.

Participant's Name (Printed or Typed):

Participant's Signature:

Date:

Principal Investigator's Signature:

Date: 
Appendix D

FOCUS GROUP INFORMED CONSENT

\section{A CASE STUDY OF SECONDARY SCHOOL LEADERS' PERCEPTIONS OF ATTENDANCE POLICIES AND PROCEDURES USED TO INCREASE ATTENDANCE}

\section{Purpose of Study:}

The purpose of this study is to explore the secondary school leaders' perceptions of attendance policies and procedures used to increase attendance in an attempt to increase achievement and meet accountability standards and the impact.

\section{Principal Investigator:}

Mark Bullimore

markabullimore@gmail.com

816-261-9091

\section{Institute:}

Northwest Missouri State University

University of Missouri Columbia

\section{Introduction:}

You are invited to participate in an interview that will become the data for this study. The study will help add to the existing body of knowledge and fill needed gaps concerning attendance policies, and the impact these policies and procedures have on school leaders and other key components of education. Additionally, research into attendance, achievement, school improvement practices, and accountability policies and procedures could provide needed guidance to schools and districts in the future.

\section{Background Information:}

This is research for a dissertation within the Educational Doctorate Program through the University of Missouri-Columbia and Northwest Missouri State University.

\section{Procedures:}

Focus Groups: In this study, the group will be asked a series of open-ended questions, which will be audio recorded. Those recordings will be transcribed verbatim. Your names will be changed to a pseudonym in the transcriptions and in the study in order to protect your privacy. All other distinguishing characteristics that might disclose your identity will also be changed.

This focus group should take no more than 30 minutes.

\section{Possible Risks or Benefits:}

There is no risk involved in this study except your valuable time. This research has the potential of having an impact on other schools and districts who are examining their attendance and accountability policies. 


\section{Right of Refusal to Participate and Withdrawal:}

You are free to choose to participate in the study. You may also withdraw at any time from the study. You may also refuse to answer some or all of the questions.

Confidentiality:

Any information you provide will remain confidential. Nobody except the principal investigators will have an access to it. Your name and identity will also not be disclosed at any time.

\section{Available Sources of Information:}

If you have further questions, you may contact Dr. Carole Edmonds

(cake@nwmissouri.edu), the researcher's dissertation advisor.

\section{AUTHORIZATION}

I have read and understand this consent form, and I volunteer to participate in this research study. I understand that I will receive a copy of this form. I voluntarily choose to participate, but I understand that my consent does not take away any legal rights in the case of negligence or other legal fault of anyone who is involved in this study. I further understand that nothing in this consent form is intended to replace any applicable federal, state, or local laws.

Participant's Name (Printed or Typed):

Participant's Signature:

Date:

Principal Investigator's Signature:

Date:

If you have any questions regarding your rights as a participant in this research and/or concerns about the study, or if you feel under any pressure to enroll or to continue to participate in this study, you may contact the University of Missouri Campus Institutional Review Board (which is a group of people who review the research studies to protect participants' rights) at (573) 8829585 or umcresearchcirb@missouri.edu.

\section{CONSENT TO BE AUDIO-RECORDED DURING THE FOCUS GROUPS}

I consent to be audio-recorded during the approximately 20-30 minute Focus Group. I understand I can decline to be recorded at any time.

Participant's Name (Printed or Typed):

Participant's Signature:

Date:

Principal Investigator's Signature:

Date: 
Appendix E

\section{IRB APPROVAL}

\section{Institutional Review Board T5 University of Missouri-Columbia}

190 Galena Hall: Dc071.00

Columbia, MO 65212

$573-882-3181$

irb@imissouri.edu

November 3,2017

Principal Investigator: Mark Bullimore

Department: Educational Leadership-EDD

Your IRB Application to project entitled $A$ Case Study of Secondary School Leaders' Perceptions of $A$ ttendance Policies and Procedures Used to Increase $A$ ttendance was reviewed and approved by the MU Institutional Review Board according to the terms and conditions described below:

$\begin{array}{ll}\text { IRB Project Number } & 2009611 \\ \text { IRB Review Number } & 230895 \\ \text { Initial Application Approval Date November } 03,2017 \\ \text { IRB Expiration Date } & \text { November } 03,2018 \\ \text { Level of Review } & \text { Exempt } \\ \text { Project Status } & \text { Active - Open to } \\ & \text { Enrollment. } \\ \text { Exempt Categories } & 15 \text { CFR } 16.101 \mathbf{b}(2) \\ \text { Risk Level } & 15 \text { CFR } 16.101 \mathbf{b}(1) \\ \text { Type of Consent } & \text { Minimal Risk } \\ \text { Internal Funding } & \text { Exempt (Consent Script) }\end{array}$

The principal investigator (PI) is responsible for all aspects and conduct of this study. The PI must comply with the following conditions of the approval:

1. No subjects may be involved in any study procedure prior to the IRB approval date or after the expiration date.

2. All unanticipated problems and deviations must be reported to the IRB within 5 business days.

3. All changes must be IRB approved prior to implementation unless they are intended to reduce immediate risk.

1. hll recruitment materials and methods must be approved by the IRB prior to being used.

5. The Continuing Review Report (CRR) nust be submitted to the IRB for review and approval at least 30 days prior to the project expiration date. If the study is complete, the Completion/Withdrawal Form may be submitted in lieu of the CRR.

6. Maintain all research records for a period of seven years from the project completion 
date.

7. Utilize the IRB stamped consent documents and other approved research documents located within the document storage section of eCompliance. These documents are highlighted green.

If you are offering subject payments and would like more information about research participant payments, please click here to view the MU Business Policy and Procedure: http://bppm.missouri.edu/chapter2/2_250.html

If you have any questions, please contact the IRB at 573-882-3181 or irb@missouri.edu.

Thank you,

MU Institutional Review Board 


\section{Appendix F}

\section{PERMISSION TO CONDUCT RESEARCH}

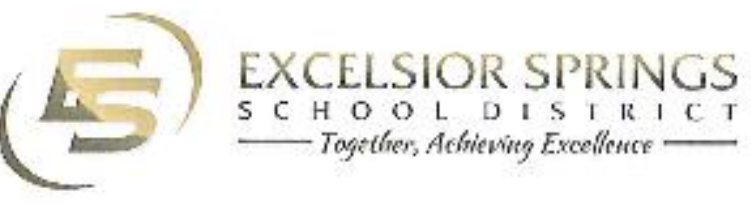

November $2^{\text {ni }}, 2017$

Cniversity of Missuri-Chlumbia

Campus Tnstiutional Rcvice Hosk

tiniversity of Missouri

Columbia, $\mathrm{MO} 65212$

Dear IRB Memberx,

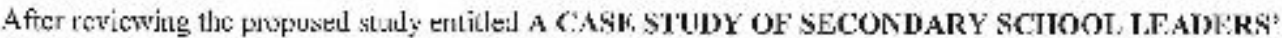

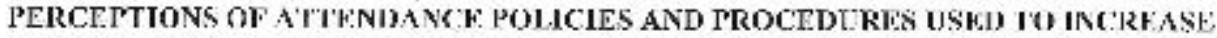

ATTENTANCE, presented by Mark is. Bullimoce. On behall of the sunferene, I have granted permission

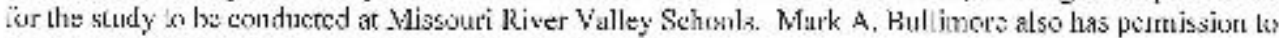
recruit at our Missouri Rjver Vulley Comlerence Schnols

I understernd that interviows and foreus groups will oce.n. I expect ths. this prigect will end nor later than Devemiber $1^{\text {st }}, 2018$.

I unders:and that Mark A. Bullimare will rescive informed consent Jur all participanls. Any dala collected by Mark A. Bullimore will be kept confidontial.

If the IRB has any concerns aboul the permission being granted by this letter, please conlact me the phons number listed below.

Sircerely,

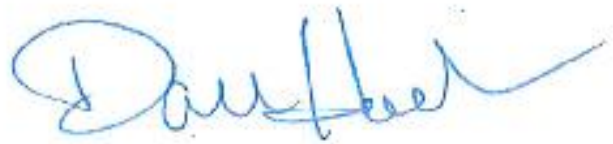

Dr. Tyan Hnchn

Sujerintendent of Schools

Universily of Missouri Pecmission Letter Templute Released: Aprid, 2013 


\section{References}

Agee, J. (2009). Developing qualitative research questions: a reflective process. International Journal of Qualitative Studies in Education, 22(4), 431-447. doi:10.1080/09518390902736512

Ambrosio, J. (2013). Changing the subject: Neoliberalism and accountability in public education. Educational Studies, 49(4), 316-333.

American Educational Research Association. (2011). Code of ethics. Educational Researcher, 40(3), 145-156.

Anderson, J. A. (2005). Accountability in education: International Institute for Educational Planning Paris.

Arthurs, N., Patterson, J., \& Bentley, A. (2014). Achievement for Students Who Are Persistently Absent: Missing School, Missing Out? Urban Review: Issues and Ideas in Public Education, 46(5), 860-876.

Attendance and the early grades: A two-generation issue. (2014). Retrieved from http://www.utahchildren.org/newsroom/item/517-attendance-and-the-earlygrades-a-two-generationissue?highlight=WyJjaHJvbmljIiwiYWJzZW5jZSIsImNocm9uaWMgYWJzZW5 iZSJd

Attendance Works. (2017). Strategies for Schools. Retrieved from http://www.attendanceworks.org/chronic-absence/addressing-chronic$\underline{\text { absence/strategies-for-school-sites/ }}$

Balfanz, R., \& Byrnes, V. (2012). The importance of being in school: A report on absenteeism in the nation's public schools. The Education Digest, 78(2), 4. 
Bardach, E., \& Patashnik, E. M. (2016). A practical guide for policy analysis: The eightfold path to more effective problem solving (5th ed.). Thousand Oaks, CA: SAGE.

Bolman, L. G., \& Deal, T. E. (2013). Reframing organizations: Artistry, choice and leadership (5th ed.). San Francisco, CA: John Wiley \& Sons.

Brinkerhoff, R. O., \& Dressler, D. (2002). Using evaluation to build organizational performance and learning capability: A strategy and a method. Performance Improvement, 41(6), 15.

Brokowski, W. W., \& Dempsey, R. A. (1979). Attendance Policies and Student Performance. Clearing House, 53(3), 129-130.

Bruffee, K. A. (1999). Collaborative learning: Higher education, interdependence, and the authority of knowledge. Baltimore, MD: Johns Hopkins University Press.

Caffarella, R. S., \& Daffron, S. R. (2013). Planning programs for adult learners: A practical guide. San Francisco, CA: John Wiley \& Sons.

Camera, L. (2016). Millions of U.S. students chronically absent. U.S. News \& World Report. Retrieved from http://www.usnews.com/news/articles/2016-0607/millions-of-us-students-chronically-absent

Chakrabarti, R., \& Schwartz, N. (2013). Unintended consequences of school accountability policies: Evidence from Florida and implications for New York. Economic Policy Review - Federal Reserve Bank of New York, 19(1), 19-43.

Chan, K. C., \& Shum, C. (1997). Class attendance and student performance in principles of finance. Financial Practice \& Education, 7(2), 58-65. 
Collins, J. C. (2001). Good to great: Why some companies make the leap... and others don't: Random House.

Constitution of the United States. (2015). Constitution State of Missouri. Public Law.

Creswell, J. W. (2013). Research design: Qualitative, quantitative, and mixed methods approaches: Sage publications.

Darling-Hammond, L. (2004). Standards, Accountability, and School Reform. Teachers College Record, 106(6), 1047-1085. doi:10.1111/j.1467-9620.2004.00372.x

Darling-Hammond, L. (2010a). Restoring our schools. The Nation, 290(23), 14-20.

Darling-Hammond, L. (2010b). Teacher education and the American future. Journal of teacher education, 61(1-2), 35-47.

Darling-Hammond, L. (2012). Soaring systems. Education Review, 24(1), 24-33.

Darling-Hammond, L., \& Wise, A. E. (1985). Beyond standardization: State standards and school improvement. The Elementary School Journal, 85(3), 315-336.

Daugherty, M. B. (2008). Attendance and other factors that influence student achievement in a Delaware public school district: ProQuest.

Fink, A. (2013). How to conduct surveys : a step-by-step guide (5 ed.). Thousand Oaks, CA: SAGE.

Gill, S. J. (2009). Developing a learning culture in nonprofit organizations. Thousand Oaks, CA: SAGE Publications.

Ginsburg, A., Jordan, P., \& Chang, H. (2014). Absences add up: How school attendance influences student success. Portland, OR: Attendance Works.

Goodwin, B., Cameron, G., \& Hein, H. (2015). Balanced Leadership for Powerful Learning: ASCD. 
Grant, C. (2006). Emerging voices on teacher leadership some South African views. Educational Management Administration \& Leadership, 34(4), 511-532.

Hallinger, P., \& Heck, R. H. (2004). Exploring the principal's contribution to school effectiveness. Educational Management, 9(2), 215.

Hanushek, E. A., \& Raymond, M. E. (2005). Does school accountability lead to improved student performance? Journal of policy analysis and management, 24(2), 297-327.

Heck, R. H., \& Mayor, R. A. (1993). School characteristics, school academic indicators and student outcomes: implications for policies to improve schools. Journal of Education Policy, 8(2), 143-154. doi:10.1080/0268093930080203

Heifetz, R. A., \& Laurie, D. L. (1997/2011). The work of leadership. Harvard business review 10 must reads on leadership.

Horng, E. L., Klasik, D., \& Loeb, S. (2010). Principal's time use and school effectiveness. American Journal of Education, 116(4), 491-523.

Ingram, D., Seashore Louis, K., \& Schroeder, R. (2004). Accountability policies and teacher decision making: Barriers to the use of data to improve practice. The Teachers College Record, 106(6), 1258-1287.

Kezar, A., Carducci, R., \& Contreras-McGavin, M. (2006). Rethinking the" L" word in higher education: The revolution of research on leadership: ASHE higher education report. San Francisco, CA: John Wiley \& Sons.

Klinger, D. A., Maggi, S., \& D'Angiulli, A. (2011). School Accountability and Assessment: Should We Put the Roof Up First? Educational Forum, 75(2), 114128. doi:10.1080/00131725.2011.552671 
Kotter, J. (1990). What Leaders Really Do. HBR's 10 must reads on leadership.

Krueger, R., \& Casey, M. (2009). Focus groups: a practical guide for applied research Thousand Oaks, CA: SAGE. (Reprinted from: 4).

Lamdin, D. J. (1996). Evidence of student attendance as an independent variable in education production functions. The Journal of educational research, 89(3), 155162.

Lawrence, R. L., \& Paige, D. S. (2016). What our ancestors knew: Teaching and learning through storytelling. New Directions for Adult and Continuing Education, 2016(149), 63-72.

Lee-Partridge, J. E., Snyder, J. L., Jarmoszko, A. T., D'Onofrio, M. J., \& Petkova, O. (2014). What Is the Influence of a Compulsory Attendance Policy on Absenteeism and Performance? Journal of Education for Business, 89(8), 433440. doi:10.1080/08832323.2014.933155

Leithwood, K., \& Jantzi, D. (2000). The effects of transformational leadership on organizational conditions and student engagement with school. Journal of Educational Administration, 38(2), 112-129.

Levi, D. (2015). Group dynamics for teams (4th ed.). Thousand Oaks, CA: Sage Publications.

Levin, H. M. (1974). A conceptual framework for accountability in education. The School Review, 363-391.

Mankins, M. C., \& Steele, R. (2006). Stop making plans; start making decisions. harvard business review, 84(1), 76. 
Marburger, D. (2006). Does Mandatory Attendance Improve Student Performance? The Journal of Economic Education, 37(2), 148-155. doi:10.3200/JECE.37.2.148-155

Maxwell, J. C. (2002). Leadership 101: What every leader needs to know: Thomas Nelson Inc.

Maxwell, J. C. (2007). The 21 irrefutable laws of leadership: Follow them and people will follow you: Thomas Nelson Inc.

Mellor, M., \& Griffith, D. (2015). Multimetric accountability systems: A next-generation vision of student success. Alexandria, VA: ASCD.

Merriam, S. B., \& Bierema, L. L. (2013). Adult learning: Linking theory and practice. San Francisco, CA: John Wiley \& Sons.

Merriam, S. B., \& Tisdell, E. J. (2015). Qualitative research: A guide to design and implementation. San Francisco, CA: John Wiley \& Sons.

Mezirow, J. (2000). Learning as Transformation: Critical Perspectives on a Theory in Progress. The Jossey-Bass Higher and Adult Education Series. San Francisco, CA: Jossey-Bass.

Mezirow, J., \& Taylor, E. (2009). Transformative Learning in Action: A Handbook for Practice: San Francisco: Jossey-Bass.

Mintzberg, H. (1979/2005). The five basic parts of the organization. In J. M. Shafritz, J. S. Ott, \& Y. S. Jang (Eds.), Classics of organization theory (6th ed., pp. 219-230). Belmont, CA: Wadsworth. (Reprinted from: The structure of organizations: A synthesis of research, pp. 18-34, by H. Mintzberg, 1979, Upper Saddle River, NJ: Prentice Hall). 
Missouri Association of School Administrators. (2015a). Show-me task force:

Accreditation and assessment. Retrieved from

http://www.masaonline.org/vnews//display.v/ART/55ba7fb180aec

Missouri Association of School Administrators. (2015b). Show-me task force:

Accreditation and assessment: Part II. Retrieved from

http://www.masaonline.org/vnews//display.v/ART/55ba7fb180aec

Missouri Association of School Administrators. (2015c). Show-me task force: State assessment systems. Retrieved from http://www.masaonline.org/vnews//display.v/ART/55ba7fb180aec

Missouri Department of Elementary \& Secondary Education. (2012a). 2012 School Annual Performance Report (APR): Excelsior springs 40. Retrieved from http://mcds.dese.mo.gov/Pages/default.aspx

Missouri Department of Elementary \& Secondary Education. (2012b). History of the missouri school improvement program. Retrieved from https://dese.mo.gov/sites/default/files/qs-esea-flexibility-waiver-msip-history.pdf Missouri Department of Elementary \& Secondary Education. (2014). MSIP5 final apr differences from 2013 to 2014 [Data file]. Retrieved from: http://mcds.dese.mo.gov/guidedinquiry/MSIP5\%20Annual\%20Performance\%20 Report\%20APR/MSIP5\%20Annual\%20Performance\%20Report\%20\%28APR\%2 9. $\operatorname{aspx} ? \mathrm{ID}=\mathrm{bk} 8100030033009300130043001300$

Missouri Department of Elementary \& Secondary Education. (2015a). 2015 School Annual Performance Report (APR): Excelsior springs high, excelsior springs 40. Retrieved from http://mcds.dese.mo.gov/Pages/default.aspx 
Missouri Department of Elementary \& Secondary Education. (2015b). MSIP5 School Breakout by Standard. Retrieved from http://mcds.dese.mo.gov/Pages/default.aspx

Missouri Department of Elementary \& Secondary Education. (2015c). MSIP 5 facts. Retrieved from dese.mo.gov/quality-schools/mo-school-improvementprogram $/$ msip-5

Missouri Department of Elementary \& Secondary Education. (2015d). MSIP 5: Preparing every child for success in school and in life. Retrieved from https://dese.mo.gov/sites/default/files/MSIP_5_2015_Comprehensive_Guide.pdf

Missouri Department of Elementary \& Secondary Education. (2016a). Definitions for school report card pages. Retrieved from Https://dese.mo.gov/data-systemmanagement/definitions-school-report-card-pages

Missouri Department of Elementary \& Secondary Education. (2016b). Facts About the Department of Elementary and Secondary Education. Retrieved from https://dese.mo.gov/state-board-education/overview

Missouri Department of Elementary \& Secondary Education. (2016c). Facts About the State Board. Retrieved from https://dese.mo.gov/state-board-education/aboutstate-board

Missouri Department of Elementary \& Secondary Education. (2016d). Organization Chart. Retrieved from https://dese.mo.gov/sites/default/files/DESE_orgchart.pdf Missouri Department of Elementary \& Secondary Education. (2016e). Vision, Mission, \& Goals. Retrieved from https://dese.mo.gov/commissioner/vision-mission-goals 
Missouri Department of Elementary \& Secondary Education. (2017). MSIP 6. Retrieved from https://dese.mo.gov/quality-schools/mo-school-improvement-program/msip$\underline{6}$

Missouri Department of Elementary and Secondary Education. (2015a). MSIP 5. Retrieved from http://dese.mo.gov/quality-schools/mo-school-improvementprogram/msip-5

Missouri Department of Elementary and Secondary Education. (2015b). Overview: Facts about the department of elementary and secondary education. Retrieved from https://dese.mo.gov/state-board-education/overview

Northouse, P. G. (2015). Leadership: Theory and practice. Thousand Oaks, CA: Sage publications.

O'Day, J. (2002). Complexity, accountability, and school improvement. Harvard educational review, 72(3), 293-329.

Paredes, R. D., \& Ugarte, G. A. (2011). Should Students be Allowed to Miss? The Journal of educational research, 104(3), 194-201.

Reid, K. (2008). Behaviour and attendance: the national picture; a synopsis. Part of the special issue, Truancy, disaffection and anti-social behaviour, 60(4), 333-344. doi:10.1080/00131910802393365

Rhodes, C., \& Brundrett, M. (2009). Leadership development and school improvement. Educational Review, 61(4), 361.

Rice, J. K. (2010). Principal Effectiveness and Leadership in an Era of Accountability: What Research Says. Brief 8. National center for analysis of longitudinal data in education research. 
Rooke, D., \& Torbert, W. R. (2005). Seven transformations of leadership. harvard business review, 83(4), 66-76.

Schein, E. H. (2005). Defining organizational theory in higher education. In J. M. Shafritz, J. S. Ott, \& Y. S. Jang (Eds.), Classics of organization theory (6th ed., pp. 360-367). Belmont, CA: Wadsworth. (Reprinted from: Organizational culture and leadership, 2nd ed., pp. 3-15, 1993, San Francisco, CA: Jossey-Bass).

Schilling, J. (2009). From Ineffectiveness to Destruction: A Qualitative Study on the Meaning of Negative Leadership. Leadership, 5(1), 102-128. doi: $10.1177 / 1742715008098312$

Seidman, I. (2013). Interviewing as qualitative research: A guide for researchers in education and the social sciences. New York: Teachers college press.

Sheppard, A. (2010). Raising school attendance. Psychologist, 23(6), 482.

Snyder, J. L., Lee-Partridge, J. E., Jarmoszko, A. T., Petkova, O., \& D’Onofrio, M. J. (2014). What Is the Influence of a Compulsory Attendance Policy on Absenteeism and Performance? Journal of Education for Business, 89(8), 433440.

StrengthsQuest. (2015). StrengthsQuest assessment by gallup's education practice. Retrieved from http://www.strengthsquest.com/home.aspx

Thoonen, E. E., Sleegers, P. J., Oort, F. J., \& Peetsma, T. T. (2012). Building schoolwide capacity for improvement: The role of leadership, school organizational conditions, and teacher factors. School Effectiveness and School Improvement, 23(4), 441-460. 
Thurlow, M. (2009). Accountability. Retrieved from

http://www.education.com/reference/article/accountability/

United States Census Bureau. (2011). Fact finder: Community facts. Retrieved from https://factfinder.census.gov/faces/nav/jsf/pages/index.xhtml

United States Department of Education. (2001). No Child Left Behind Act. Public Law, 107-110.

United States Department of Education. (2010a). An Overview of the U.S. Department of Education. Retrieved from https://www2.ed.gov/about/overview/focus/what.html\#whatis

United States Department of Education. (2010b). Race to the top program guidance and frequently asked questions. Retrieved from http://www2.ed.gov/programs/racetothetop/faq.pdf

United States Department of Education. (2010c). What we do. Retrieved from https://www2.ed.gov/about/what-we-do.html

United States Department of Education. (2017a). Operating Structure. Retrieved from https://www2.ed.gov/print/about/offices/or/index.html

United States Department of Education. (2017b). What Is the U.S. Department of Education? Retrieved from https://www2.ed.gov/about/overview/focus/what.html\#whatis

Wilkins, J. (2008). School characteristics that influence student attendance: Experiences of students in a school avoidance program. The high school journal, 91(3), 12-24. Zalaznick, M. (2015). How Schools Are Tackling Truancy. The Education Digest, 80(9), 44. 


\section{VITA}

The author of this study, Mark A. Bullimore, was born and raised in Saint Joseph, MO. Throughout his 13 year career in K-12 public education, Mark has enjoyed continued education and leadership in many faucets.

After graduation from Northwest Missouri State University with Bachelors in Physical Education and Health, Mark's first teaching assignment was at the Excelsior Springs School District as an elementary physical education teacher. He also began coaching soccer and middle school basketball during these early years. Mark worked for two additional years as a teacher before the completion of his Masters of Arts in Educational Administration from William Woods University. Mark's third year in Excelsior Springs he transferred to the high school where he taught physical education, health, human performance, officiating, and lifetime fitness courses. During Mark's 5th

year in the district, he completed his Specialist in School Superintendency from William Woods University, and was promoted to Head Boys and Girls Soccer coach.

After 10 years in the district, Mark then accepted an Assistant Principal position at Excelsior Springs High School. In this administrative role, one of the many facets of his position was to help develop, implement, and oversee school improvement strategies. Specifically, he led the implementation of an attendance committee with the charge of improving secondary attendance.

It was during this time Mark began the Educational Leadership and Policy Analysis Educational Doctorate with Cohort Ten through the University of Missouri Statewide Cooperative Program. Currently Mark serves the Excelsior Springs School District as the Middle School Principal. 